\title{
Enantiospecific Total Synthesis and Absolute Configuration Assignment of Chabrolobenzoquinone $\mathrm{H}$
}

\section{Supporting Information}

Stergios R. Rizos, Konstantinos A. Ouzounthanasis, Alexandros E. Koumbis* Laboratory of Organic Chemistry, Department of Chemistry, Aristotle University of Thessaloniki, Thessaloniki 54124, Greece

akoumbis@chem.auth.gr

Table of Contents

Comparison of natural and synthetic chabrolobenzoquinone $\mathrm{H}$.........................S2

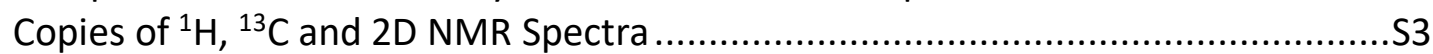




\section{Comparison of natural and synthetic chabrolobenzoquinone $\mathrm{H}$}

Table S1. Comparison of NMR data for natural and synthetic chabrolobenzoquinone $H$ (1)

\begin{tabular}{|c|c|c|c|c|}
\hline \multirow[b]{2}{*}{ Frequency } & \multicolumn{2}{|c|}{ NATURAL SAMPLE ${ }^{a}$} & \multicolumn{2}{|c|}{ SYNTHETIC SAMPLE } \\
\hline & $300 \mathrm{MHz}$ & $75 \mathrm{MHz}$ & $500 \mathrm{MHz}$ & $126 \mathrm{MHz}$ \\
\hline $\mathrm{C} / \mathrm{H}$ & $\delta_{H}$ & $\delta_{c}$ & $\delta_{H}$ & $\delta_{c}$ \\
\hline $1^{\prime}$ & - & 187.9 & - & 187.9 \\
\hline $2^{\prime}$ & - & 148.6 & - & 148.5 \\
\hline $3^{\prime}$ & $6.50 \mathrm{~s}$ & 132.4 & $6.50 \mathrm{t}(1.8 \mathrm{~Hz})$ & 132.4 \\
\hline $4^{\prime}$ & - & 188.4 & - & 188.4 \\
\hline $5^{\prime}$ & - & 145.7 & - & 145.7 \\
\hline $6^{\prime}$ & $6.60 \mathrm{q}(1.5 \mathrm{~Hz})$ & 133.6 & $6.60 q(1.6$ & 133.6 \\
\hline $7^{\prime}$ & $2.04 \mathrm{~d}(1.5 \mathrm{~Hz})$ & 15.5 & $2.04 \mathrm{~d}(1.6 \mathrm{~Hz})$ & 15.5 \\
\hline 1 & $3.11 \mathrm{~d}(7.2 \mathrm{~Hz})$ & 27.2 & $3.11 \mathrm{~d}(6.3 \mathrm{~Hz})$ & 27.1 \\
\hline 2 & $5.13 \mathrm{t}(7.2 \mathrm{~Hz})$ & 118.0 & $5.14 \mathrm{td}(7.3,1.3 \mathrm{~Hz})$ & 118.0 \\
\hline 3 & - & 139.8 & - & 139.8 \\
\hline 4 & $2.09 \mathrm{~m}$ & 39.6 & $2.08 \mathrm{~m}$ & 39.5 \\
\hline 5 & $2.12 \mathrm{~m}$ & 26.4 & $2.12 \mathrm{~m}$ & 26.4 \\
\hline 6 & $5.11 \mathrm{~m}$ & 124.3 & $5.11 \mathrm{~m}$ & 124.3 \\
\hline 7 & - & 134.6 & - & 134.6 \\
\hline 8 & $1.96 \mathrm{~m}$ & 36.2 & $1.96 \mathrm{~m}$ & 36.2 \\
\hline 9 & $1.71 \mathrm{~m}$ & 27.7 & $1.75-1.66 \mathrm{~m}$ & 27.6 \\
\hline 10 & $4.85 \mathrm{dd}(9.6,3.0 \mathrm{~Hz})$ & 79.1 & $\begin{array}{c}4.85 \mathrm{dd}(10.2,2.6 \\
\mathrm{Hz})\end{array}$ & 79.1 \\
\hline 11 & - & 74.2 & - & 74.2 \\
\hline 12 & $1.43 \mathrm{~m}, 1.54 \mathrm{~m}$ & 37.8 & $1.44 \mathrm{~m}, 1.55 \mathrm{~m}$ & 37.8 \\
\hline 13 & $2.05 \mathrm{~m}$ & 22.1 & $2.05 \mathrm{~m}$ & 22.1 \\
\hline 14 & $5.11 \mathrm{~m}$ & 124.5 & $5.11 \mathrm{~m}$ & 124.5 \\
\hline 15 & - & 132.1 & - & 132.1 \\
\hline 16 & $1.68 \mathrm{~s}$ & 25.8 & $1.69 \mathrm{~s}$ & 25.7 \\
\hline 17 & $1.62 \mathrm{~s}$ & 17.7 & $1.62 \mathrm{~s}$ & 17.7 \\
\hline 18 & $1.17 \mathrm{~s}$ & 23.6 & $1.17 \mathrm{~s}$ & 23.6 \\
\hline 19 & $1.60 \mathrm{~s}$ & 16.2 & $1.60 \mathrm{~s}$ & 16.2 \\
\hline 20 & $1.62 \mathrm{~s}$ & 16.1 & $1.62 \mathrm{~s}$ & 16.1 \\
\hline 21 & - & 171.1 & - & 171.1 \\
\hline 22 & $2.11 \mathrm{~s}$ & 21.1 & $2.11 \mathrm{~s}$ & 21.1 \\
\hline $\mathrm{OH}$ & Not observed & - & Not observed & - \\
\hline
\end{tabular}

Taken from the isolation report. ${ }^{1}$ Note: There is no information on the reference shift used in that report. ${ }^{b}$ For synthetic 1 , the reference shift of $\mathrm{CDCl}_{3}$ was set to 7.27 for ${ }^{1} \mathrm{H}$ and 77.00 for ${ }^{13} \mathrm{C}$.

${ }^{1}$ Su, J-H.; Ahmed, A. F.; Sung, P-J.; Wu, Y-C.; Sheu, J-H. Meroditerpenoids from a Formosan Soft Coral Nephthea Chabrolii. J. Nat. Prod. 2005, 68, 1651-1655. 


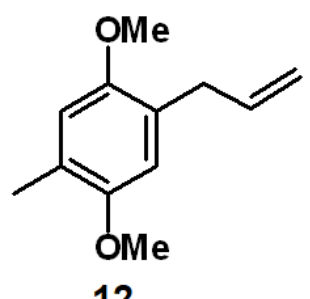

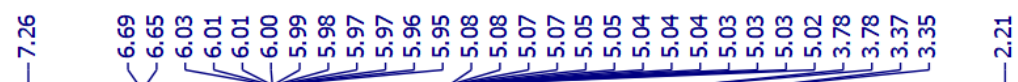

$\mathrm{H} \mathrm{NMR}, 500 \mathrm{MHz}, \mathrm{CDCl}_{3}$

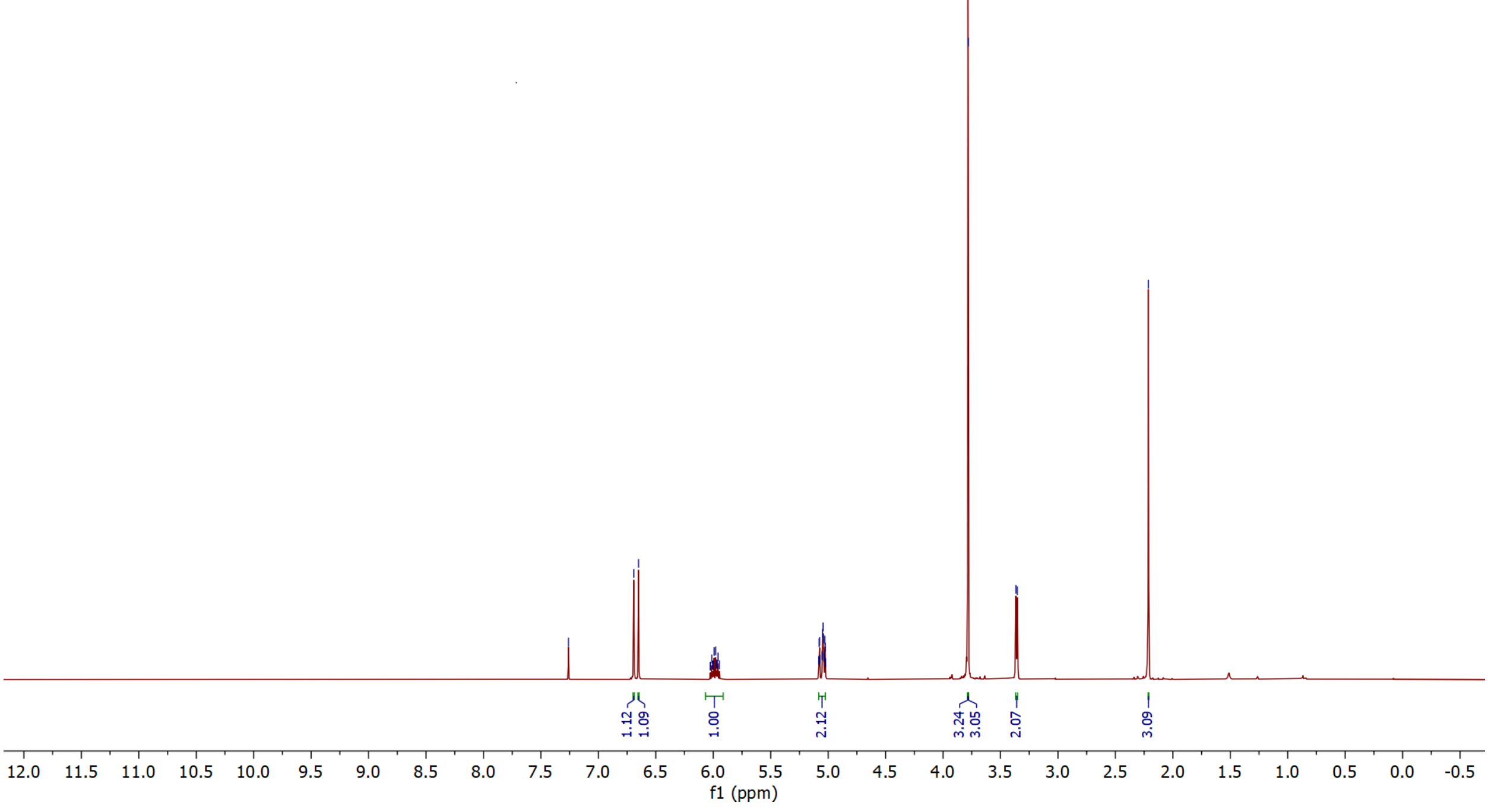




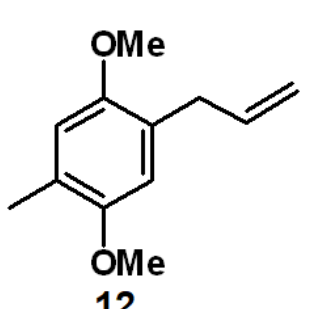

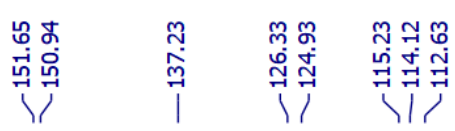

${ }^{13} \mathrm{C}\left\{{ }^{1} \mathrm{H}\right\} \mathrm{NMR}, 126 \mathrm{MHz}, \mathrm{CDCl}_{3}$

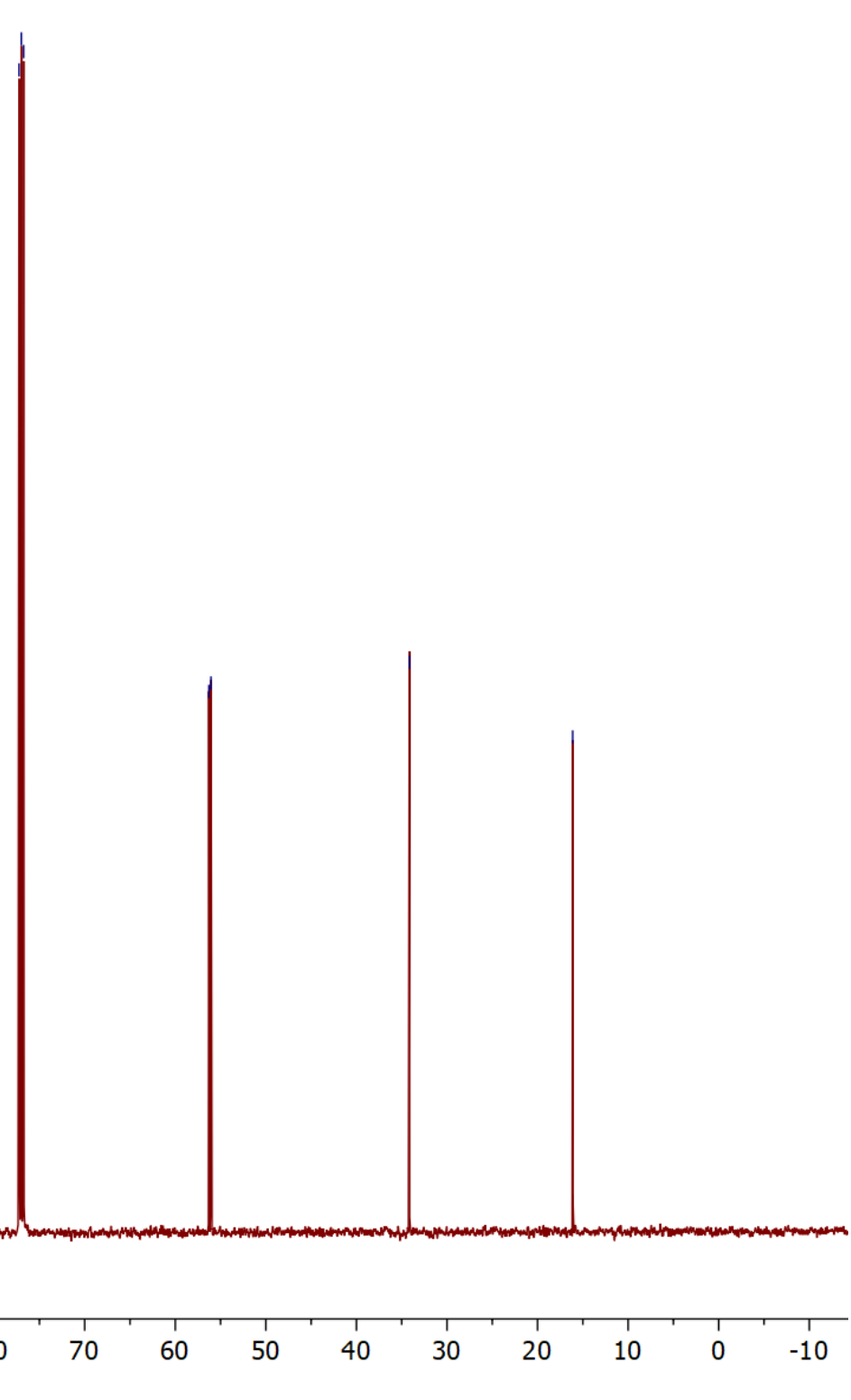




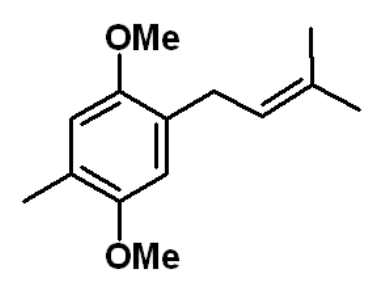

i

${ }^{1} \mathrm{H} \mathrm{NMR}, 500 \mathrm{MHz}, \mathrm{CDCl}_{3}$

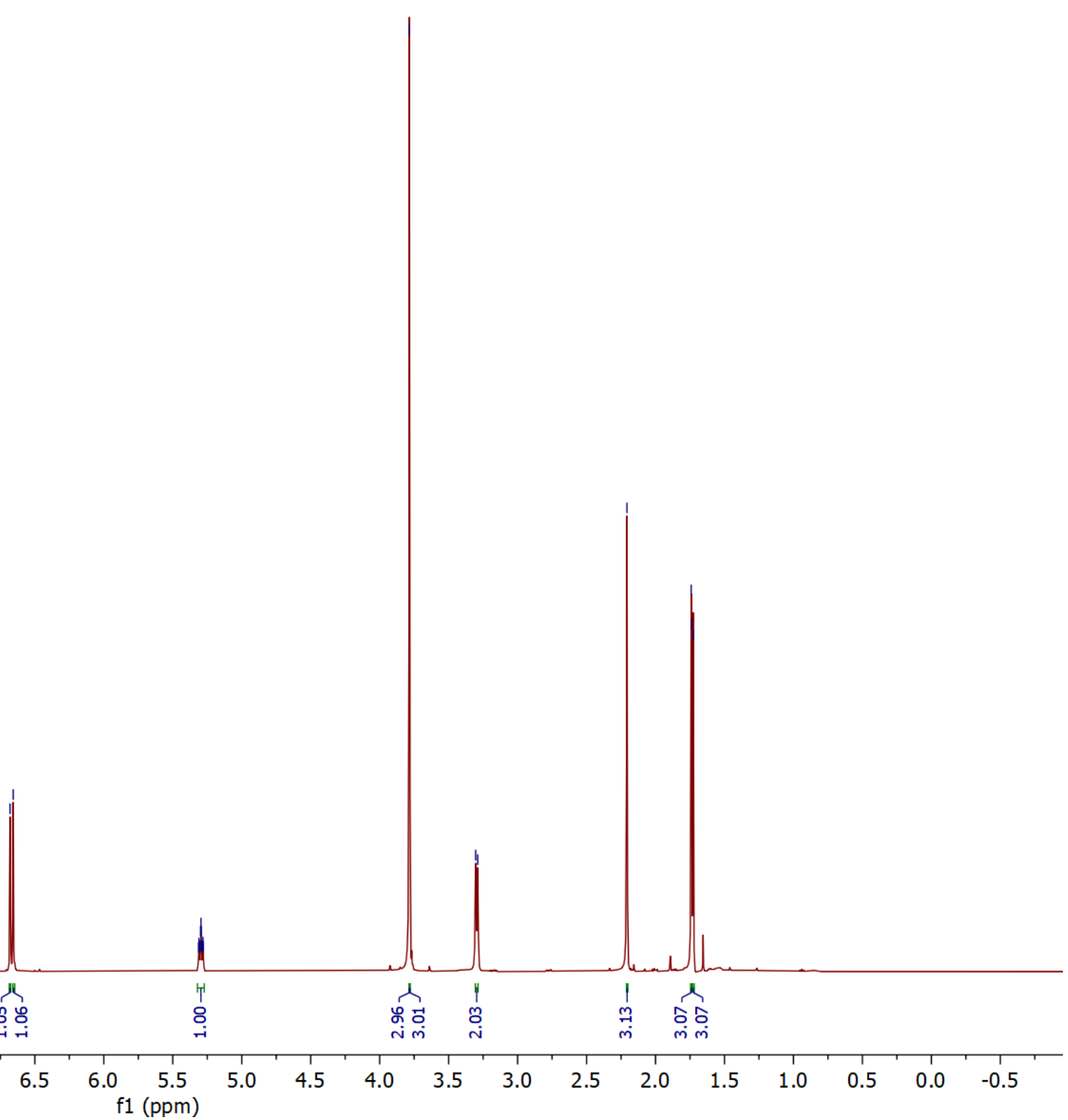




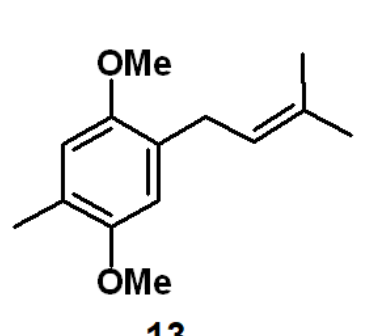

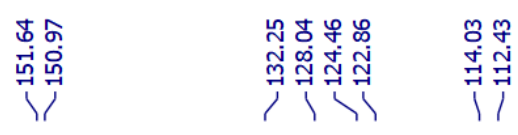

นุำ ำ

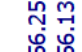

m

13

${ }^{13} \mathrm{C}\left\{{ }^{1} \mathrm{H}\right\} \mathrm{NMR}, 126 \mathrm{MHz}, \mathrm{CDCl}_{3}$

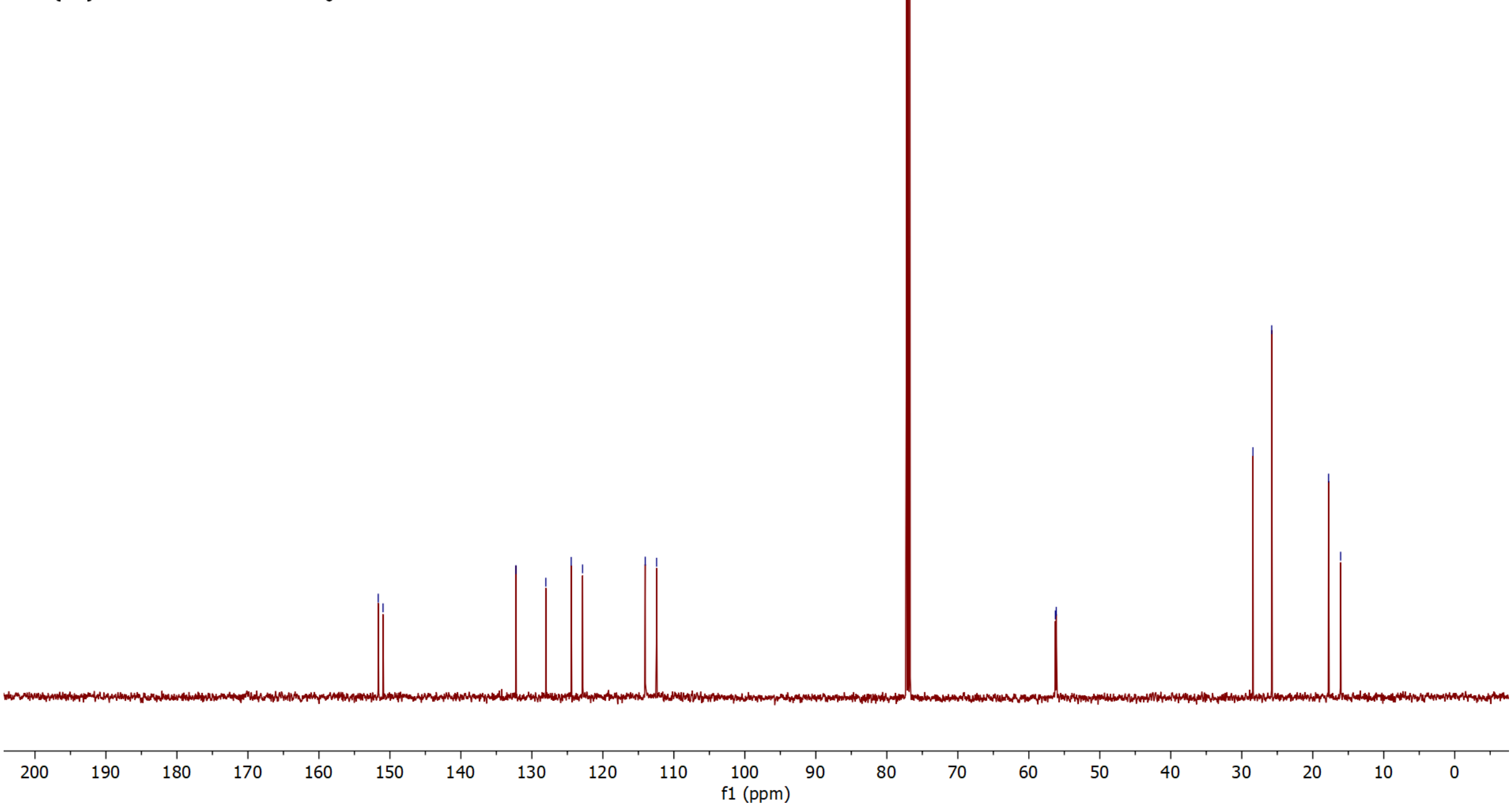




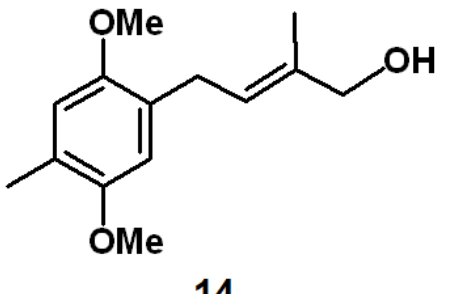

lo

1H NMR, 500 MHz, DMSO-d6

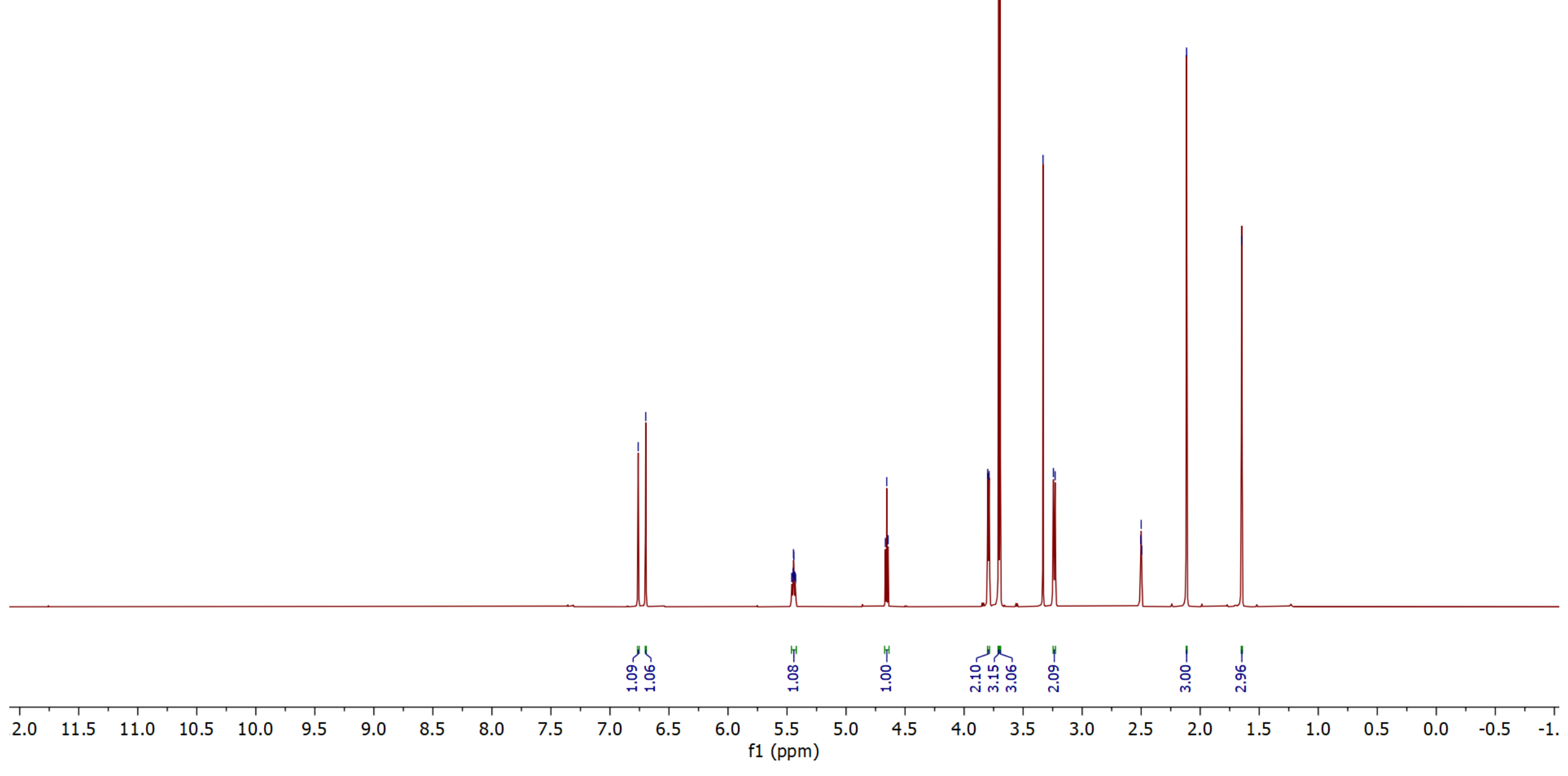




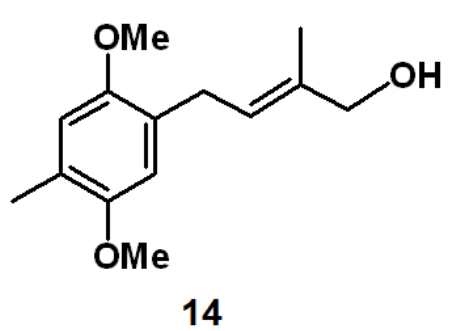

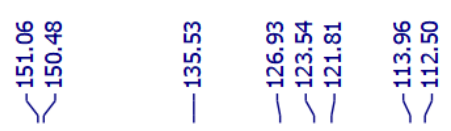

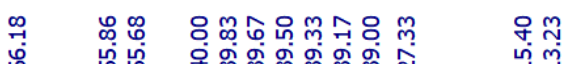

ํํำ

${ }^{13} \mathrm{C}\left\{{ }^{1} \mathrm{H}\right\} \mathrm{NMR}, 126 \mathrm{MHz}$, DMSO-d6

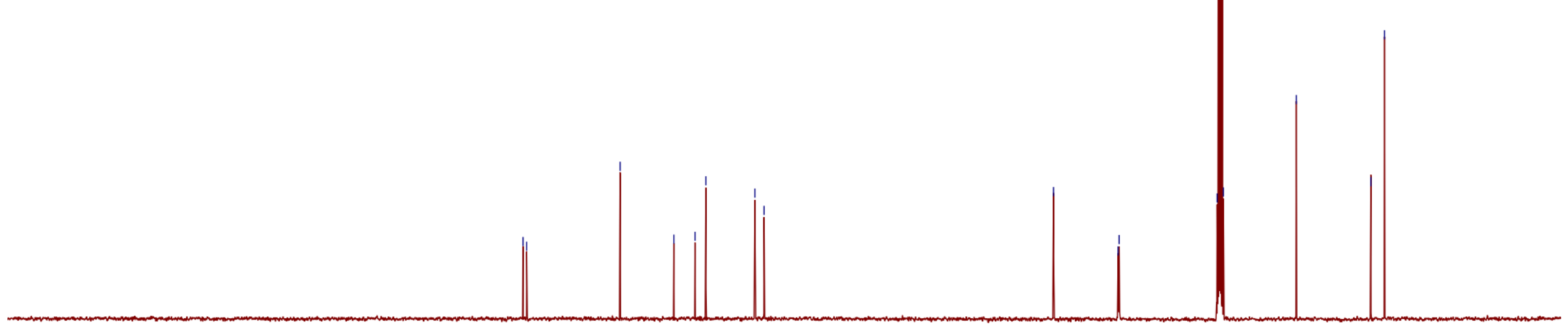




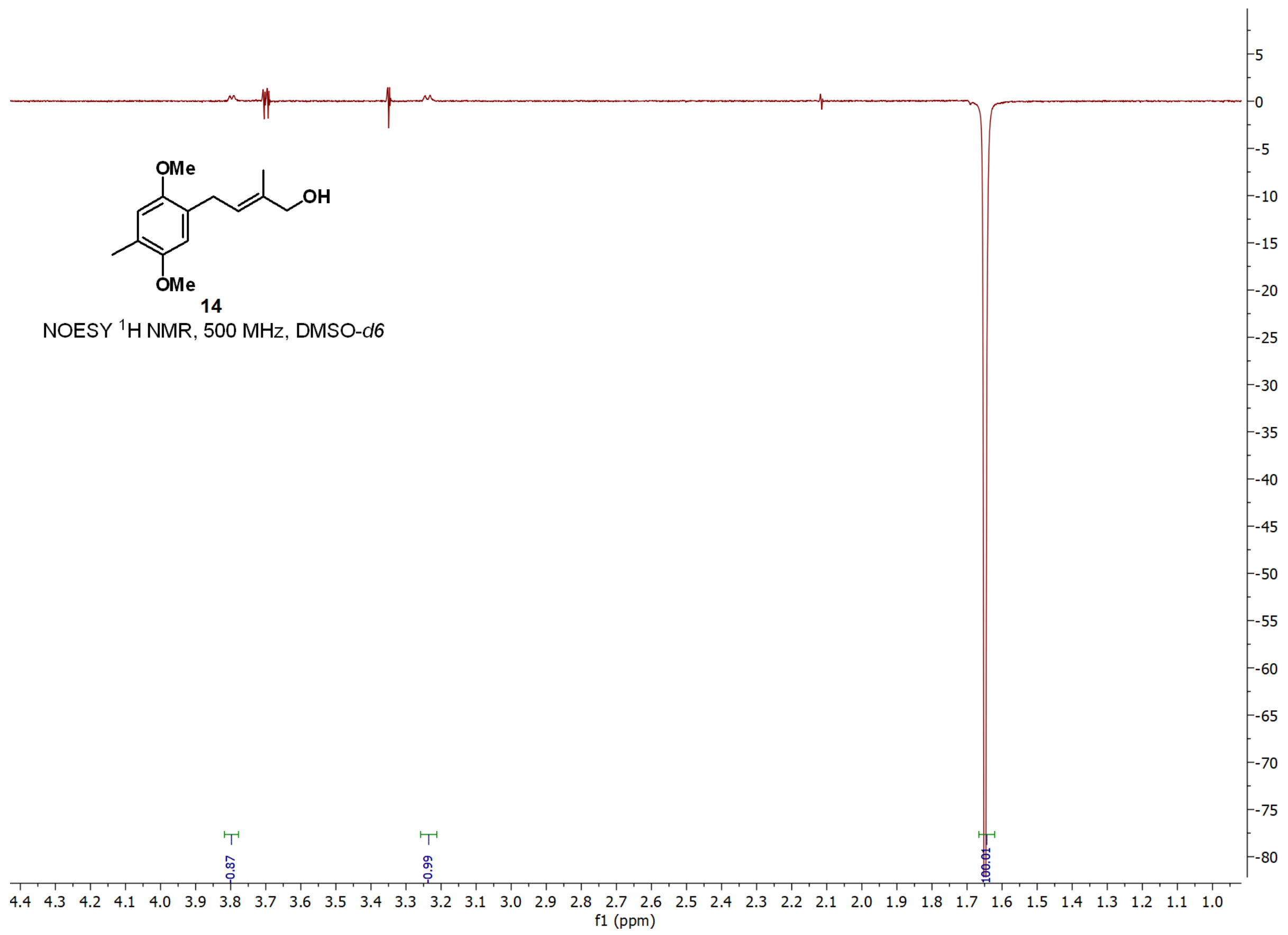




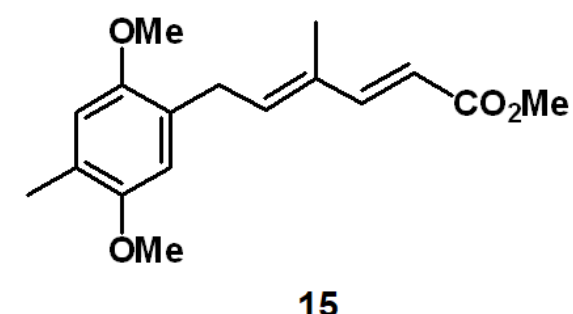

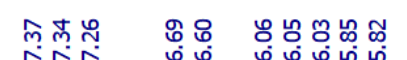

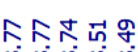

$\underbrace{m} m^{m}$

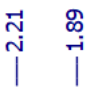

15

${ }^{1} \mathrm{H} \mathrm{NMR}, 500 \mathrm{MHz}, \mathrm{CDCl}_{3}$

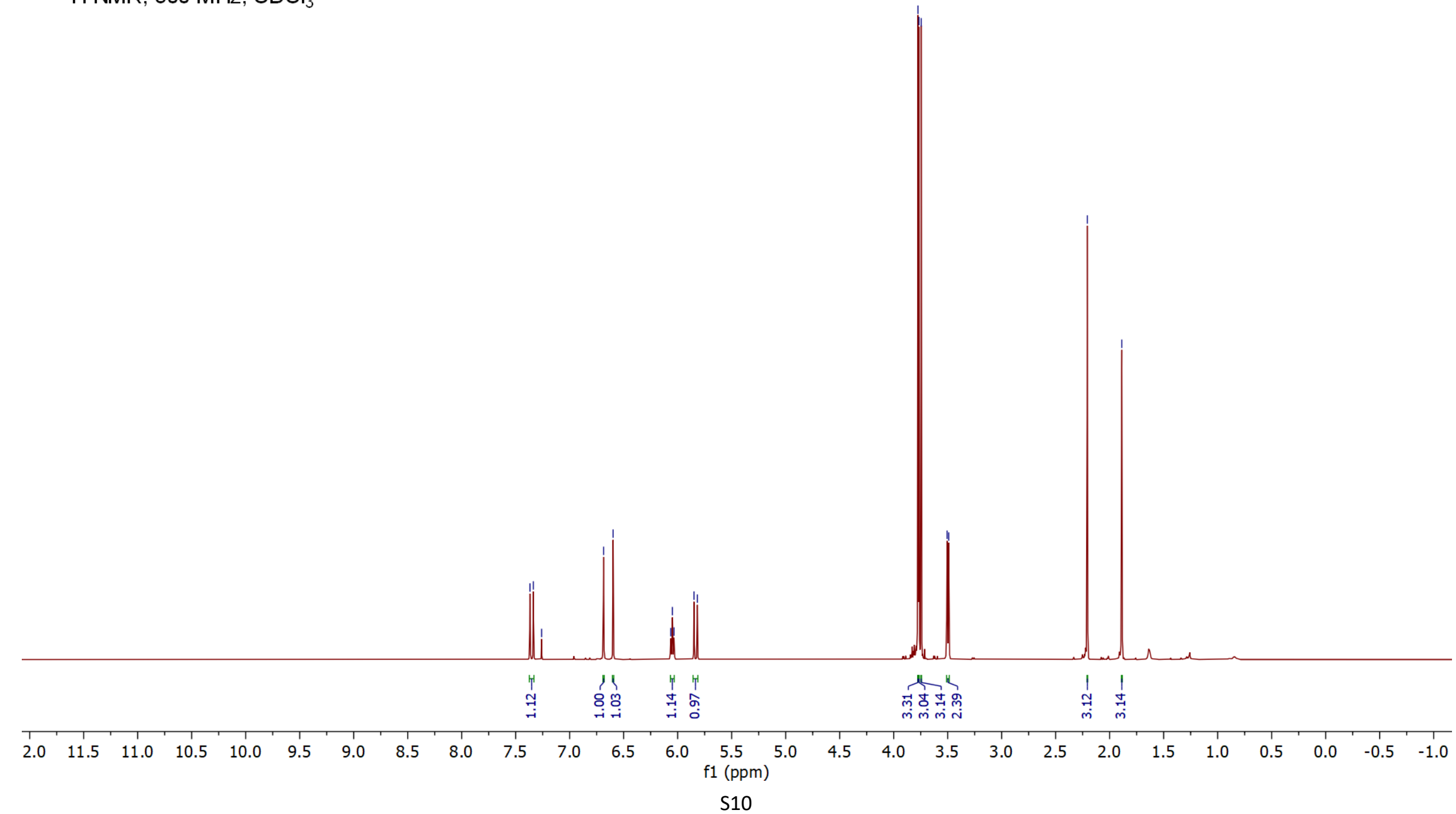




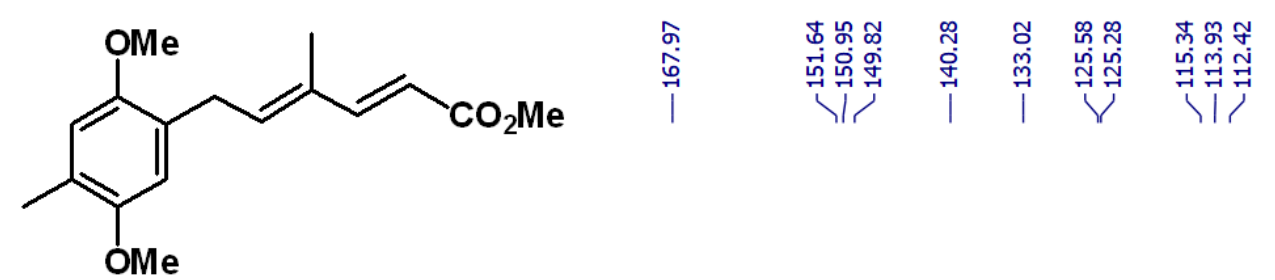

\section{5}

${ }^{13} \mathrm{C}\left\{{ }^{1} \mathrm{H}\right\} \mathrm{NMR}, 126 \mathrm{MHz}, \mathrm{CDCl}_{3}$
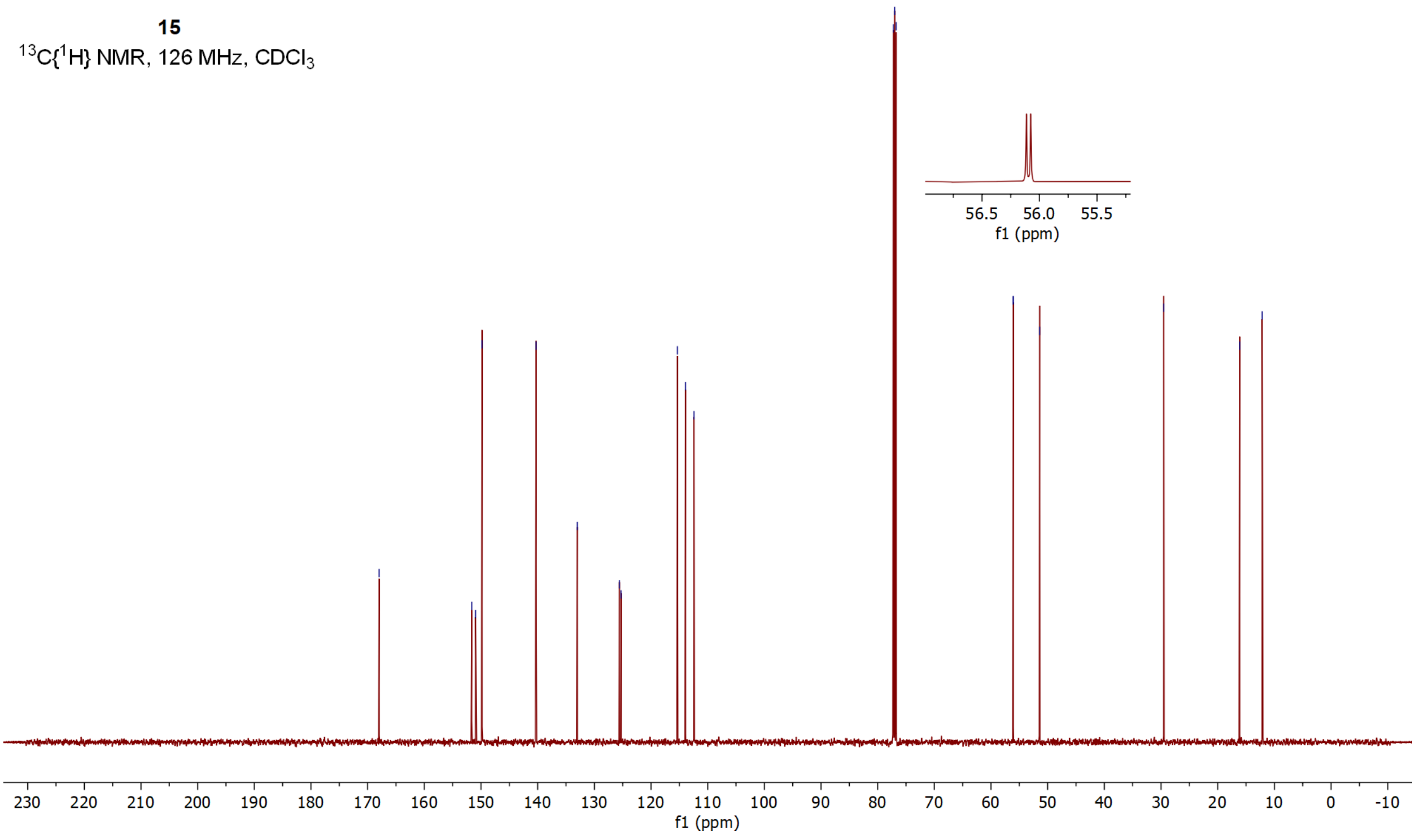


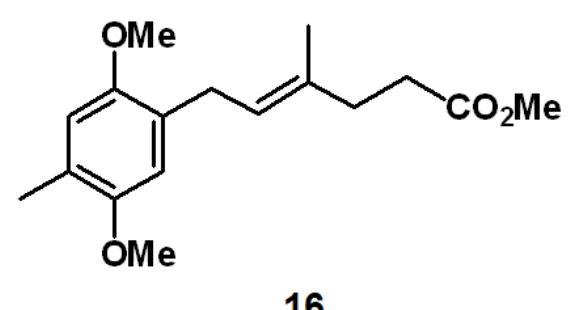

16

${ }^{1} \mathrm{H}$ NMR, $500 \mathrm{MHz}$, DMSO-d6

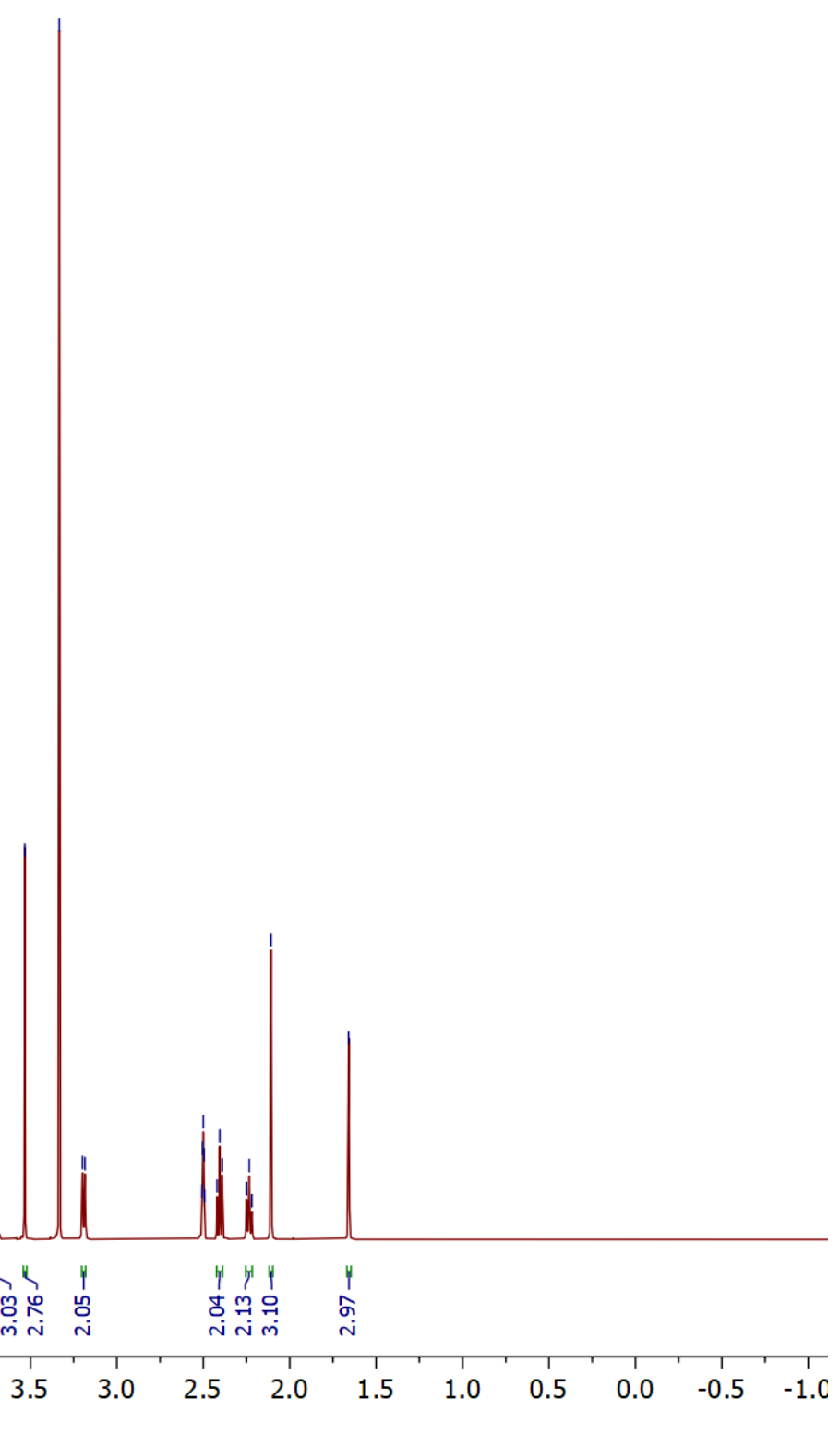

$\begin{array}{llllllllllllll}12.0 & 11.5 & 11.0 & 10.5 & 10.0 & 9.5 & 9.0 & 8.5 & 8.0 & 7.5 & 7.0 & 6.5 & 6.0 & 5.5 \\ & & & & & & & & & & & & & \end{array}$ 


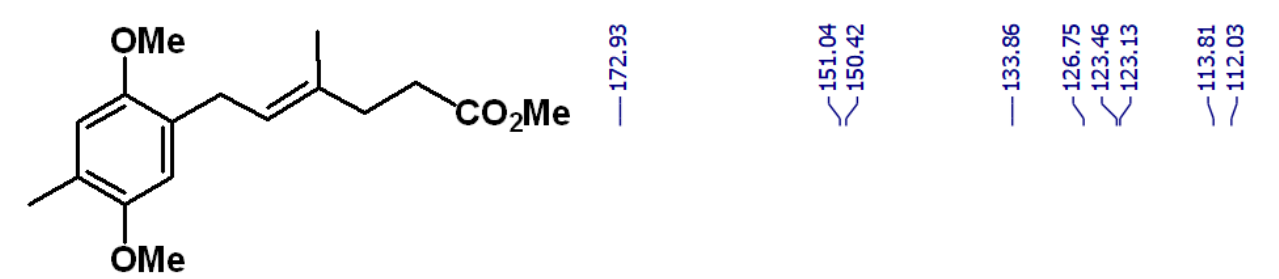

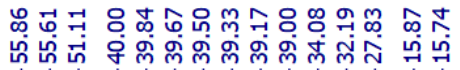

16

${ }^{13} \mathrm{C}\left\{{ }^{1} \mathrm{H}\right\} \mathrm{NMR}, 126 \mathrm{MHz}$, DMSO-d6

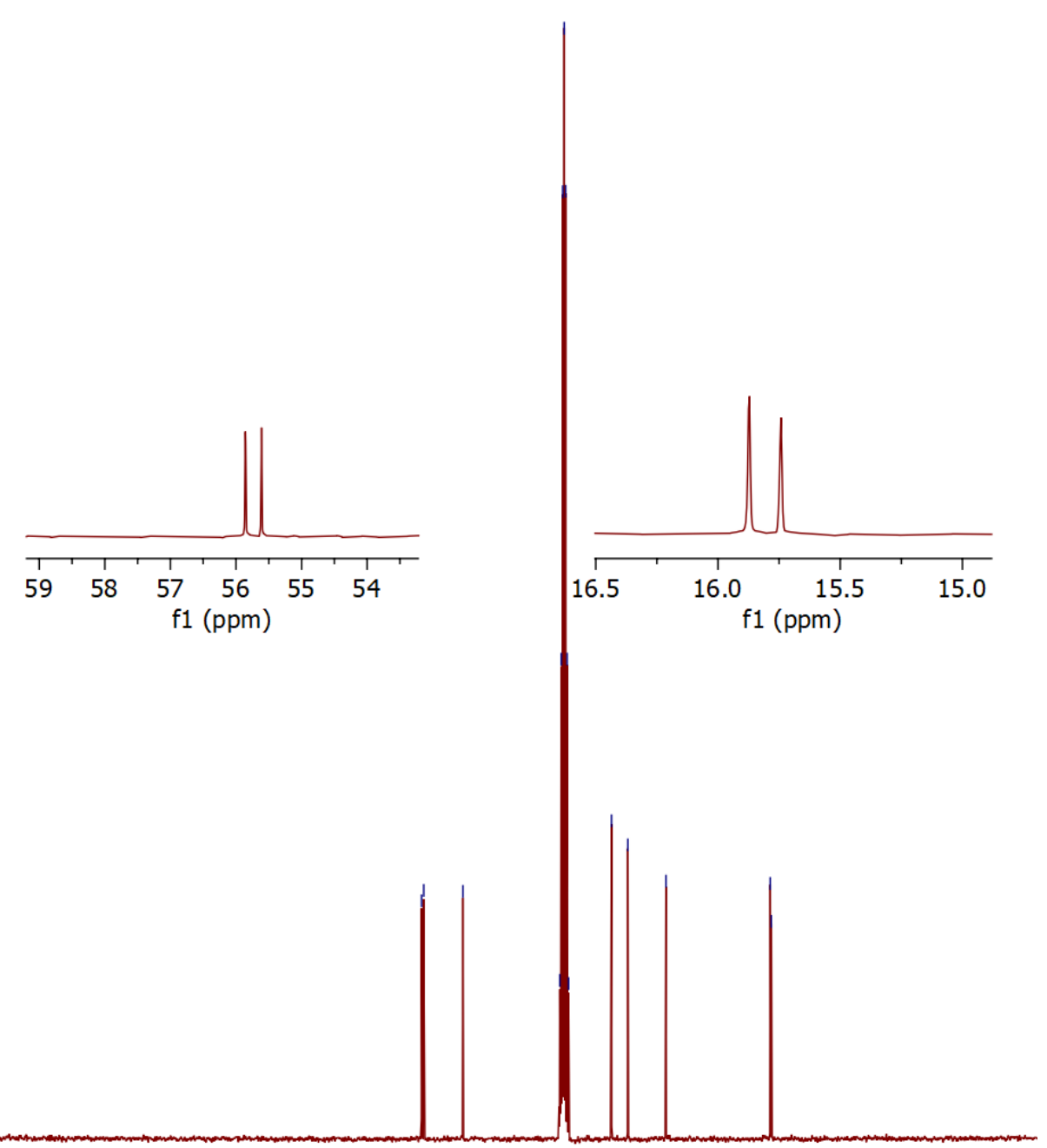




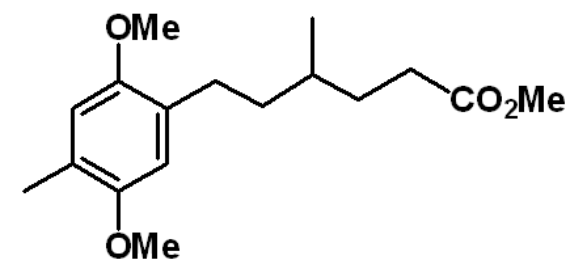

17

${ }^{1} \mathrm{H} \mathrm{NMR}, 500 \mathrm{MHz}, \mathrm{CDCl}_{3}$

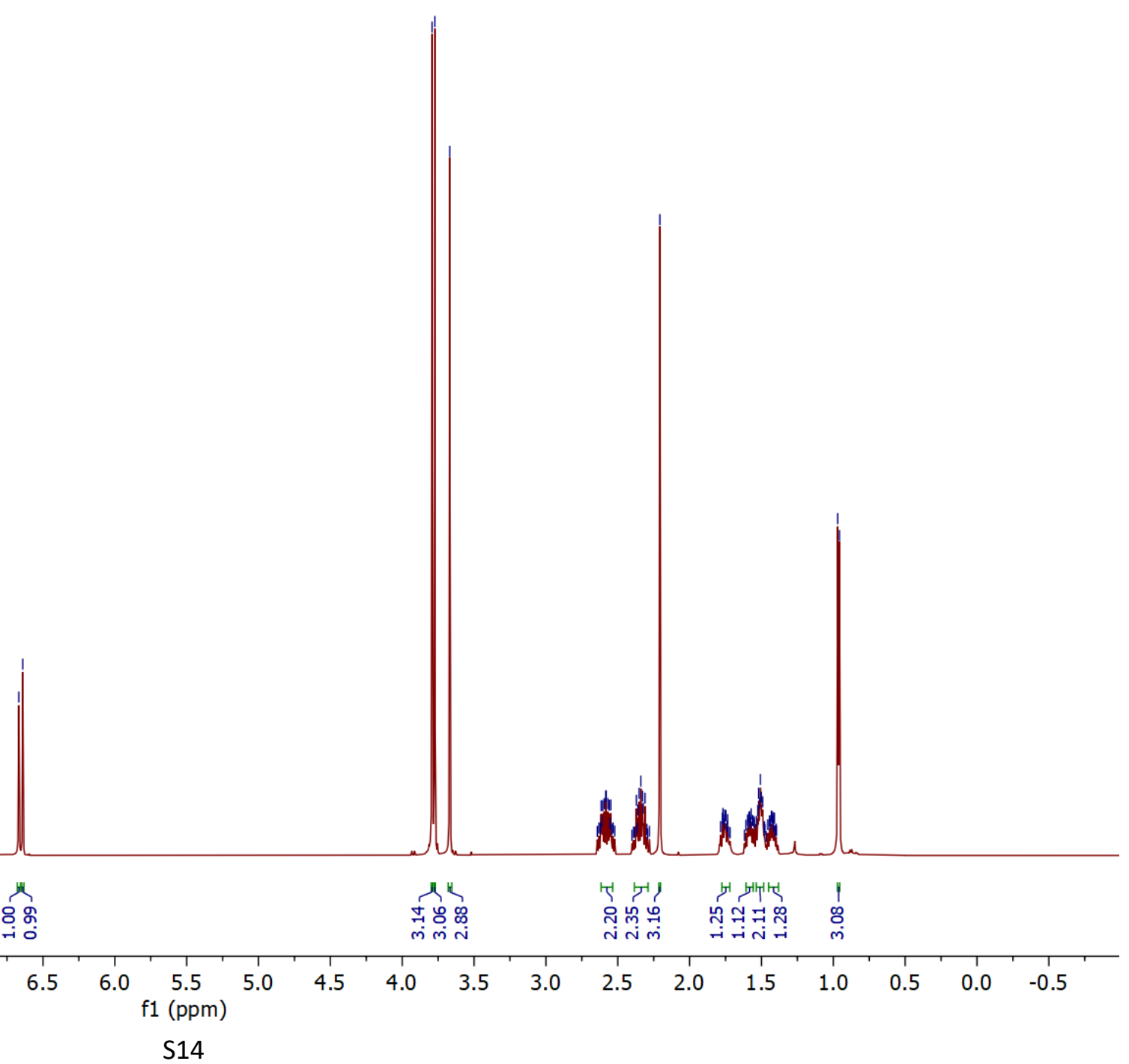




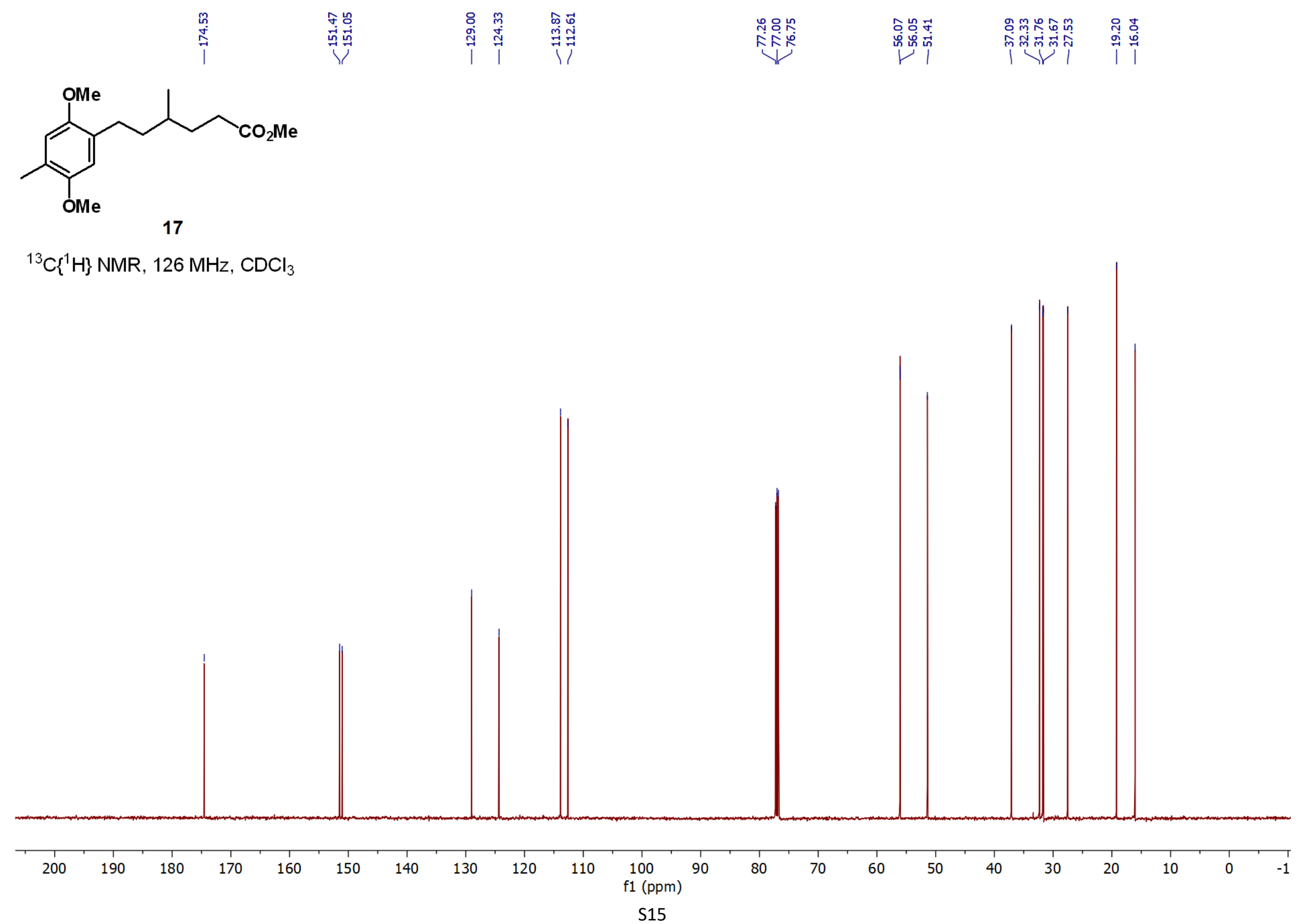




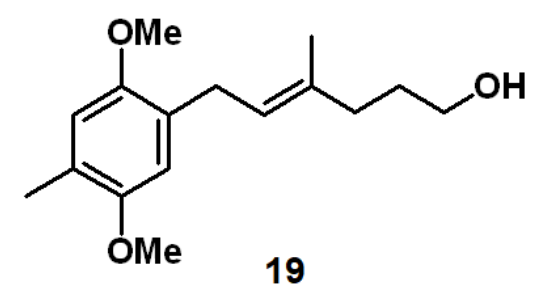

${ }^{1} \mathrm{H}$ NMR, $500 \mathrm{MHz}$, DMSO-d6

1HNMR, $500 \mathrm{MHZ}, \mathrm{DMSO}-16$

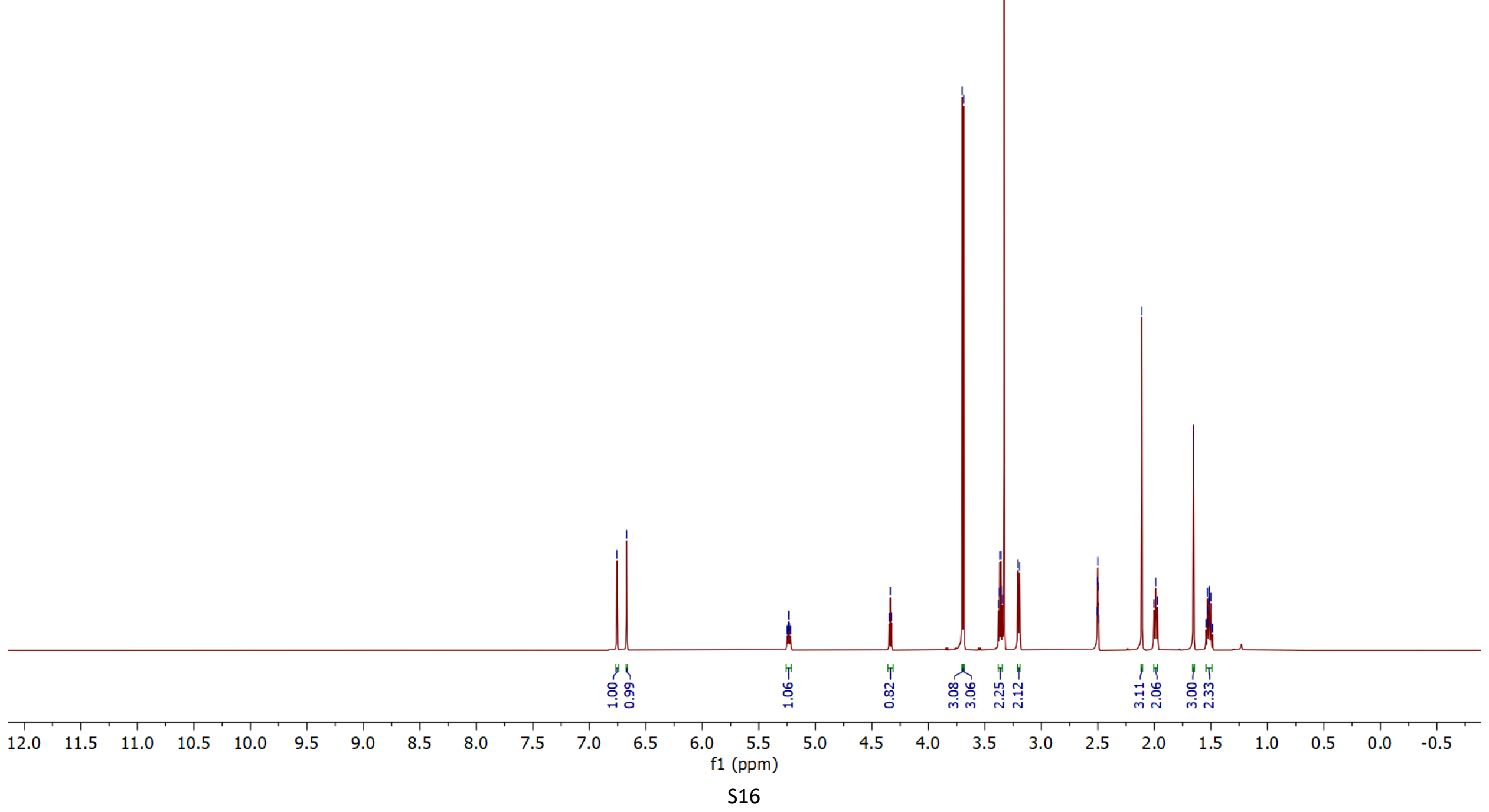




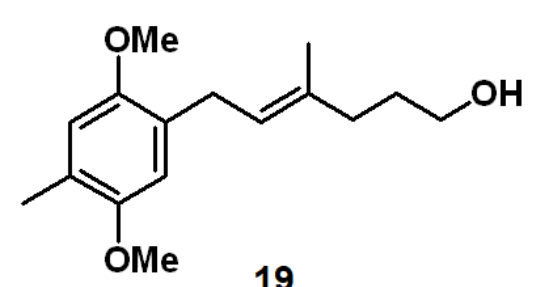

${ }^{13} \mathrm{C}\left\{{ }^{1} \mathrm{H}\right\} \mathrm{NMR}, 126 \mathrm{MHz}$, DMSO-d6
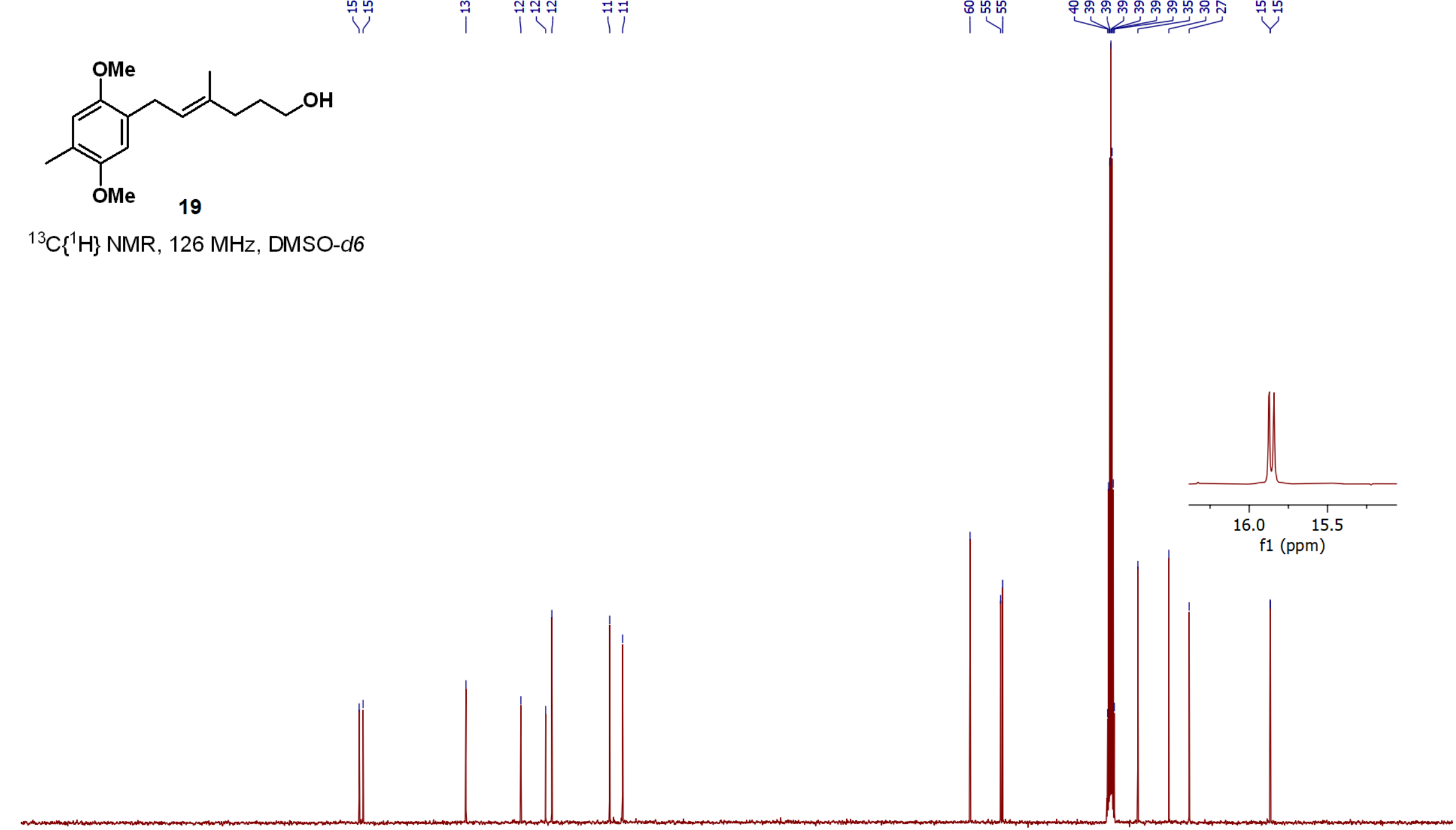


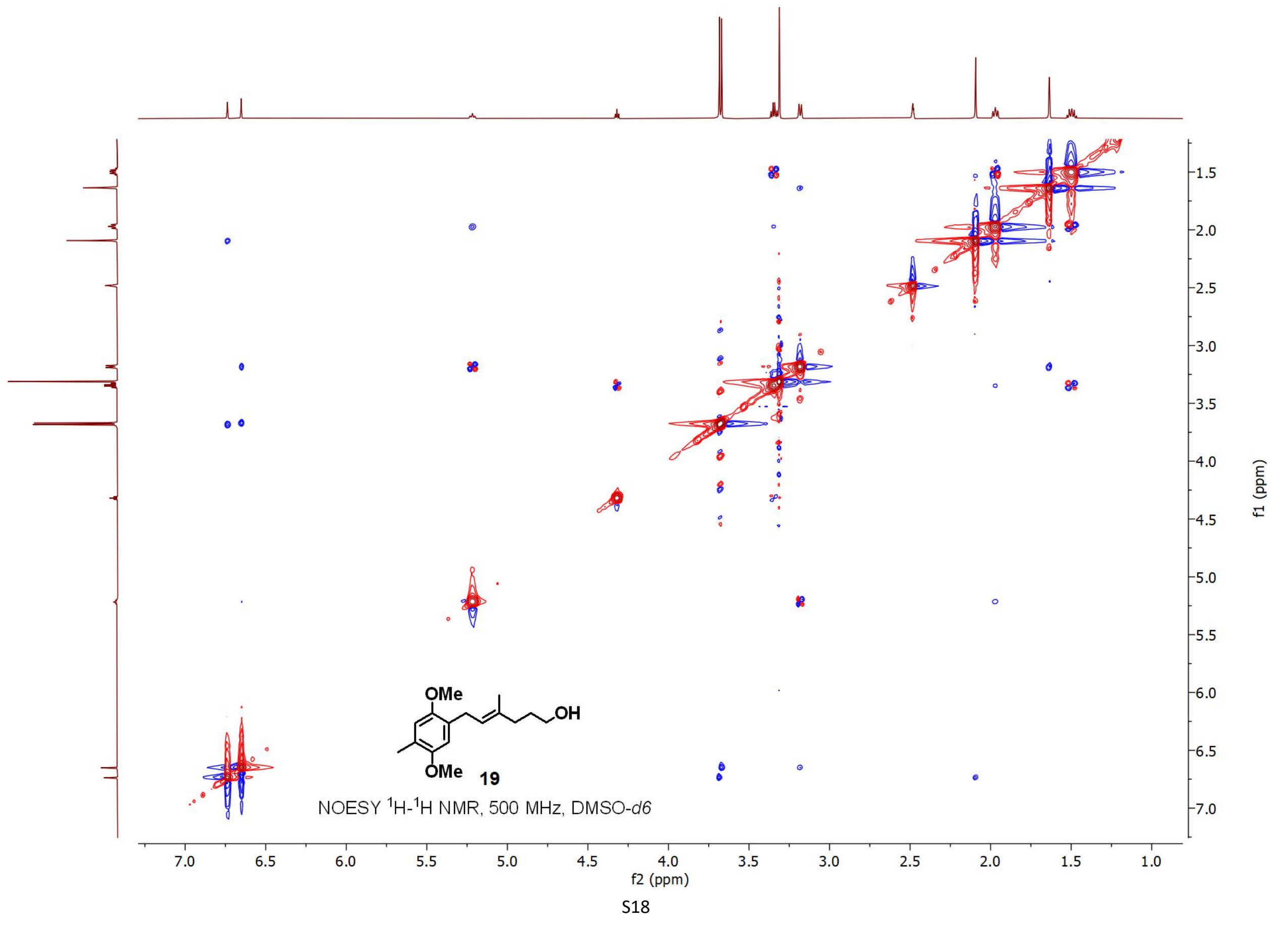




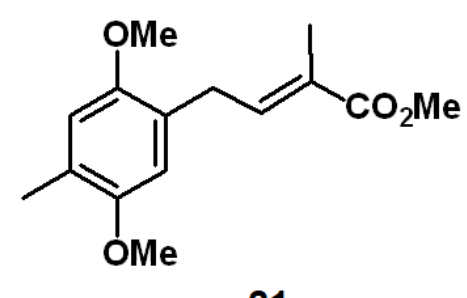

21

${ }^{1} \mathrm{H}$ NMR, $500 \mathrm{MHz}$, DMSO-d6

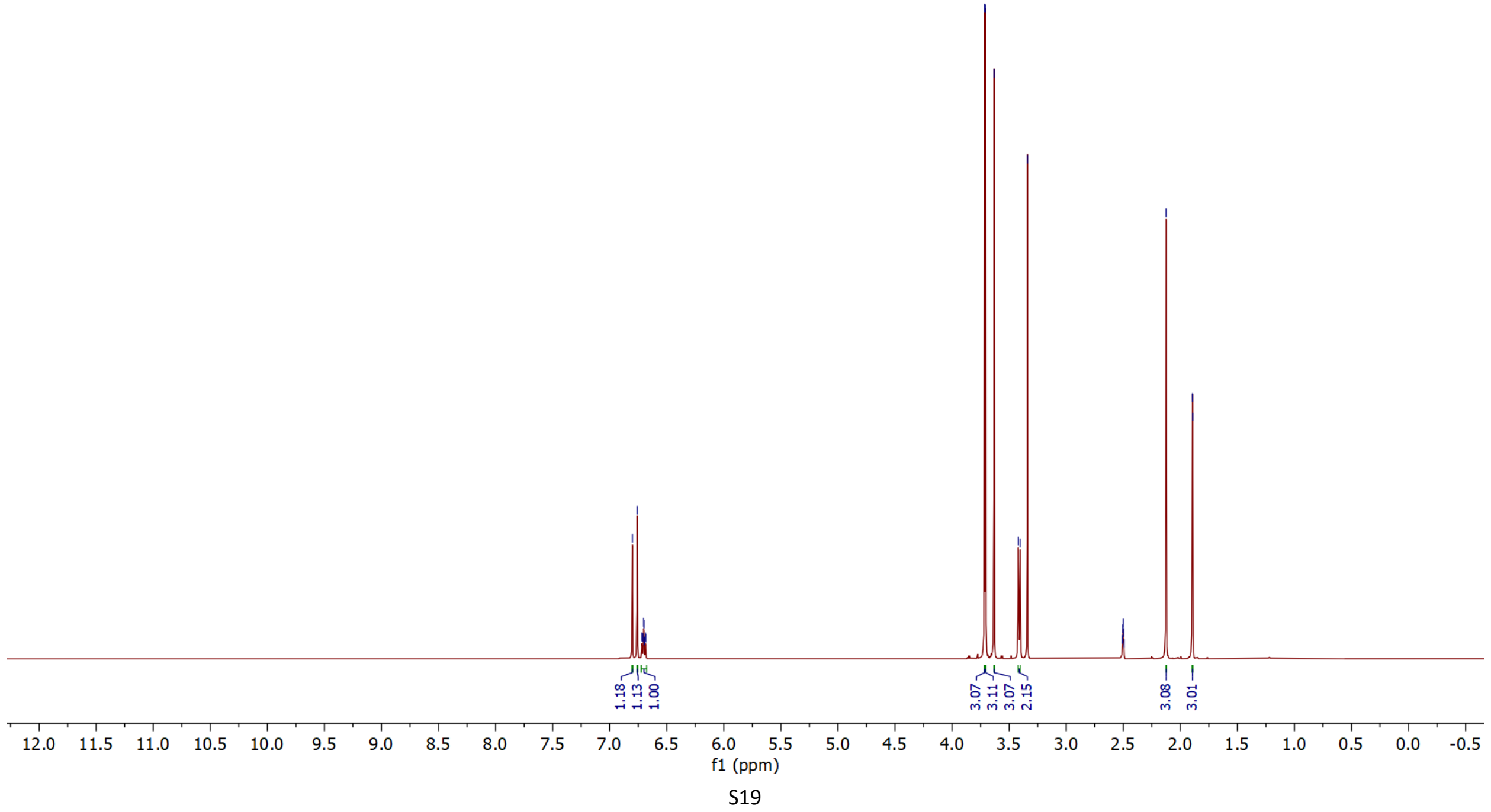




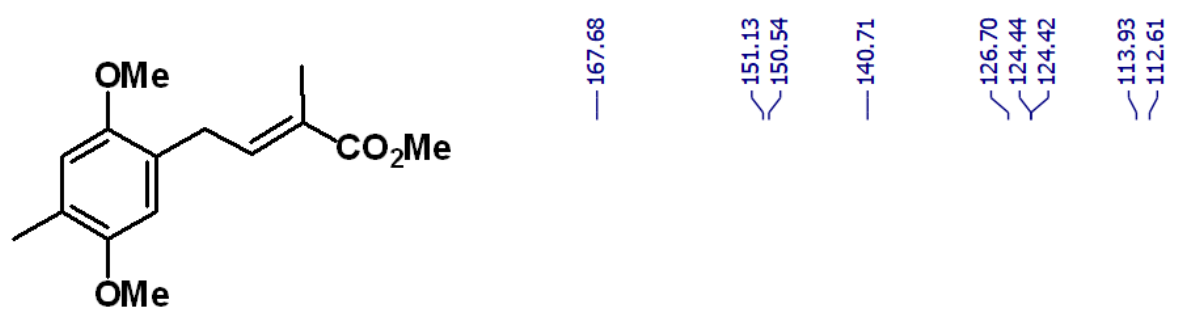

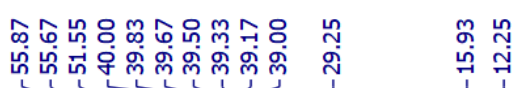

21

${ }^{13} \mathrm{C}\left\{{ }^{1} \mathrm{H}\right\} \mathrm{NMR}, 126 \mathrm{MHz}$, DMSO-d6
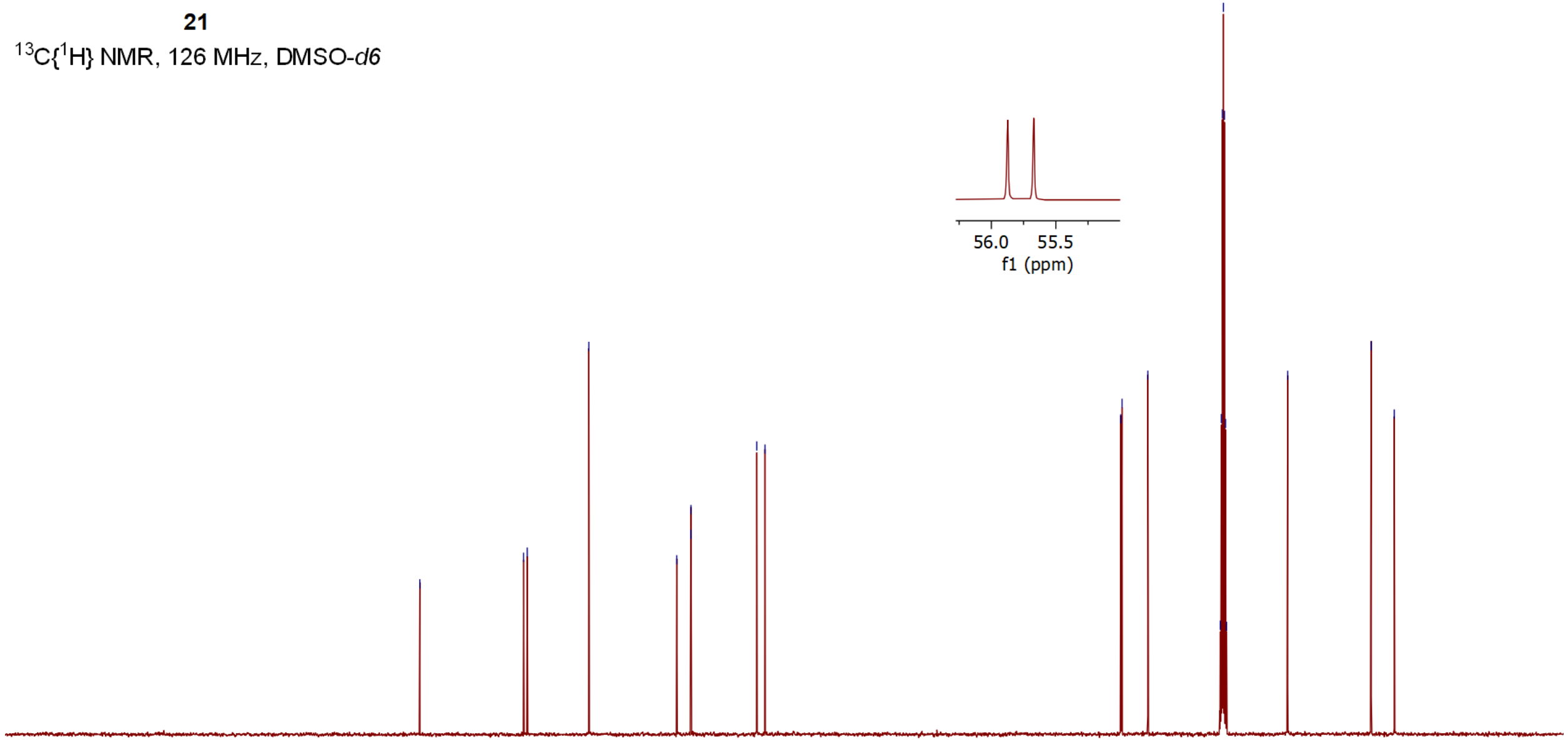


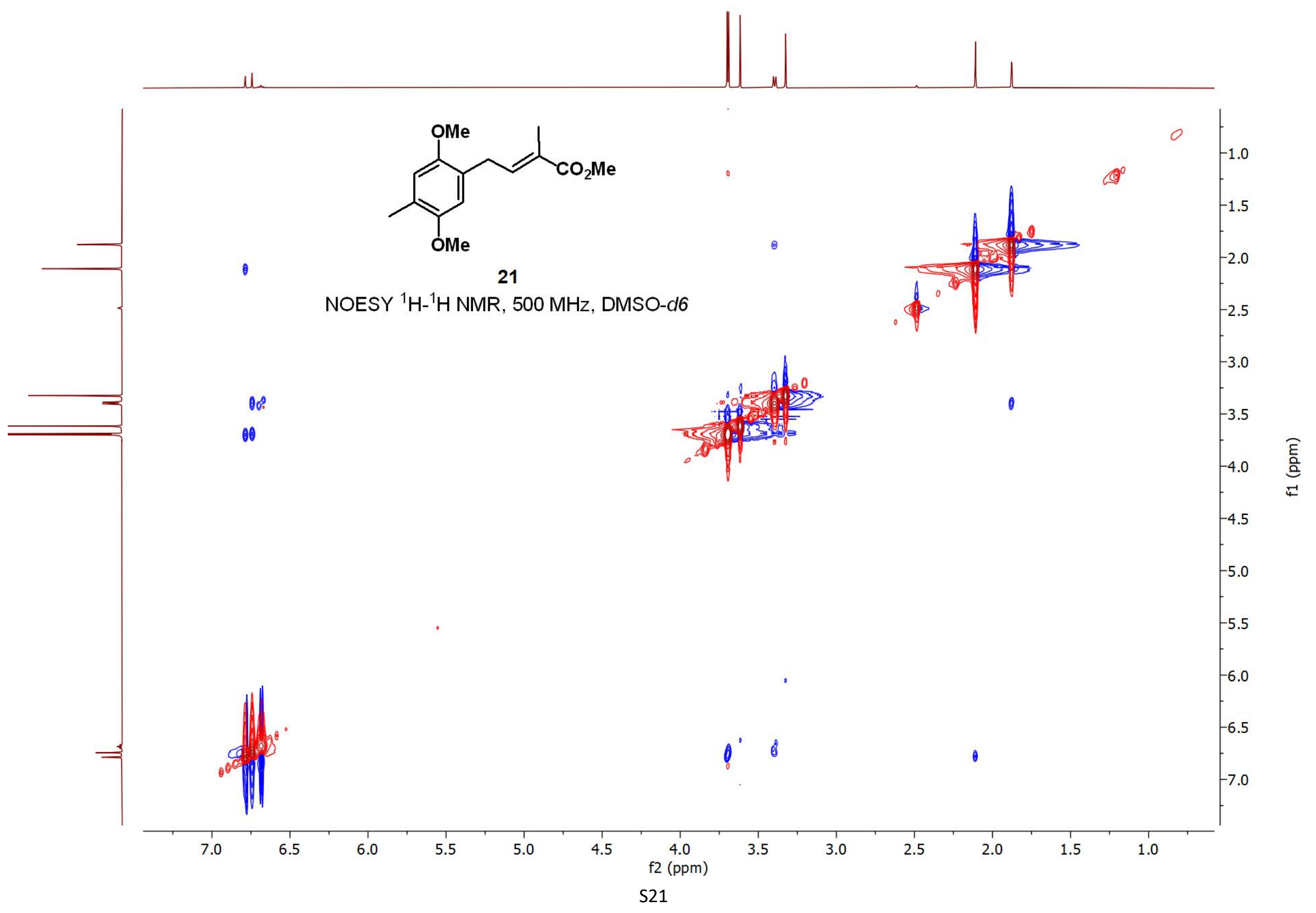




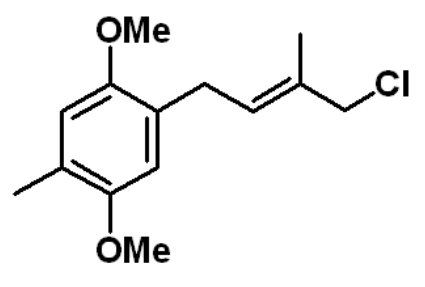

${ }^{1} \mathrm{H}$ NMR, $500 \mathrm{MHz}$, DMSO-d6

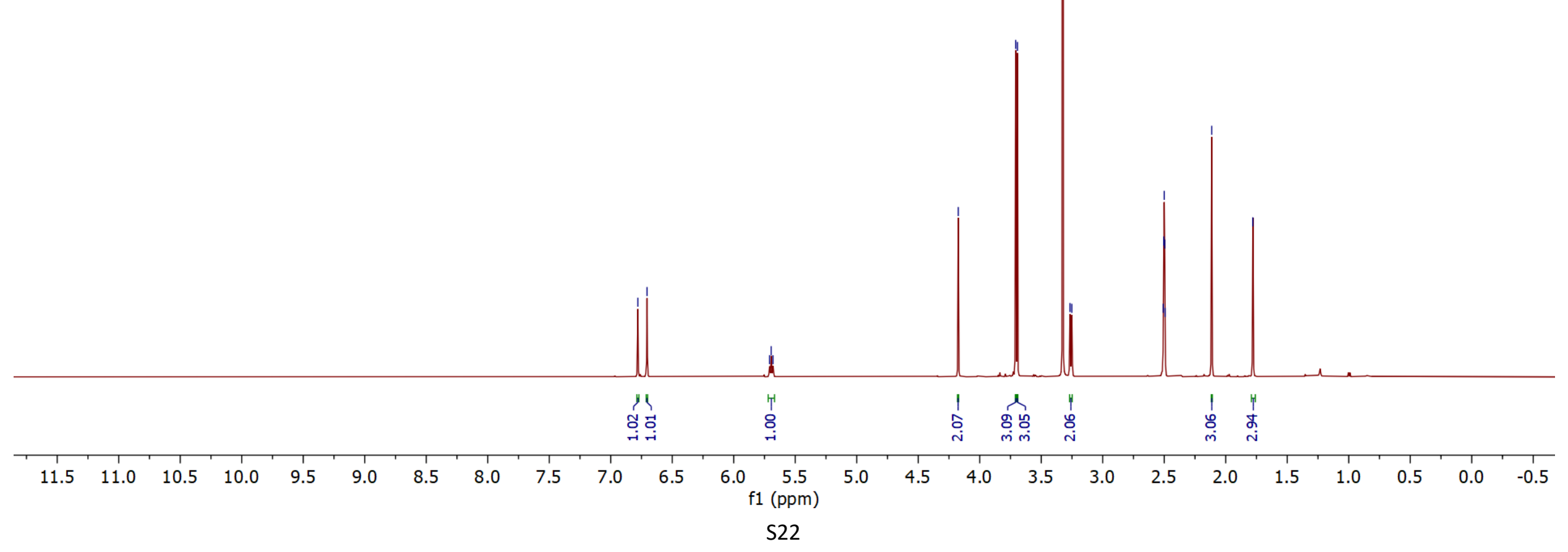




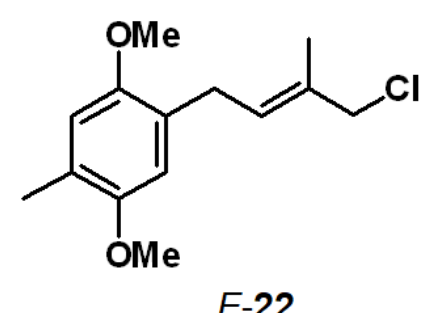

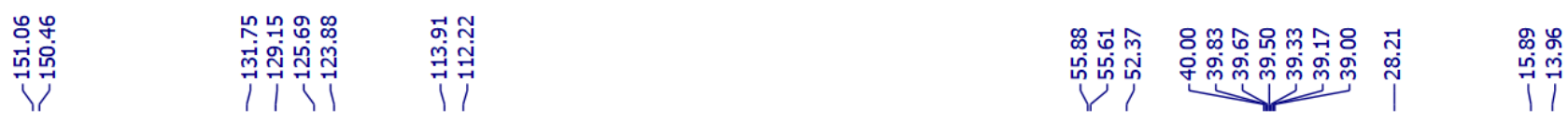

${ }^{13} \mathrm{C}\left\{{ }^{1} \mathrm{H}\right\} \mathrm{NMR}, 126 \mathrm{MHz}$, DMSO-d6

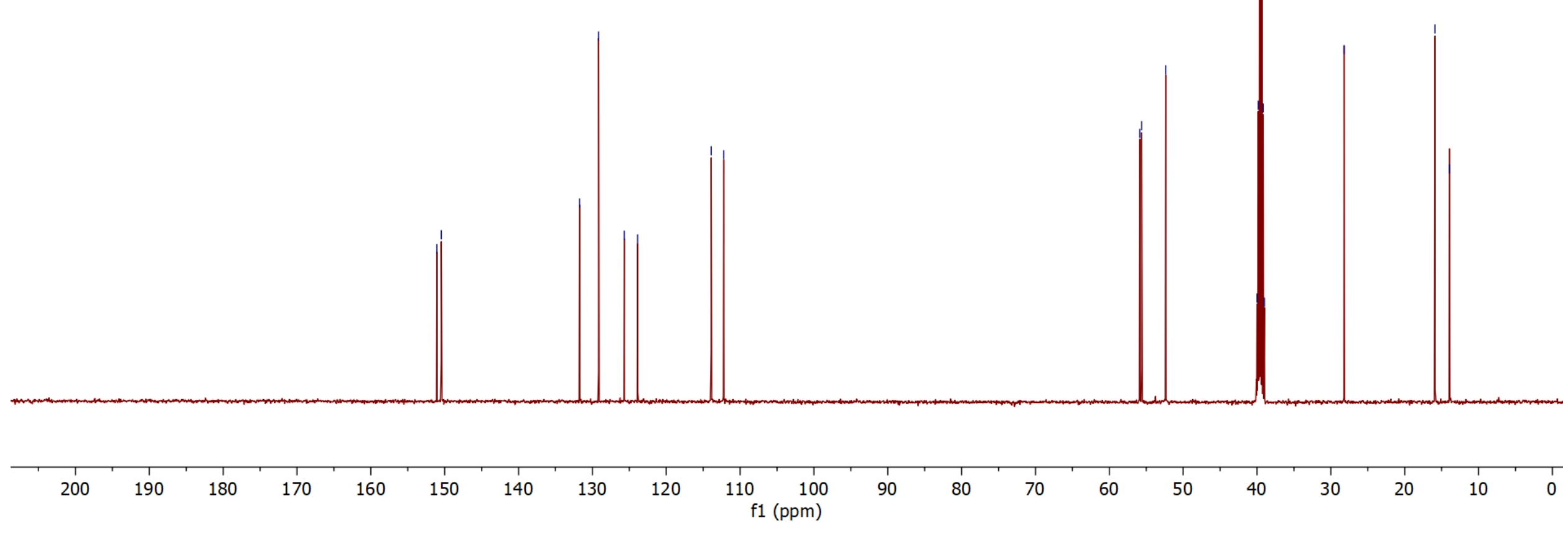




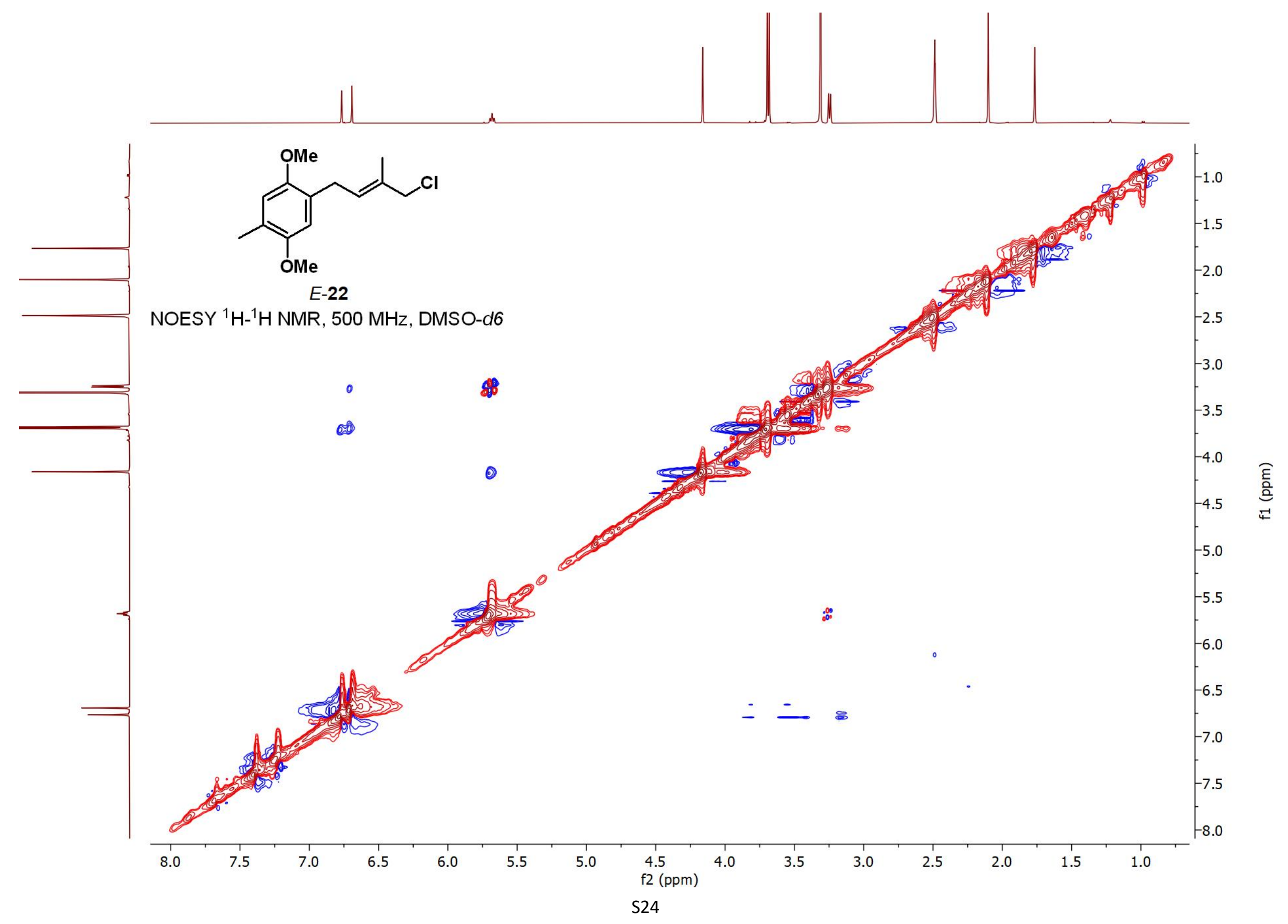




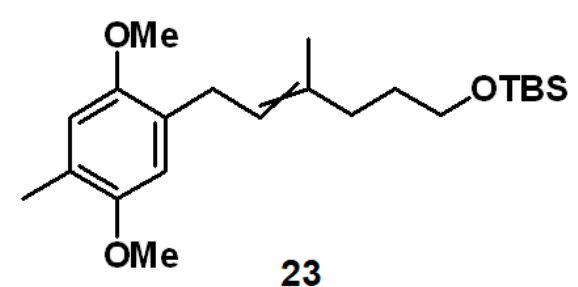

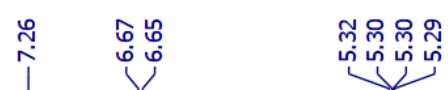

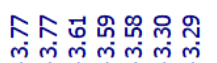

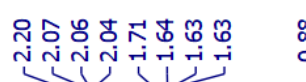

$\stackrel{m}{i}$

${ }^{1} \mathrm{H}$ NMR, $500 \mathrm{MHz}, \mathrm{CDCl}_{3}$

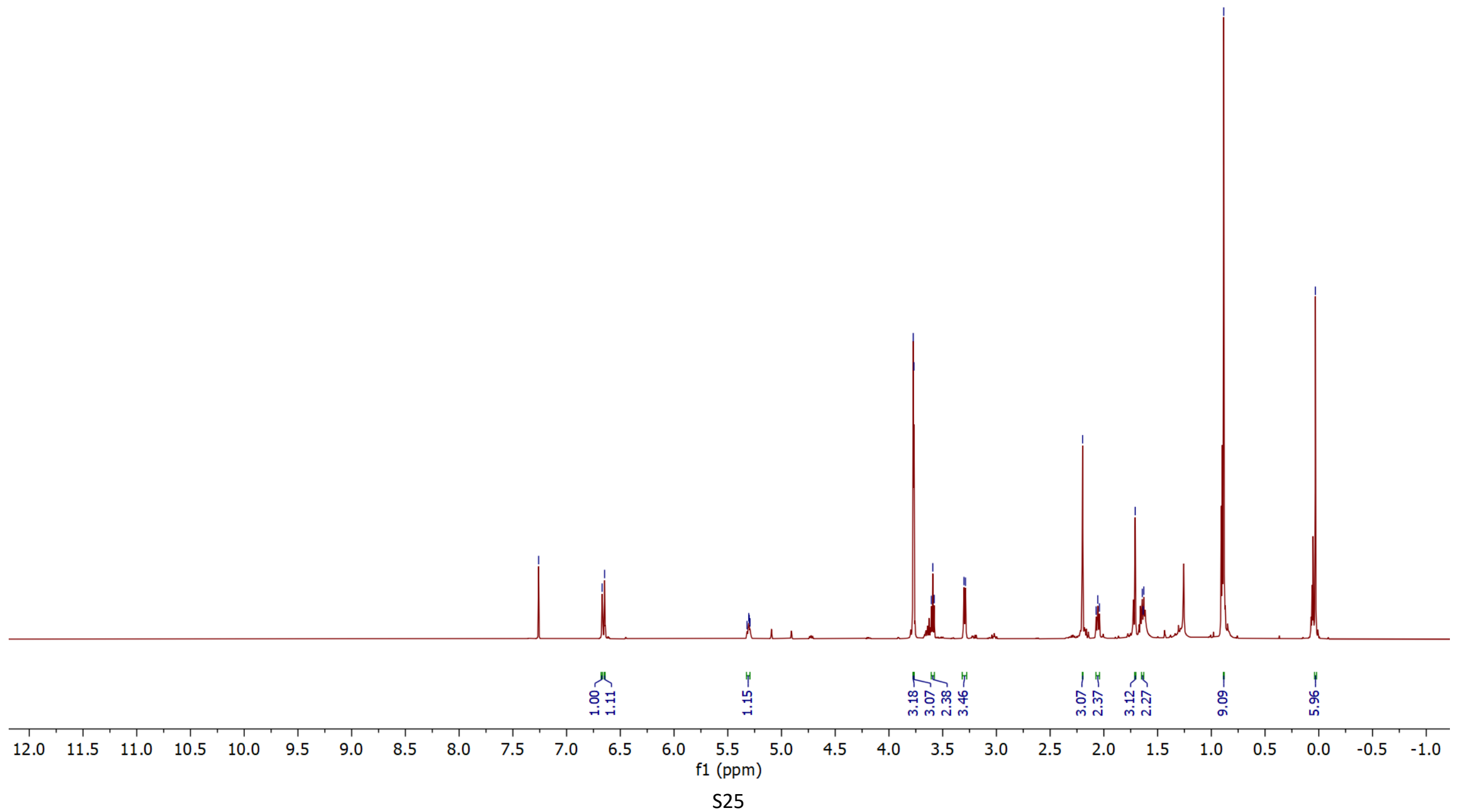



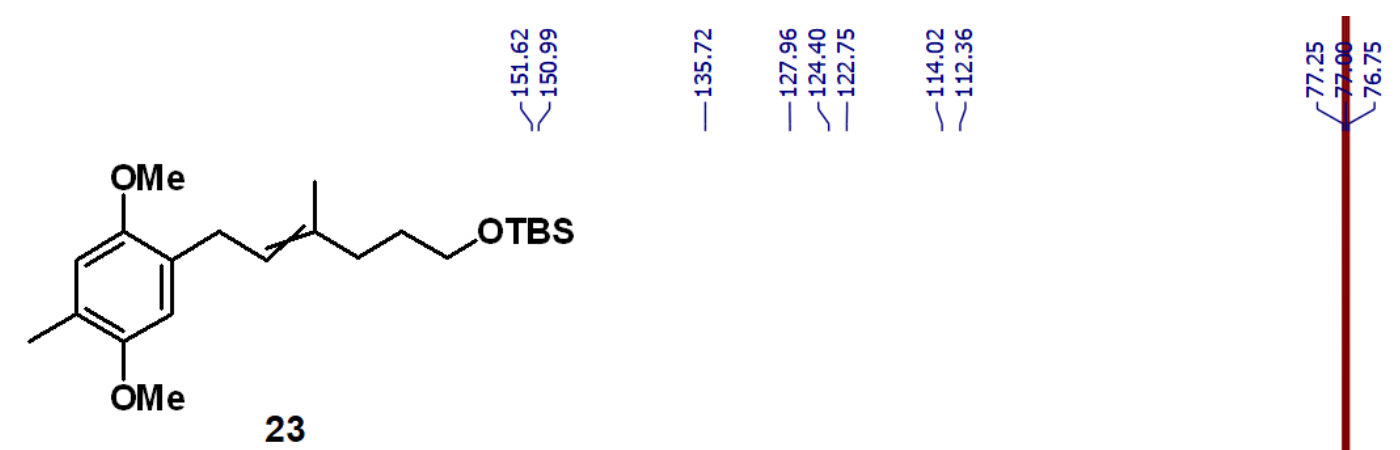

茫

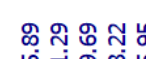

$m \infty$

în

$-15$

${ }^{13} \mathrm{C}\left\{{ }^{1} \mathrm{H}\right\} \mathrm{NMR}, 126 \mathrm{MHz}, \mathrm{CDCl}_{3}$

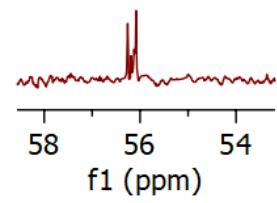




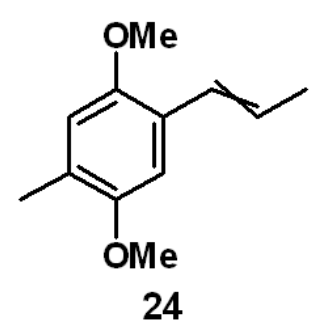

${ }^{1} \mathrm{H} \mathrm{NMR}, 500 \mathrm{MHz}, \mathrm{CDCl}_{3}$

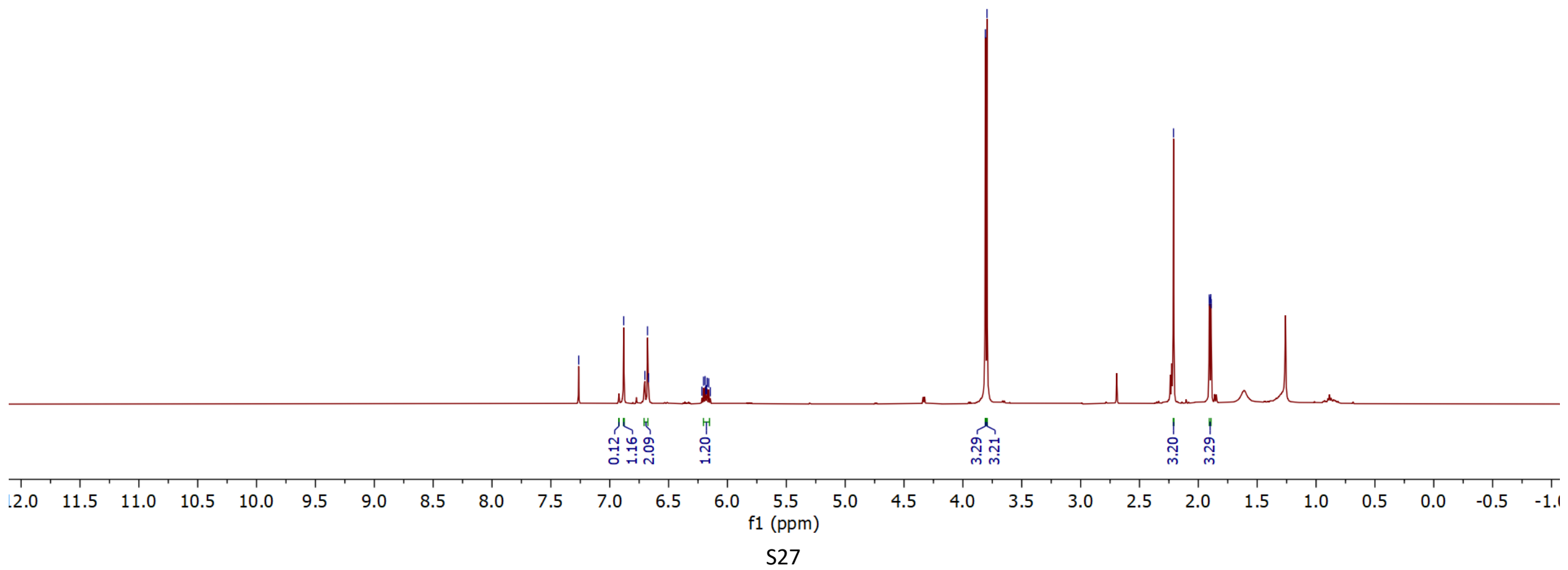




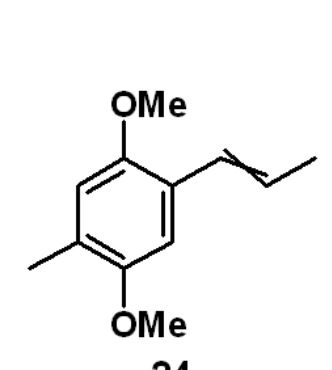

욱

웅요

离

24

${ }^{13} \mathrm{C}\left\{{ }^{1} \mathrm{H}\right\} \mathrm{NMR}, 126 \mathrm{MHz}, \mathrm{CDCl}_{3}$

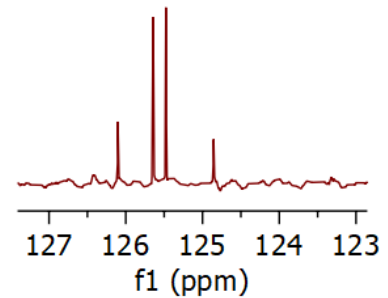

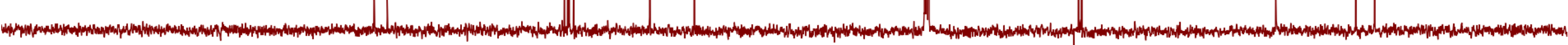




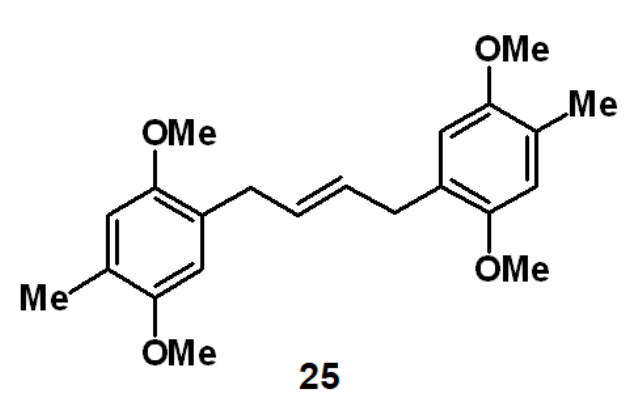

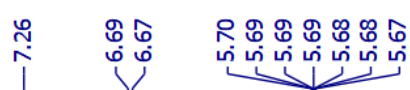

খ

${ }^{1} \mathrm{H} \mathrm{NMR}, 500 \mathrm{MHz}, \mathrm{CDCl}_{3}$

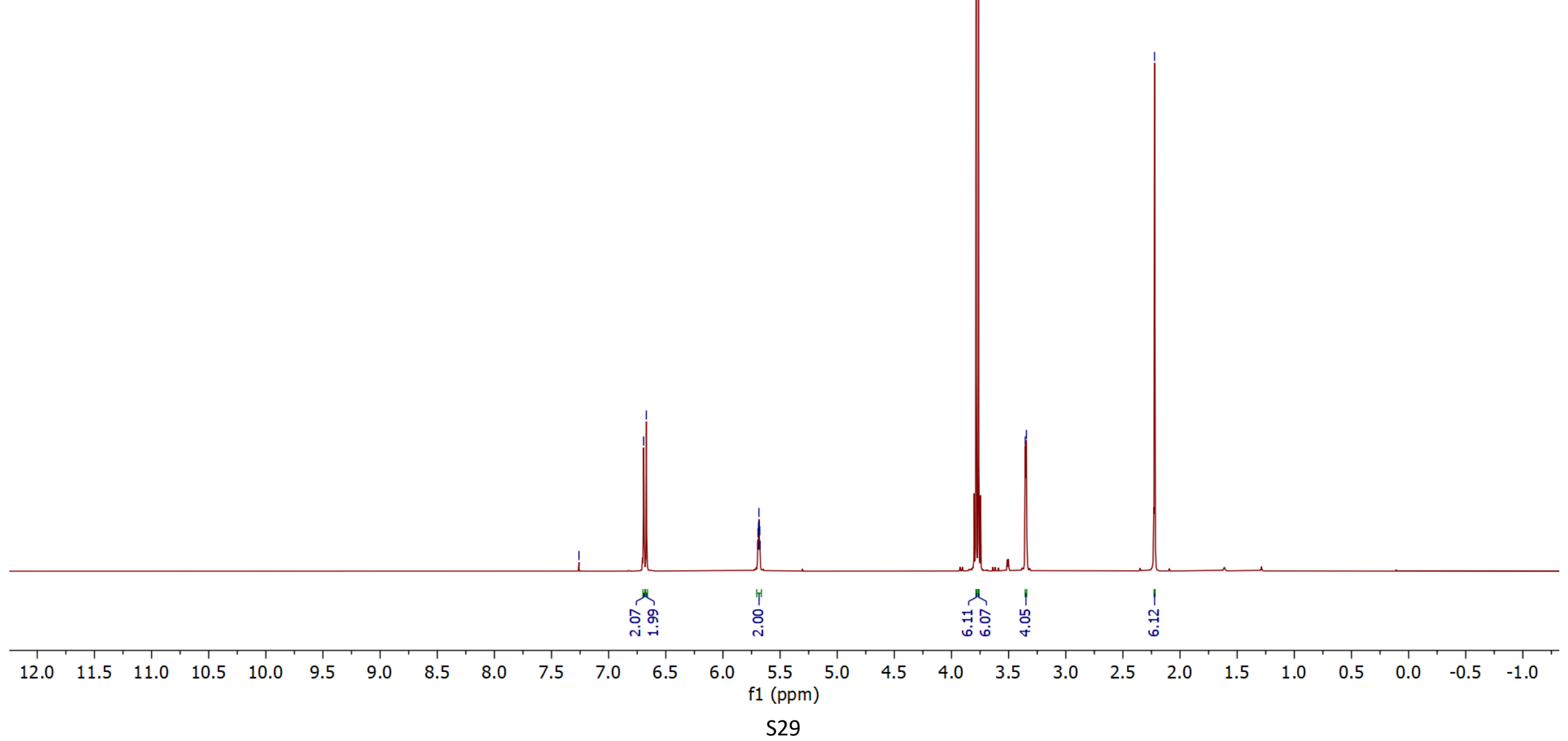




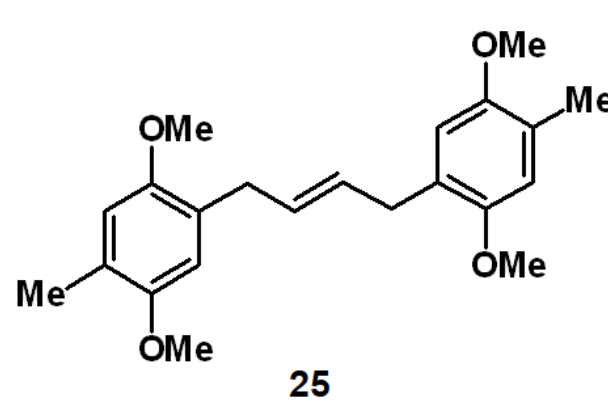

${ }^{13} \mathrm{C}\left\{{ }^{1} \mathrm{H}\right\} \mathrm{NMR}, 126 \mathrm{MHz}, \mathrm{CDCl}_{3}$

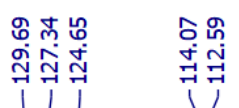

ำ

年年

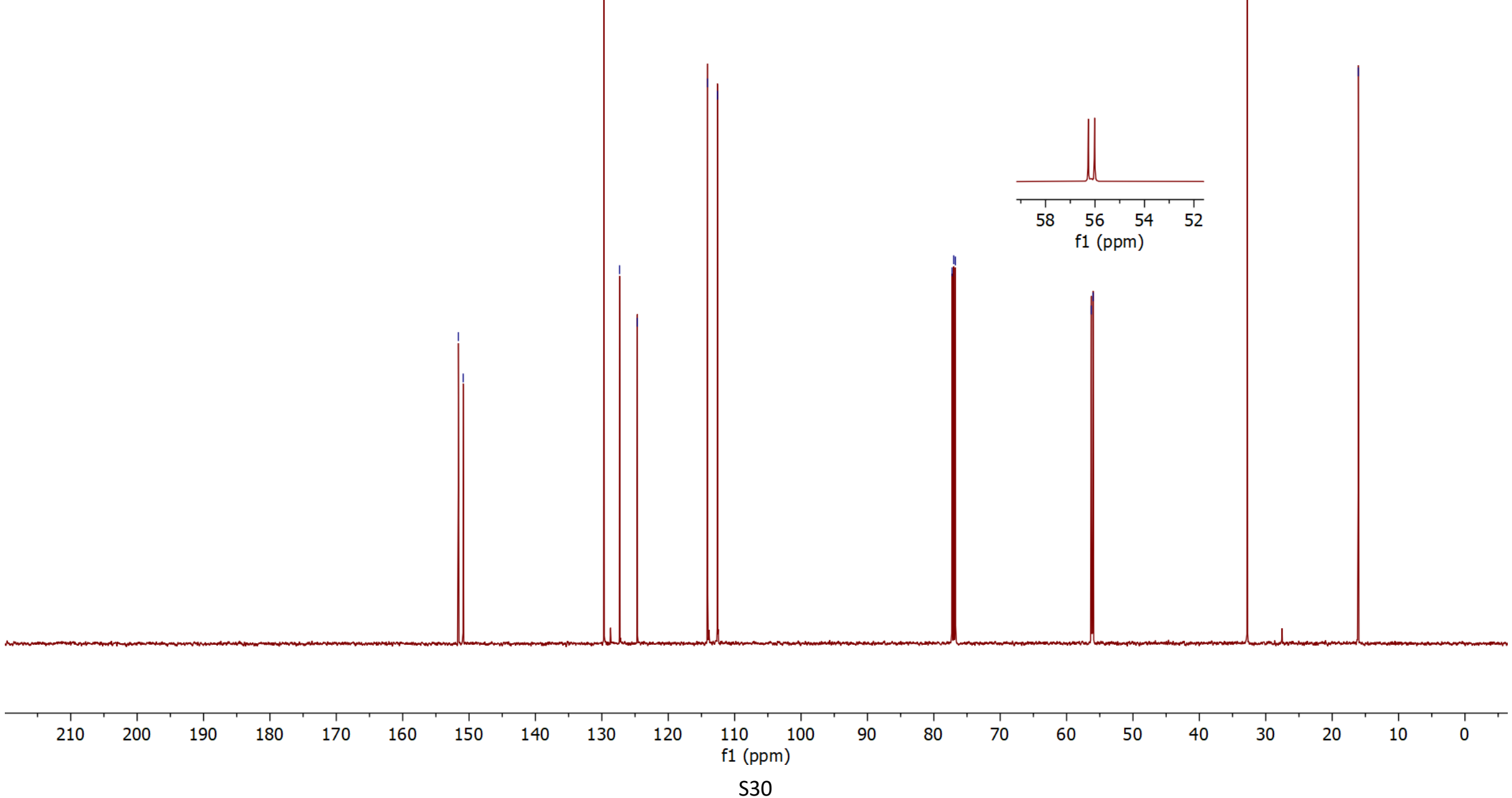




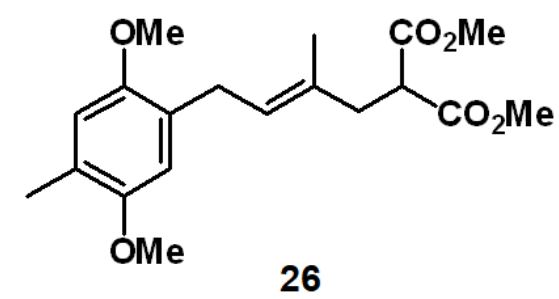

${ }^{1} \mathrm{H}$ NMR, $500 \mathrm{MHz}$, DMSO-d6

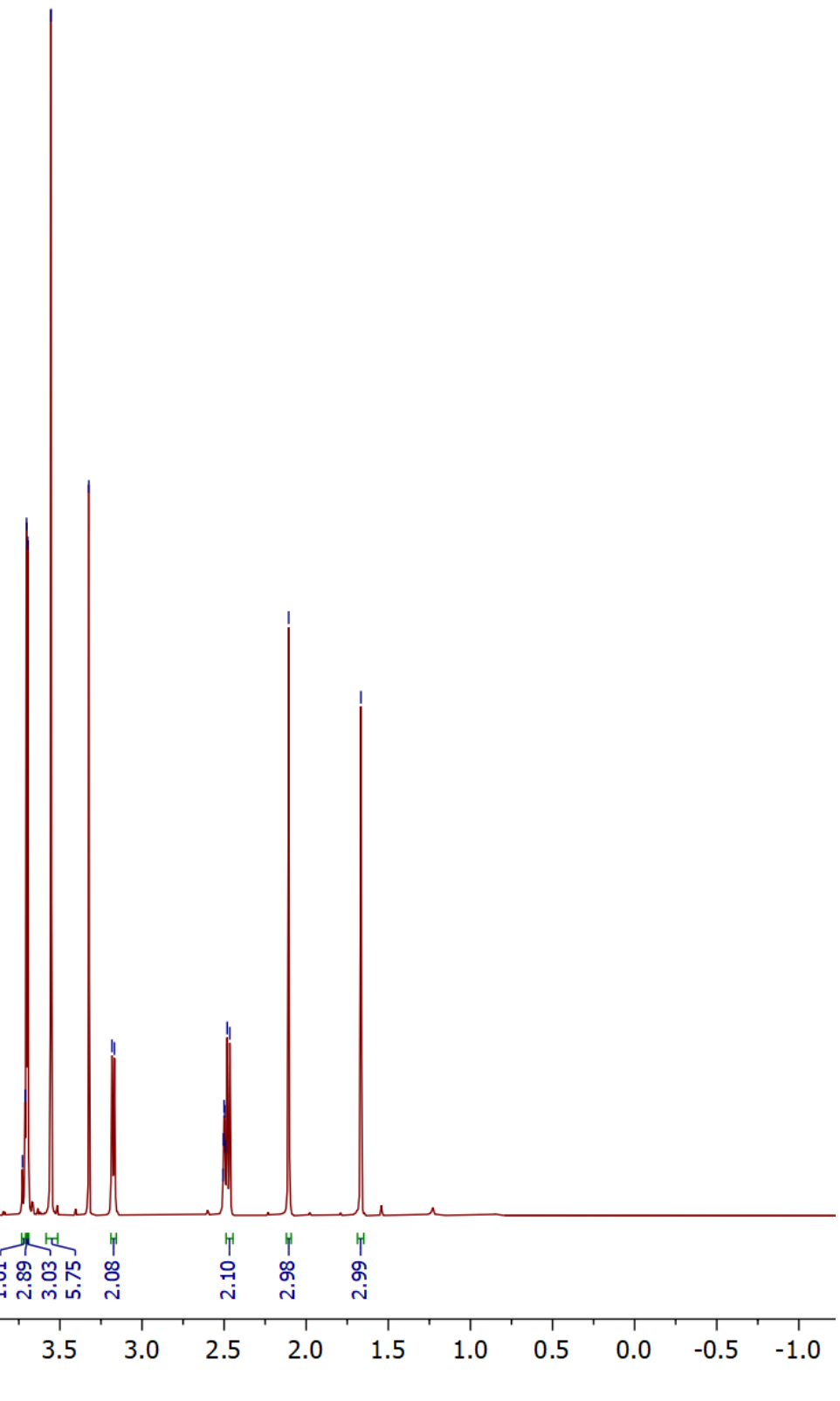

$\begin{array}{lllllll}2.0 & 11.5 & 11.0 & 10.5 & 10.0 & 9.5 & 9.0\end{array}$

$\begin{array}{lllllll}8.5 & 8.0 & 7.5 & 7.0 & 6.5 & 6.0 & \begin{array}{c}5.5 \\ \mathrm{f} 1(\mathrm{ppm})\end{array}\end{array}$




lo

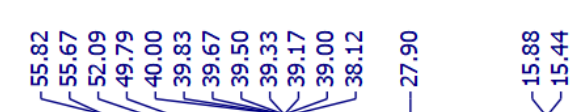

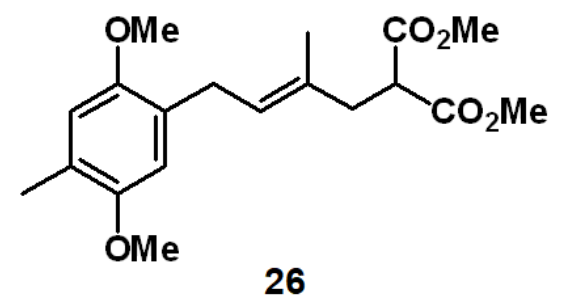

${ }^{13} \mathrm{C}\left\{{ }^{1} \mathrm{H}\right\} \mathrm{NMR}, 126 \mathrm{MHz}$, DMSO-d6
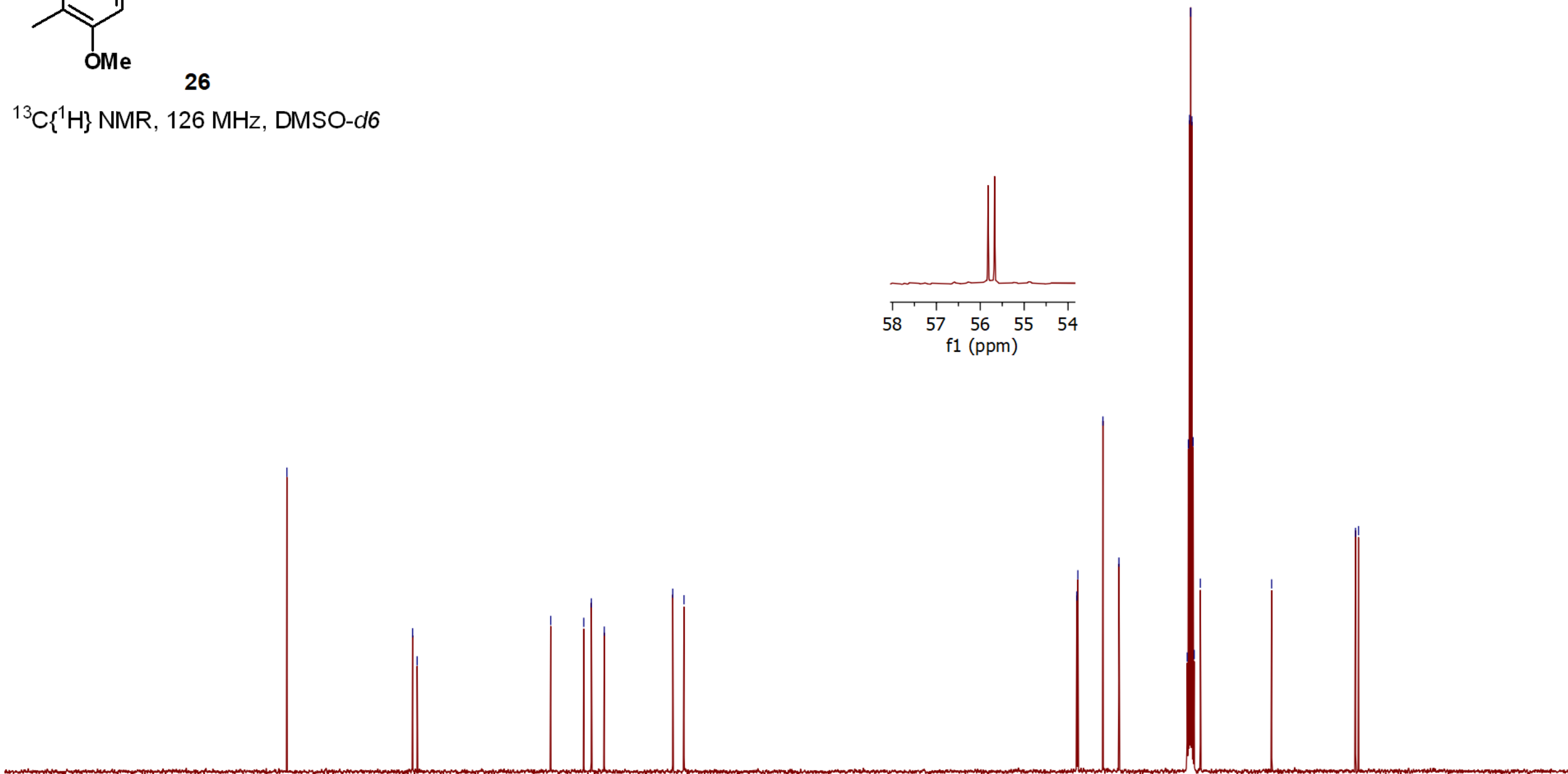


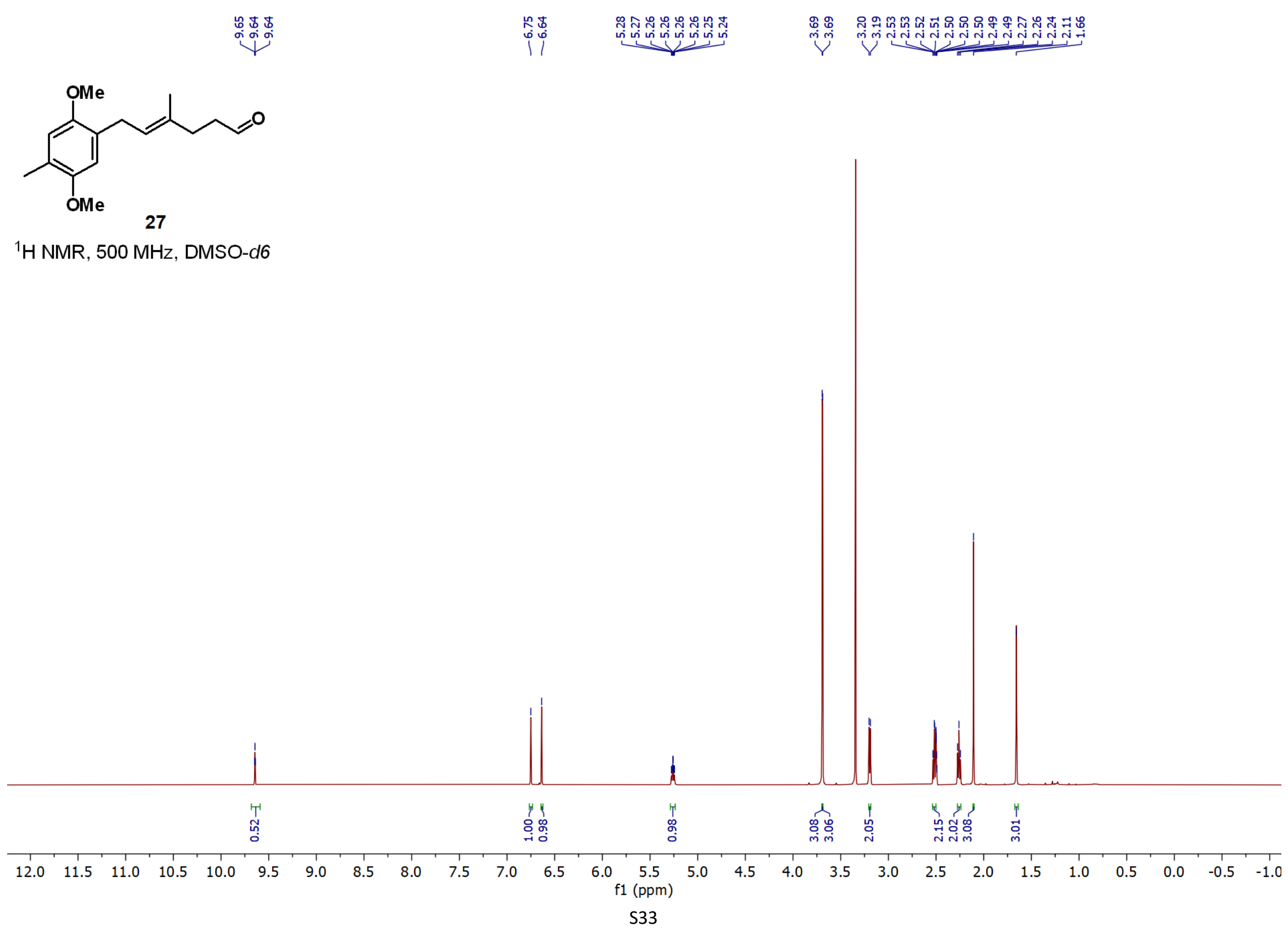




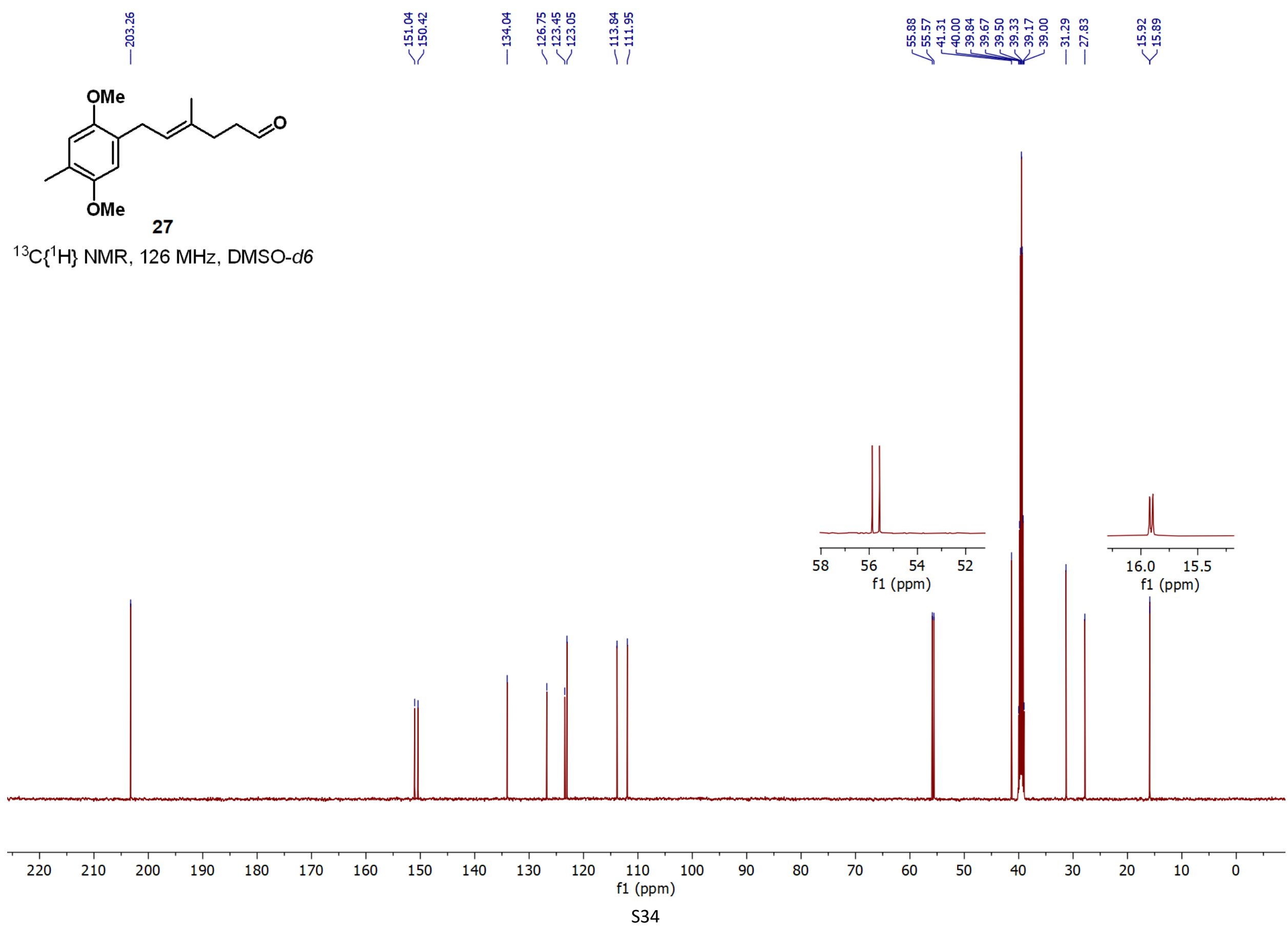




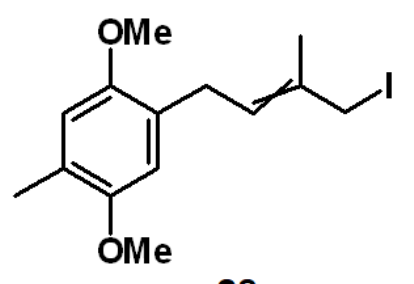

${ }^{1} \mathrm{H}$ NMR, $500 \mathrm{MHz}$, DMSO-d6

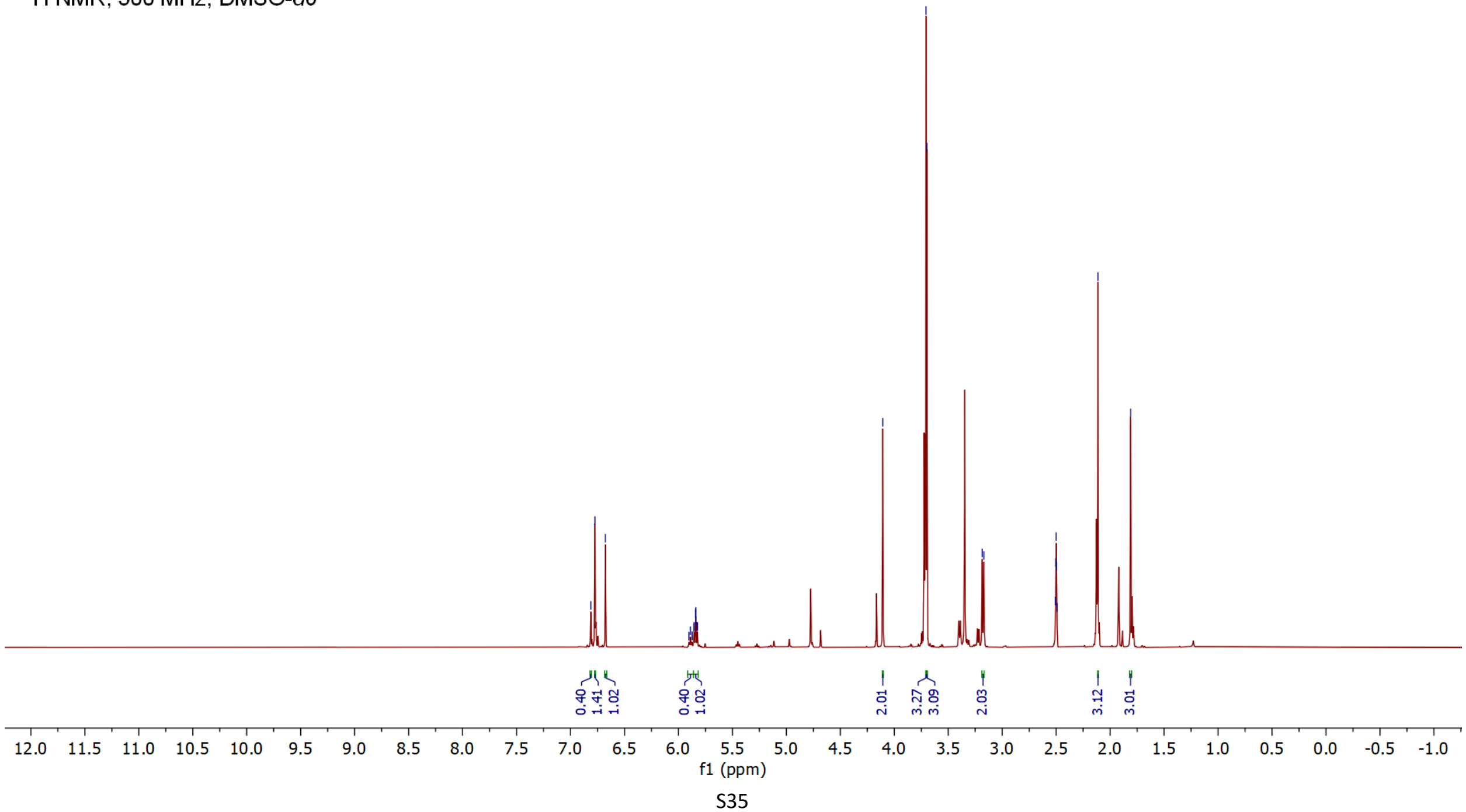




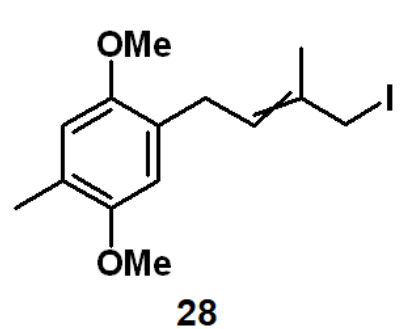

my

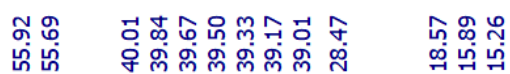

28

${ }^{13} \mathrm{C}\left\{{ }^{1} \mathrm{H}\right\} \mathrm{NMR}, 126 \mathrm{MHz}$, DMSO-d6

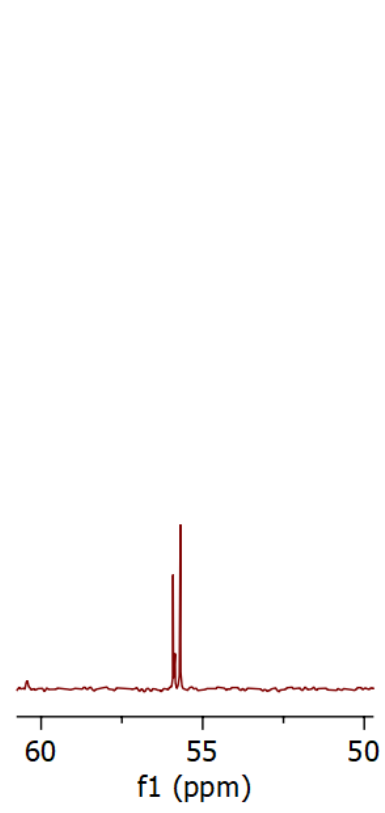




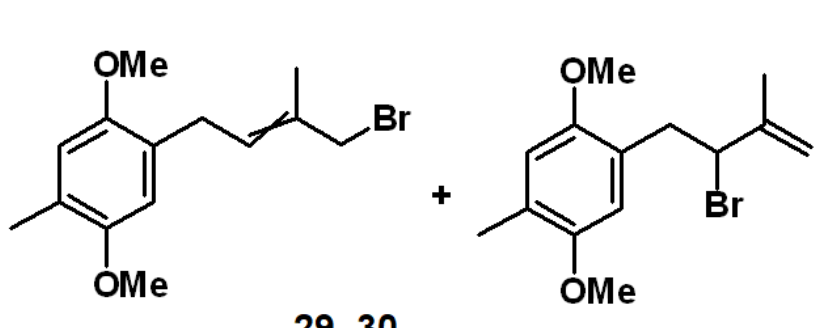

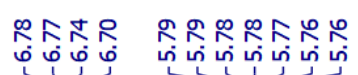

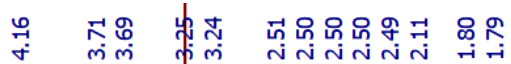

29,30

${ }^{1} \mathrm{H}$ NMR, $500 \mathrm{MHz}$, DMSO-d6

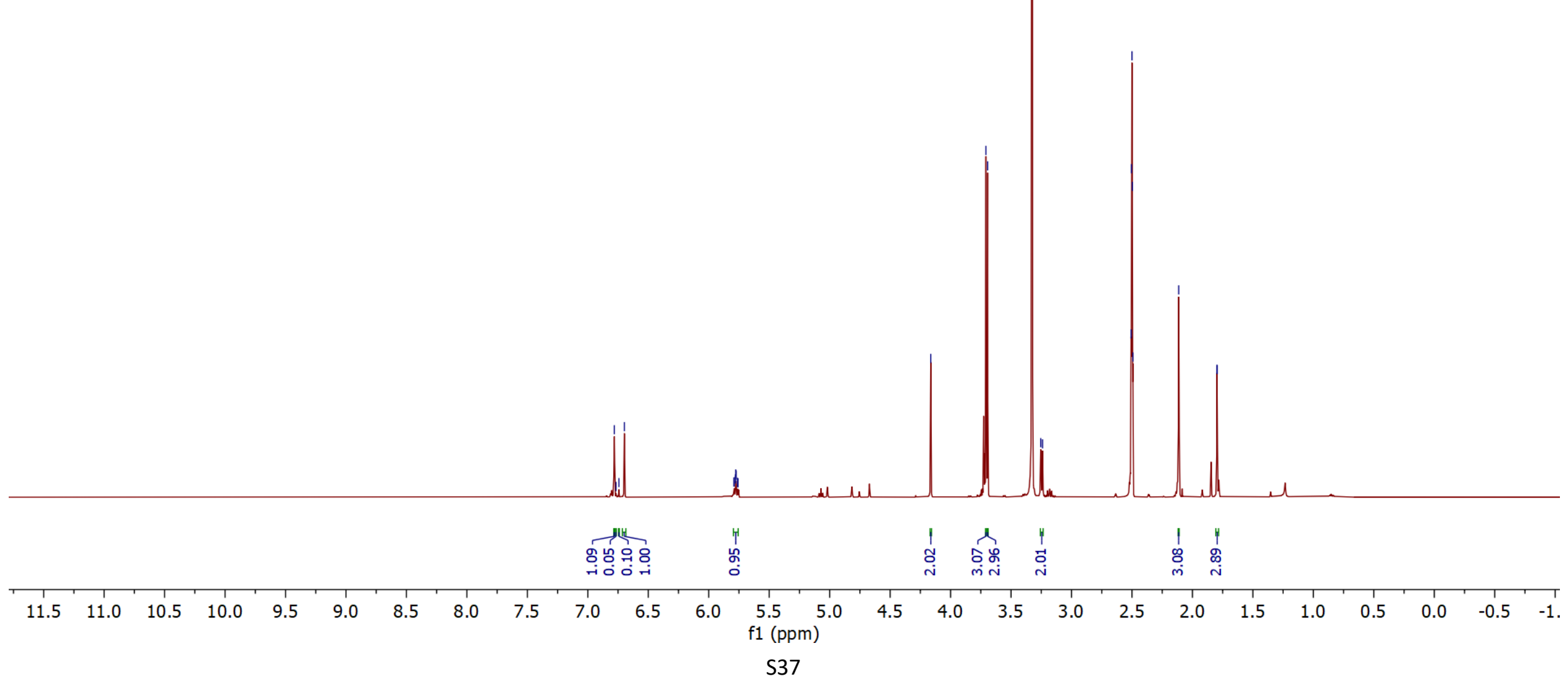




|l

\丶<smiles>C=C(C)C(Br)Cc1cc(OC)c(C)cc1OC</smiles>

29, 30

${ }^{13} \mathrm{C}\left\{{ }^{1} \mathrm{H}\right\}$ NMR, $126 \mathrm{MHz}$, DMSO-d6

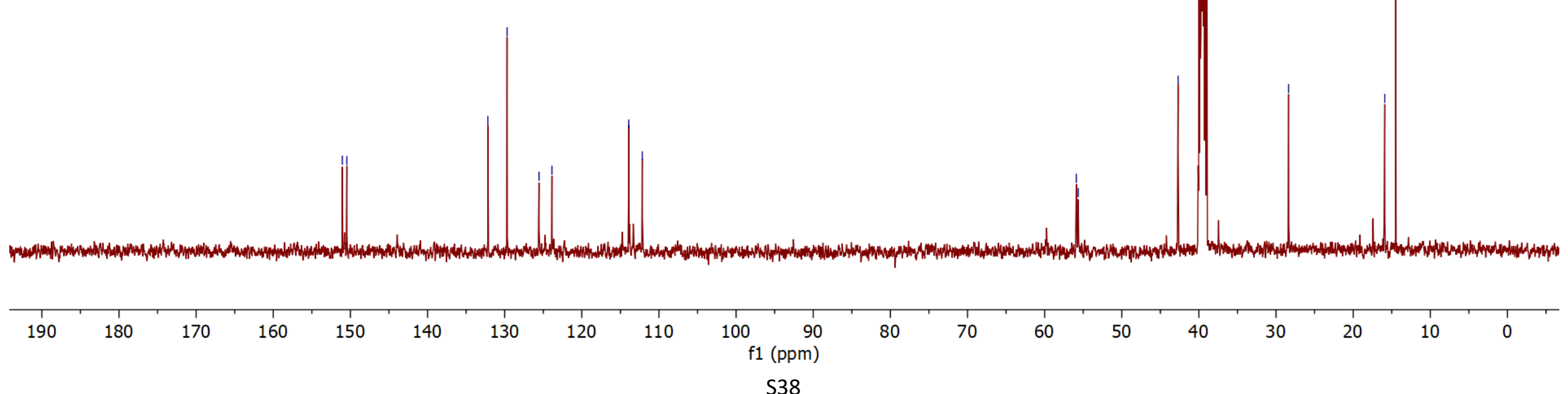




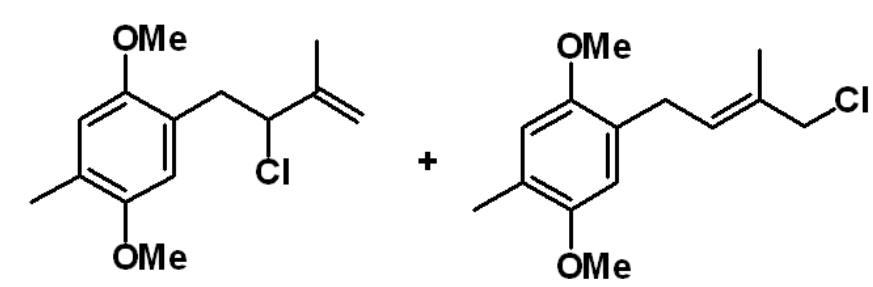

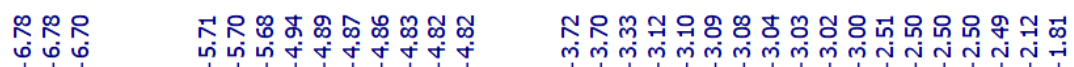

31, E-22

${ }^{1} \mathrm{H}$ NMR, $500 \mathrm{MHz}$, DMSO-d6

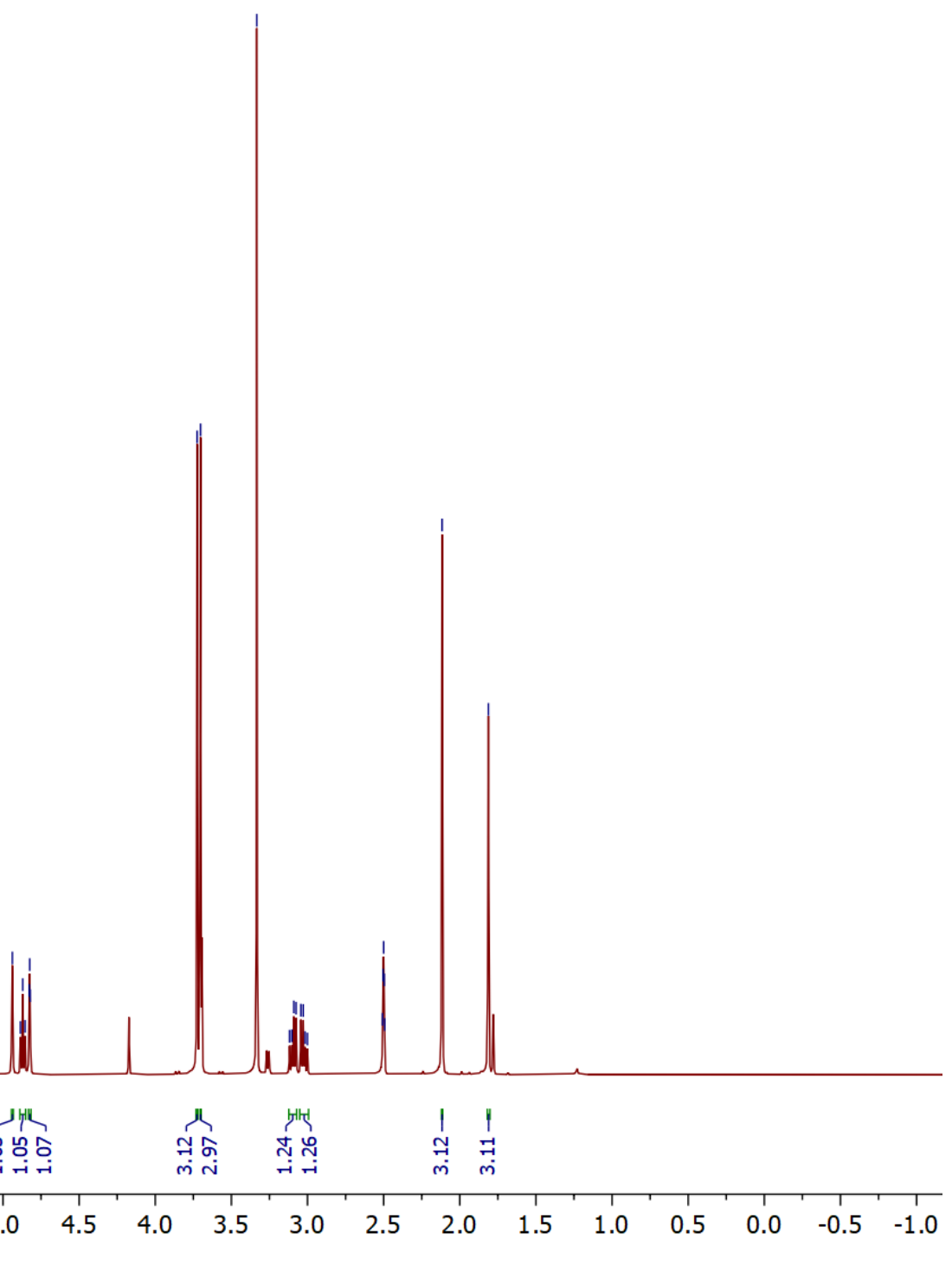

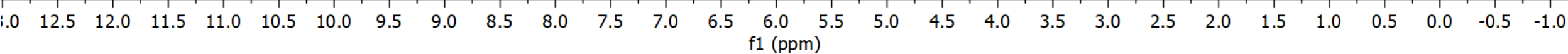




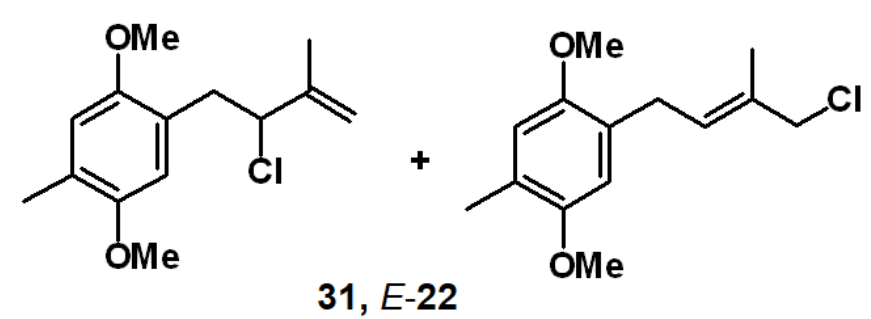

${ }^{13} \mathrm{C}\left\{{ }^{1} \mathrm{H}\right\} \mathrm{NMR}, 126 \mathrm{MHz}$, DMSO-d6

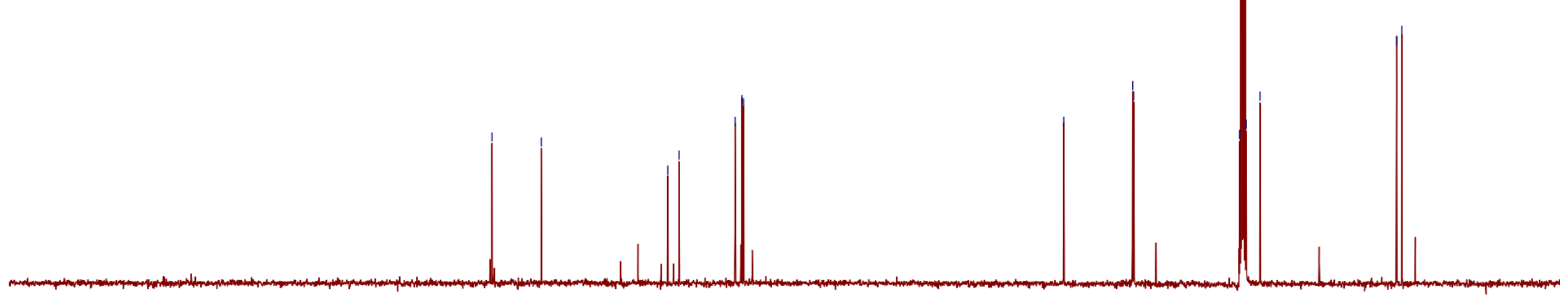




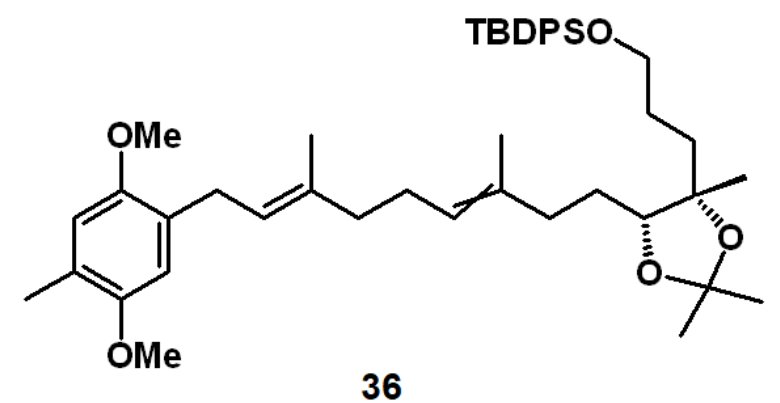

${ }^{1} \mathrm{H}$ NMR, $500 \mathrm{MHz}$, DMSO-d6

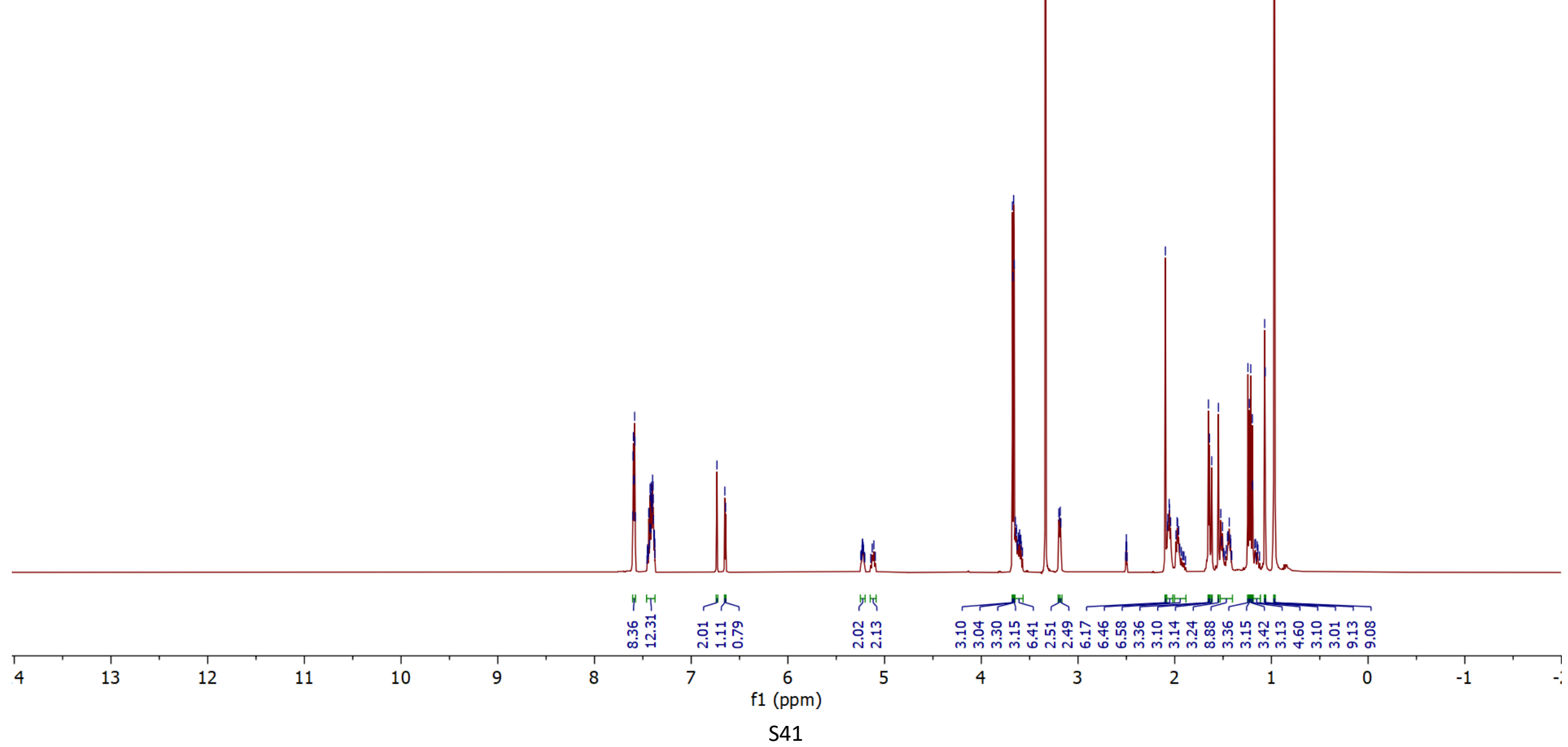




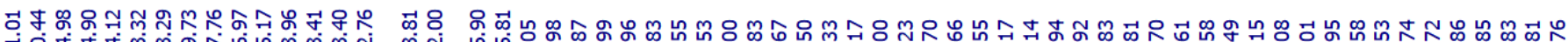

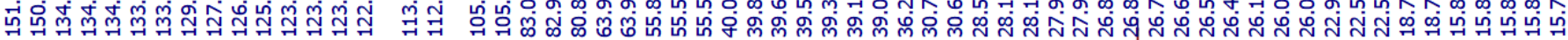

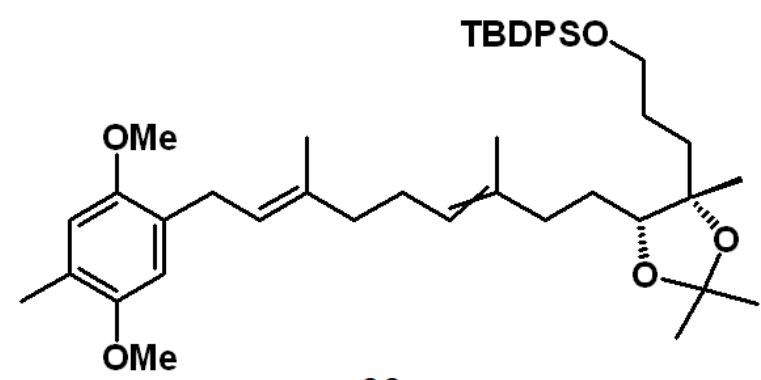

36

${ }^{13} \mathrm{C}\left\{{ }^{1} \mathrm{H}\right\} \mathrm{NMR}, 126 \mathrm{MHz}$, DMSO-d6
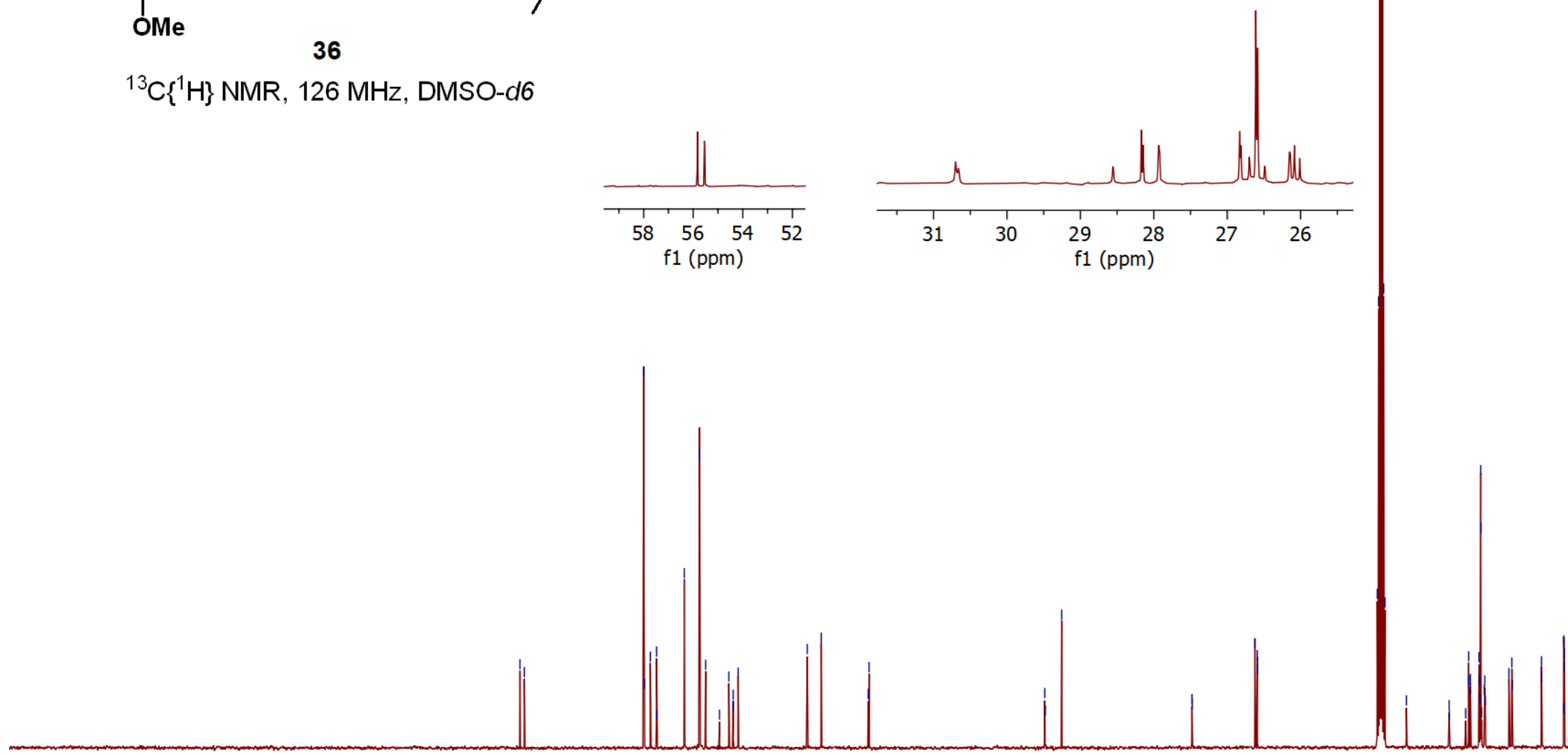


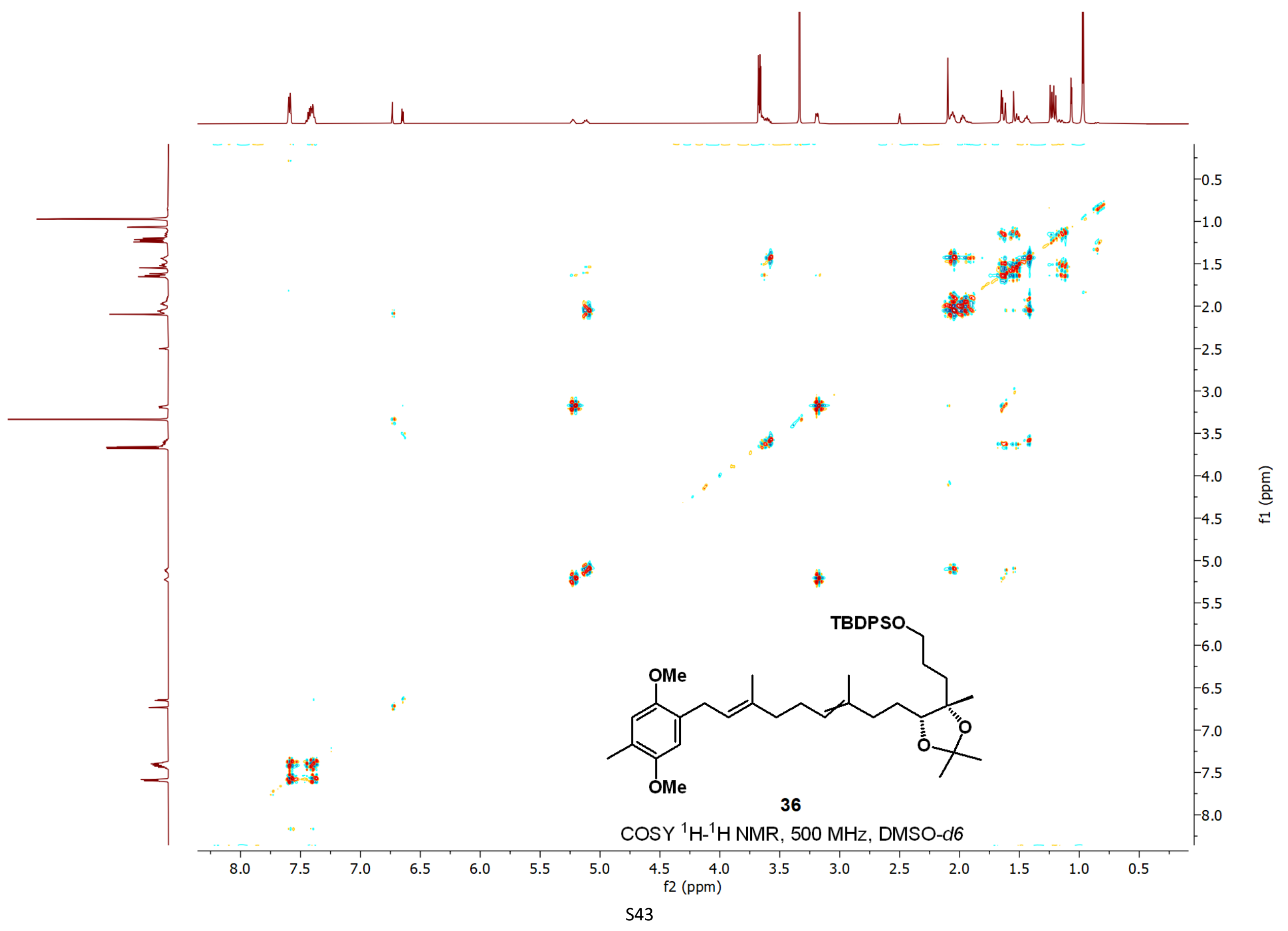




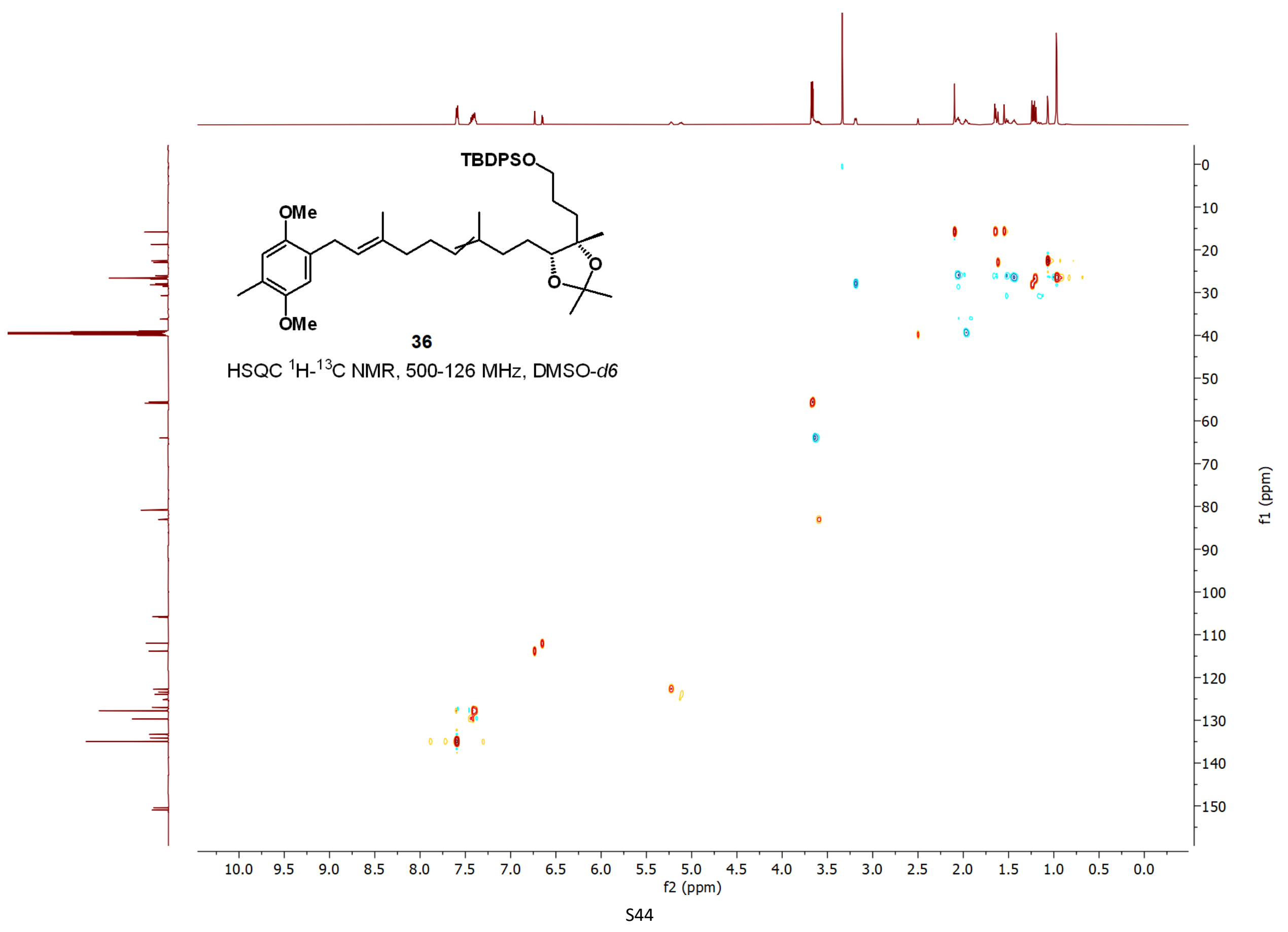




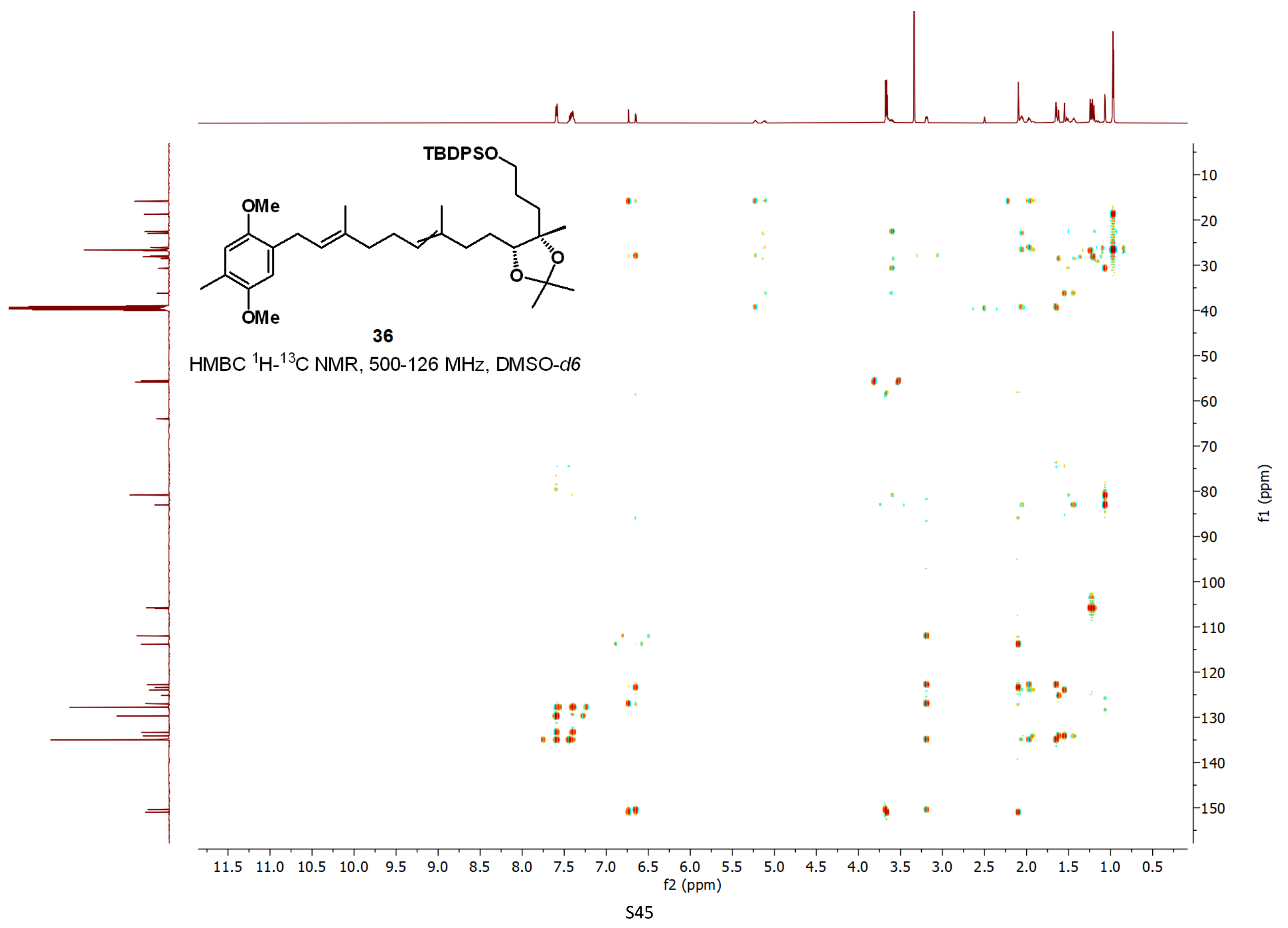




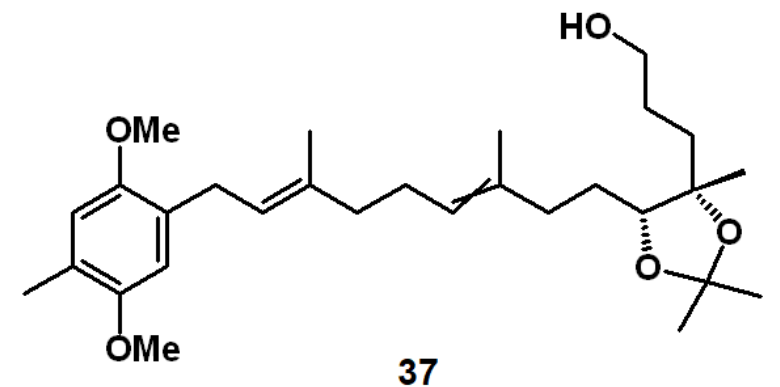

${ }^{1} \mathrm{H}$ NMR, $500 \mathrm{MHz}$, DMSO-d6

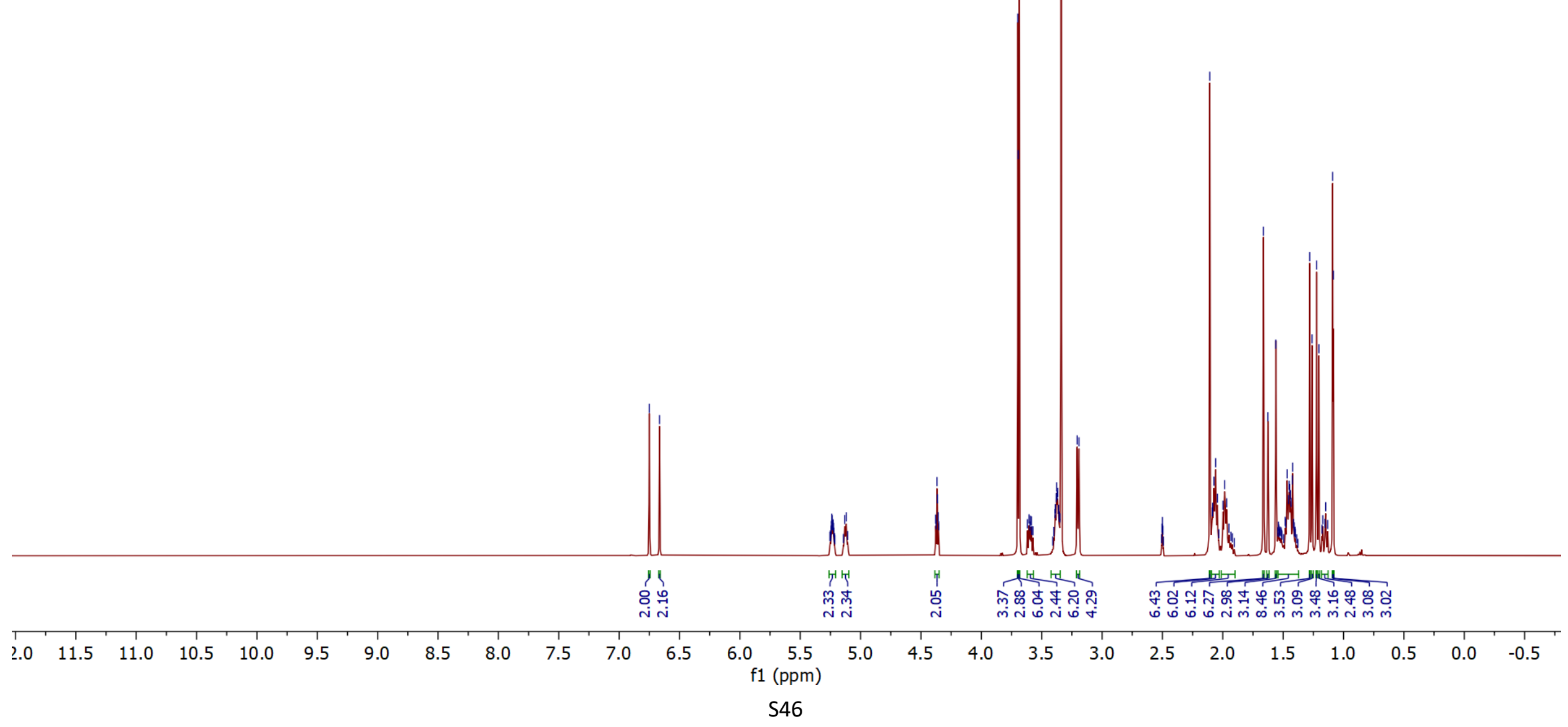




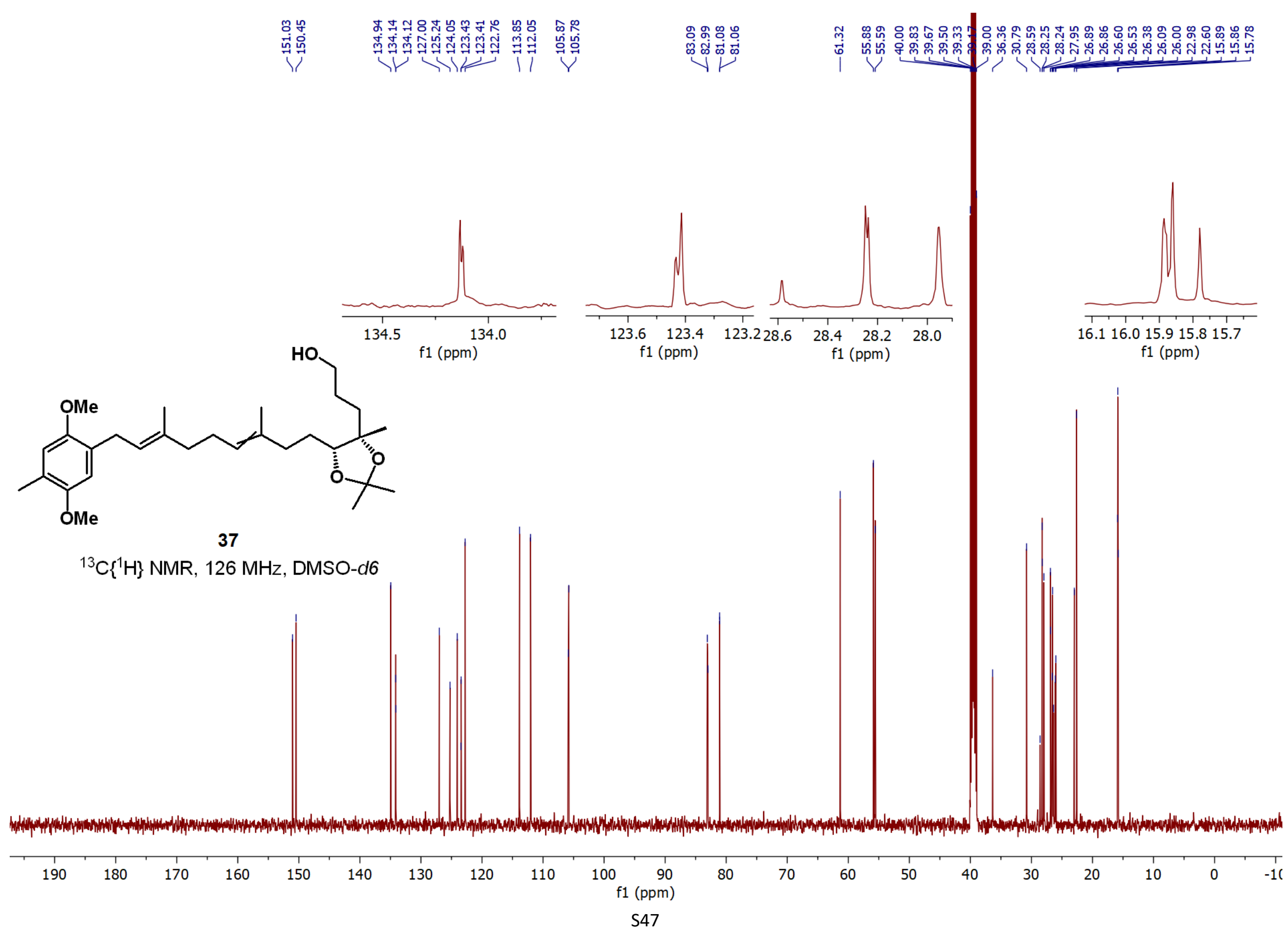




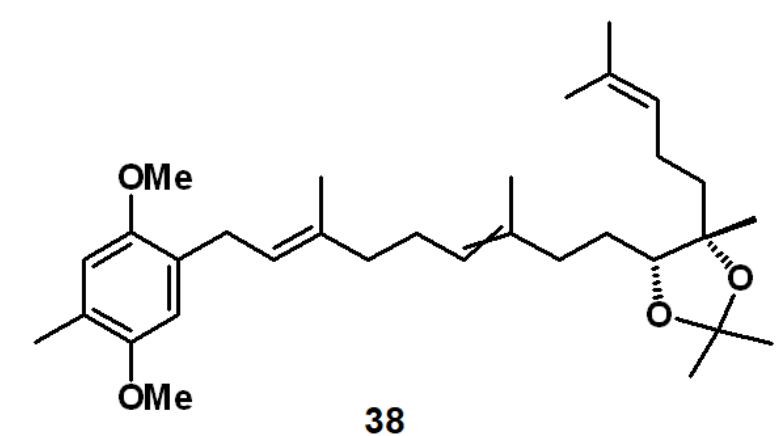

${ }^{1} \mathrm{H}$ NMR, $500 \mathrm{MHz}$, DMSO-d6
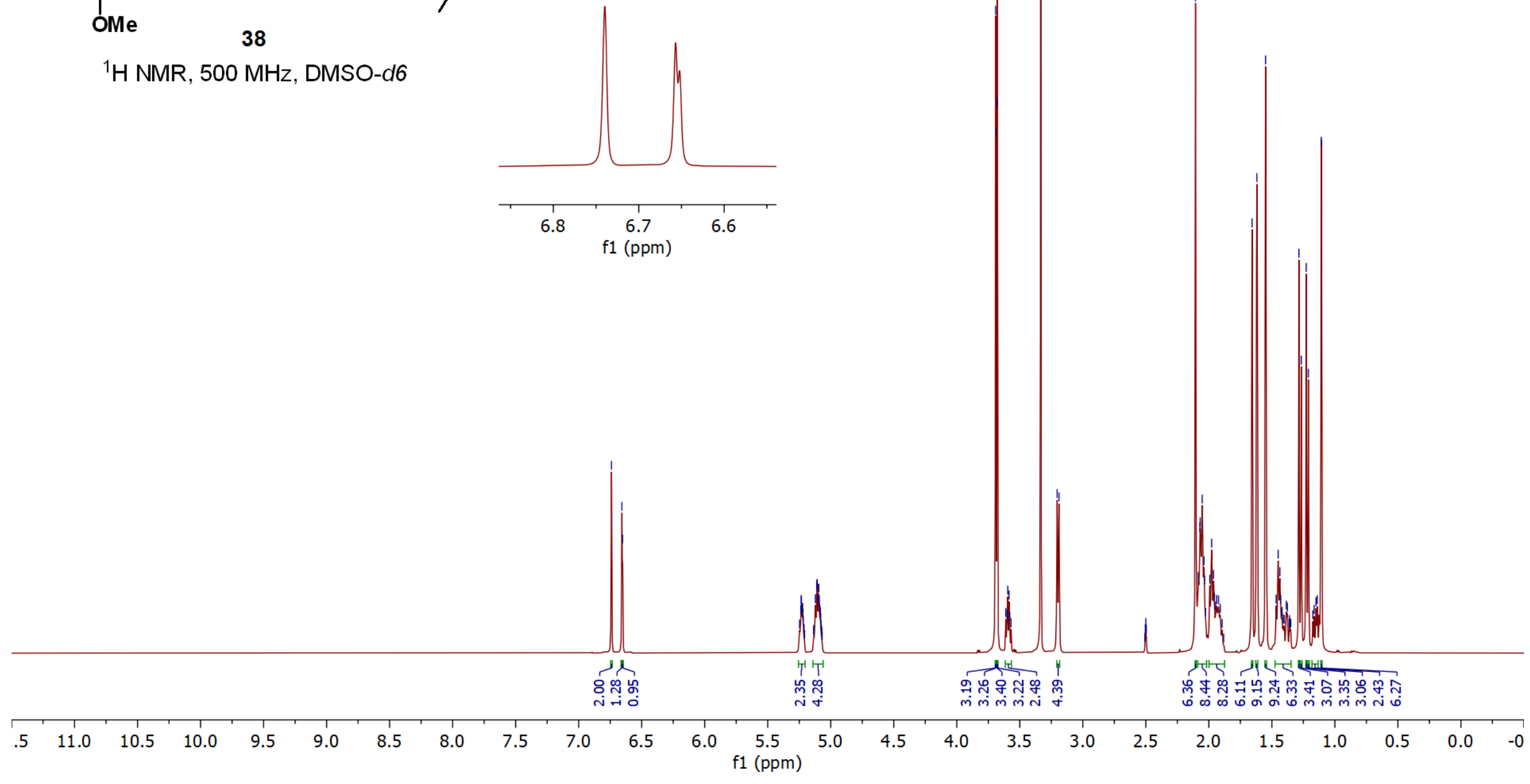


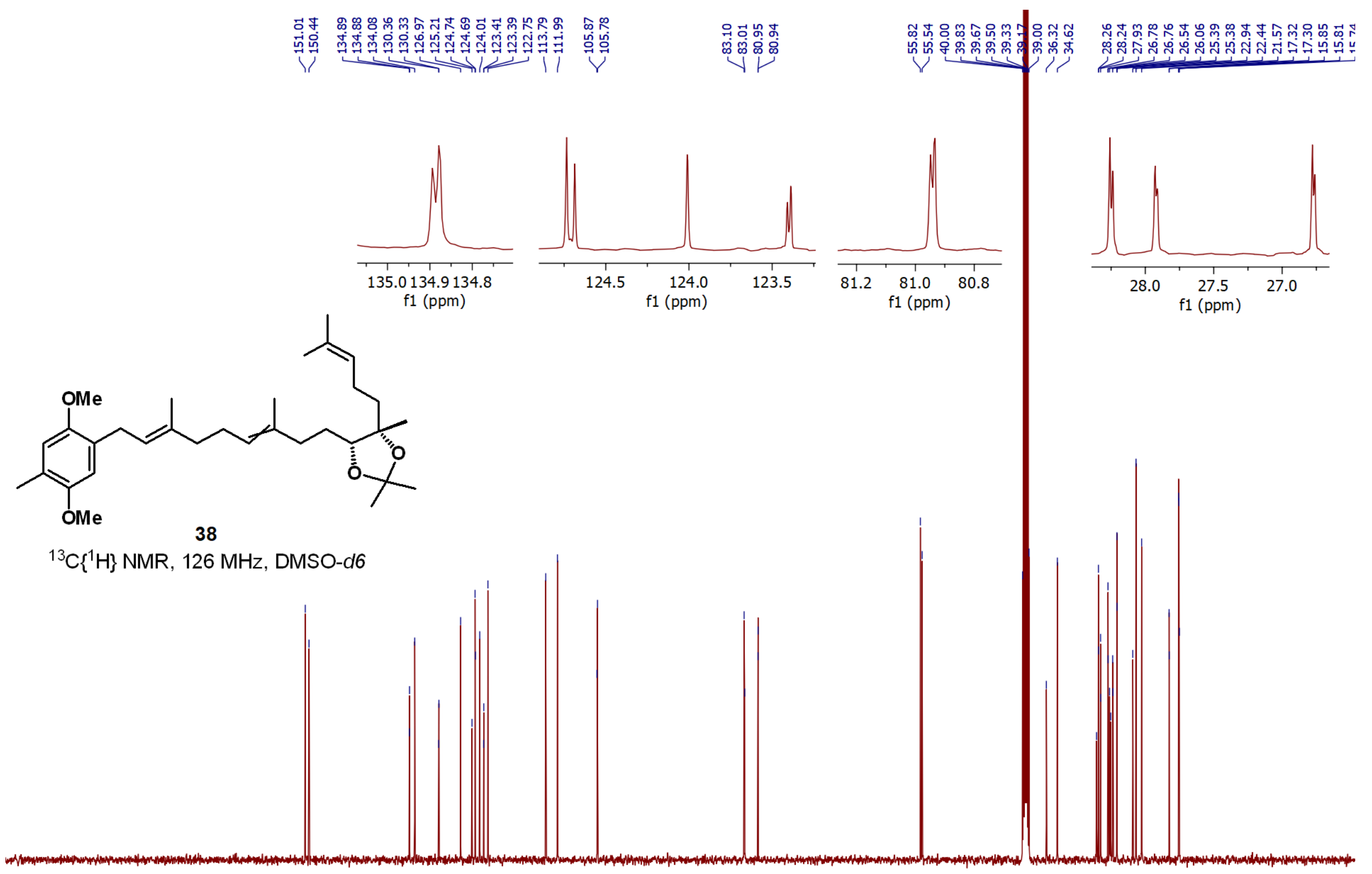

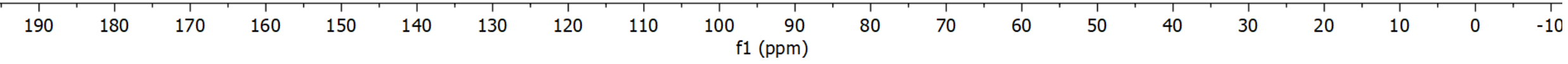




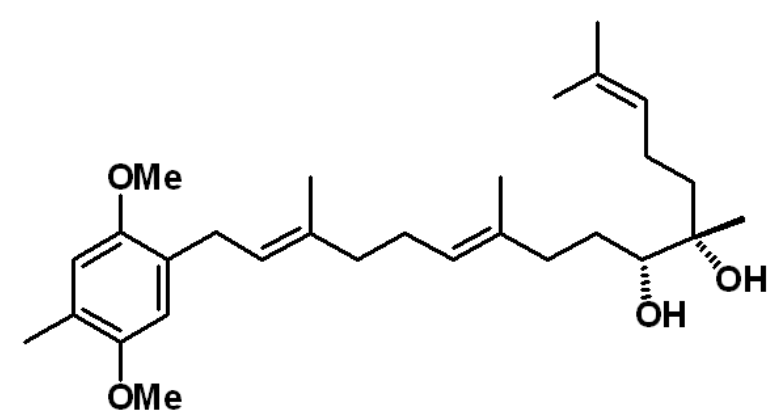

E-39

${ }^{1} \mathrm{H} \mathrm{NMR}, 500 \mathrm{MHz}, \mathrm{MeOD}-\mathrm{d} 4$

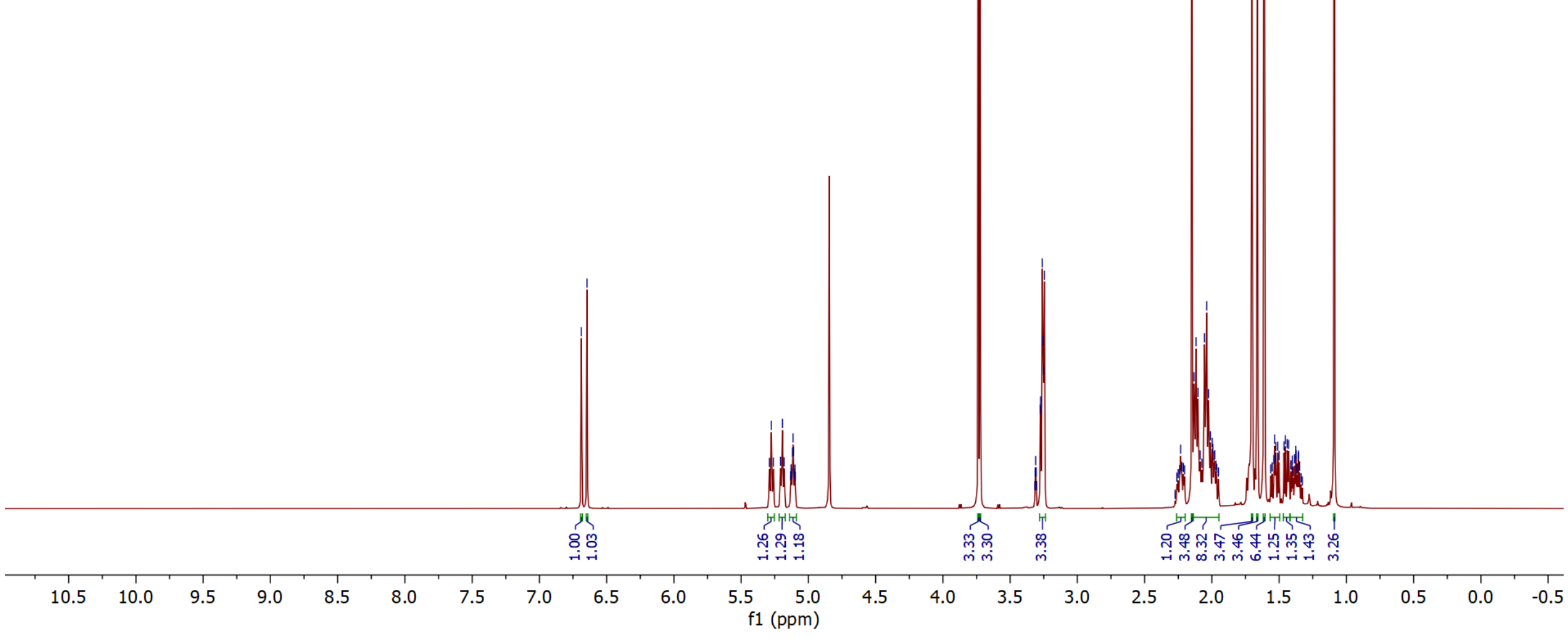




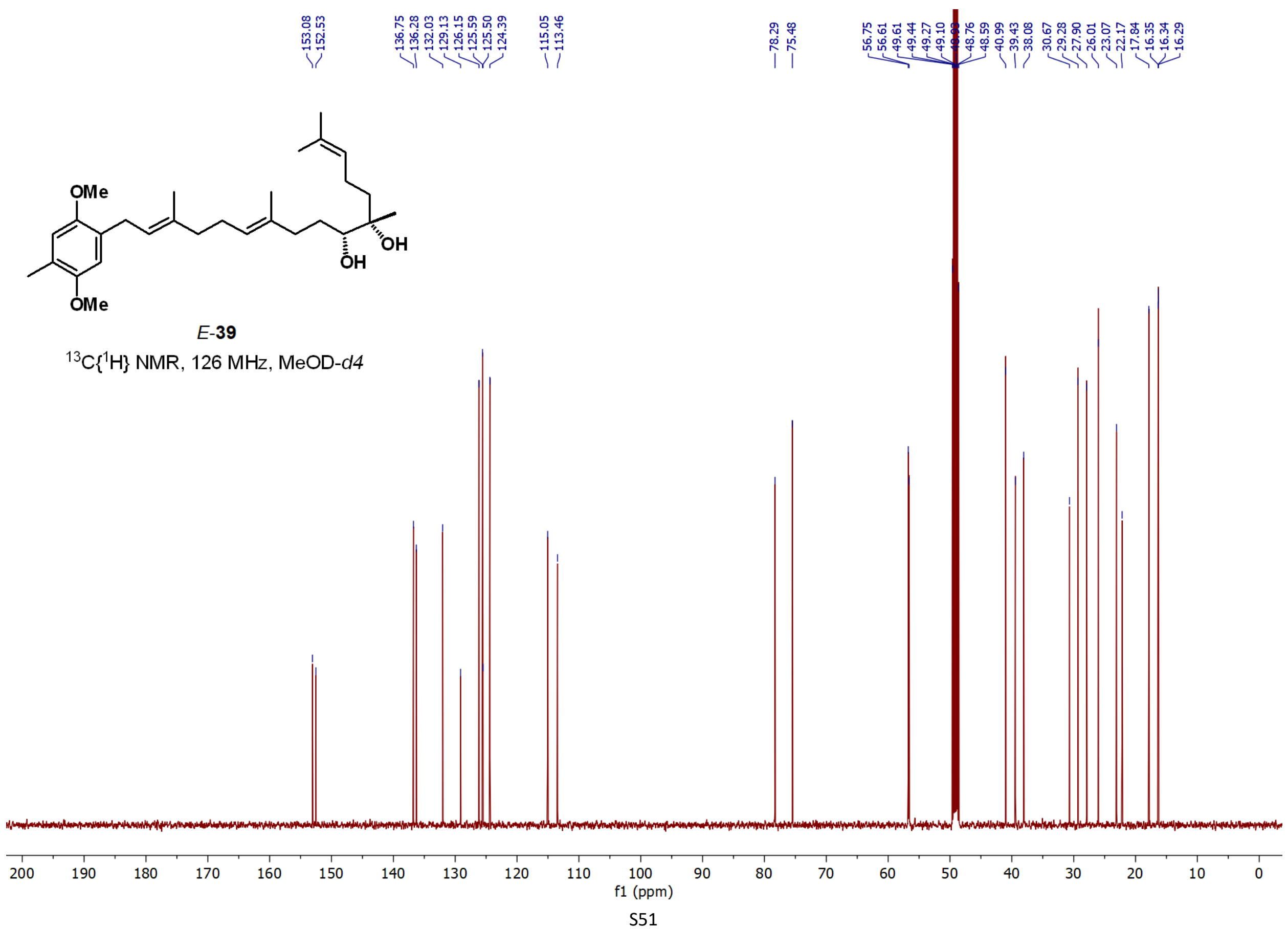




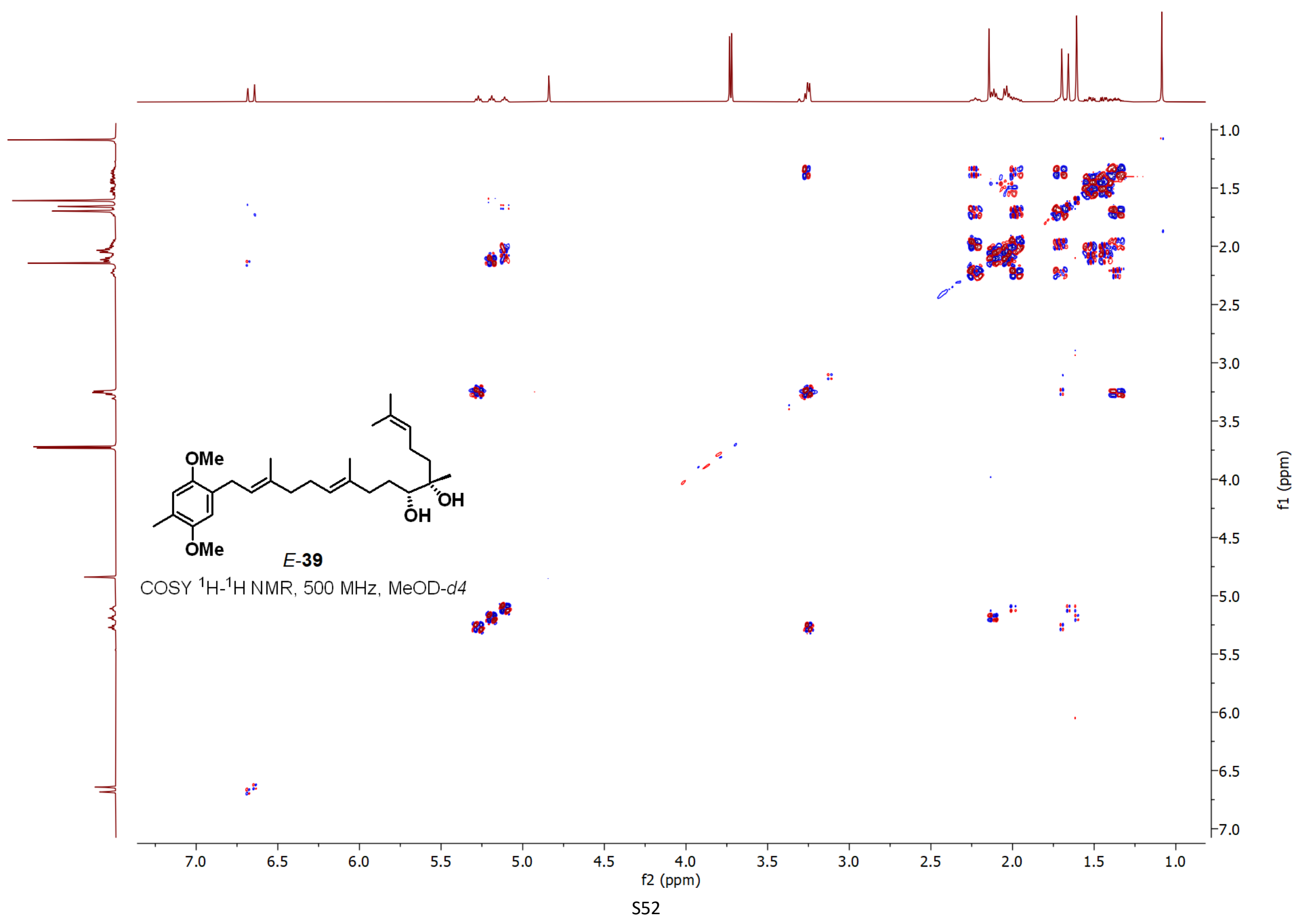




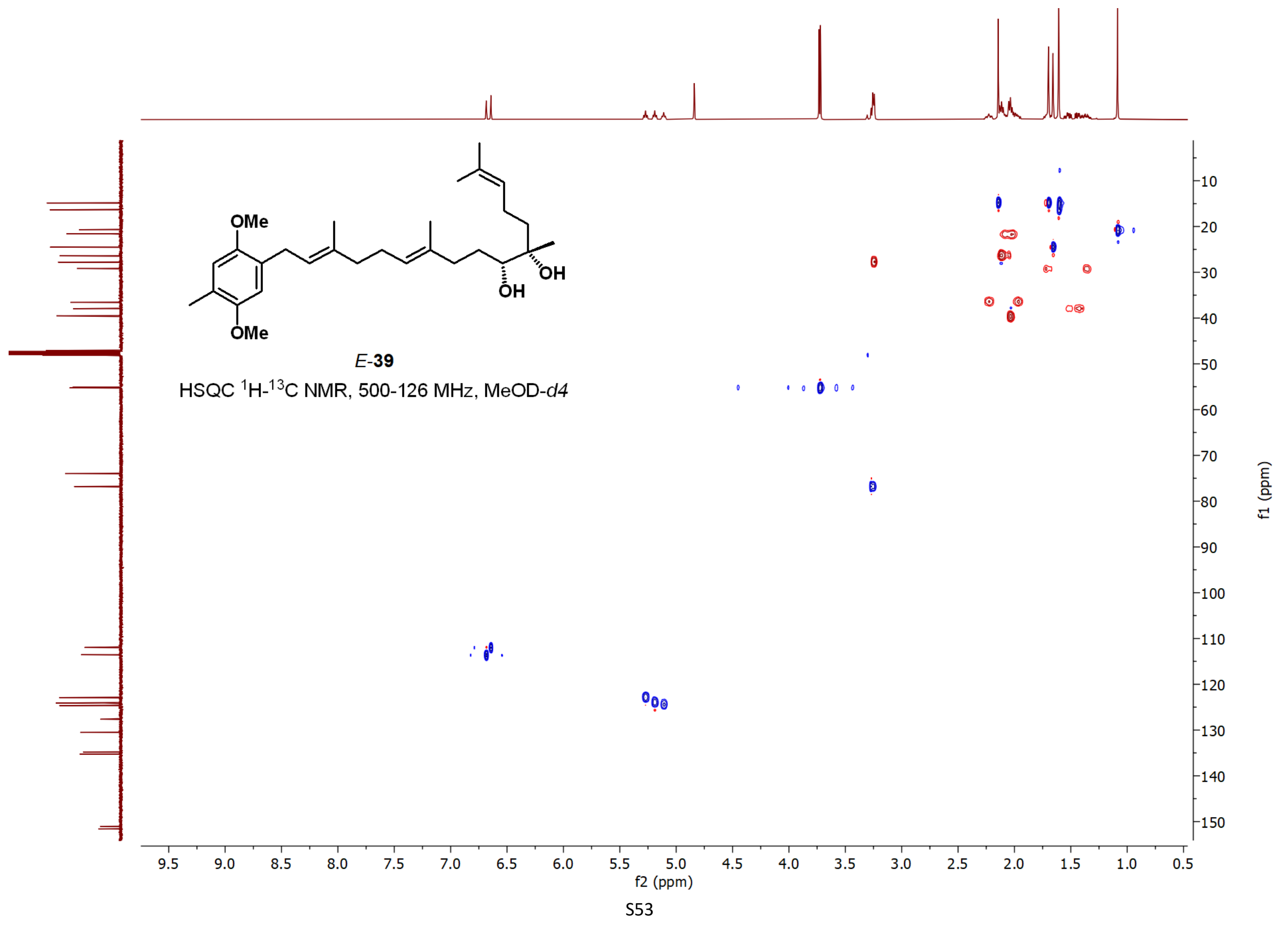




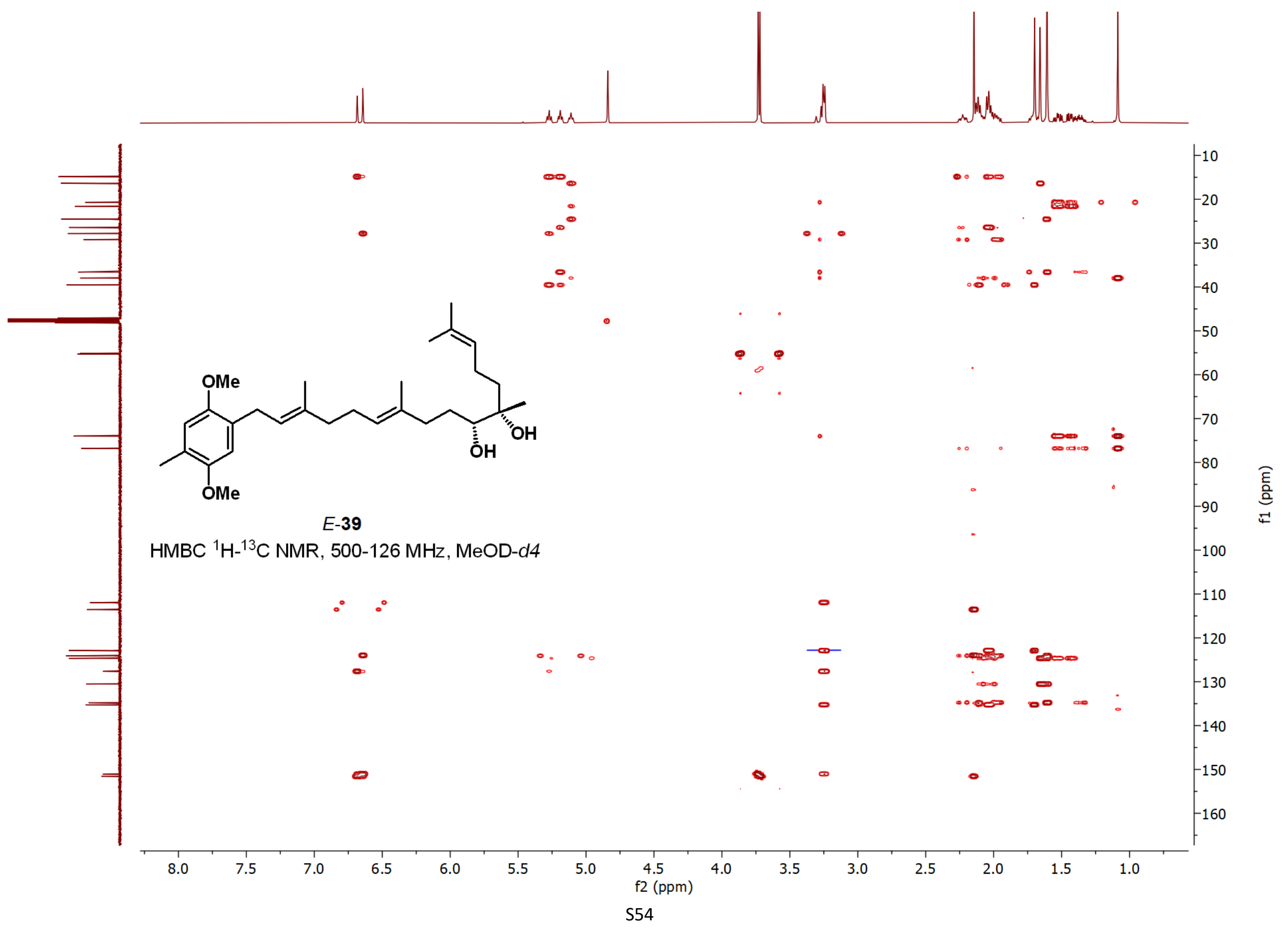




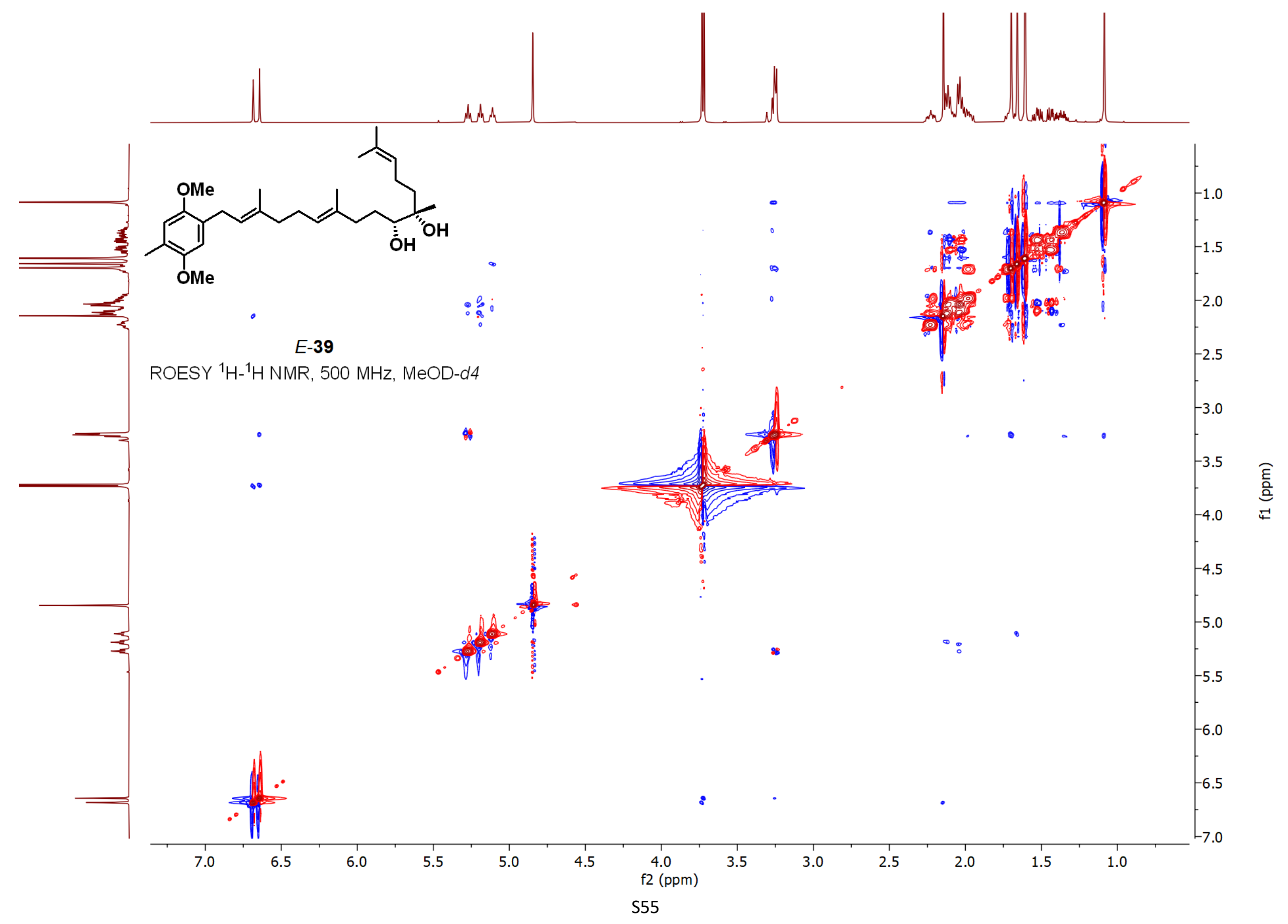



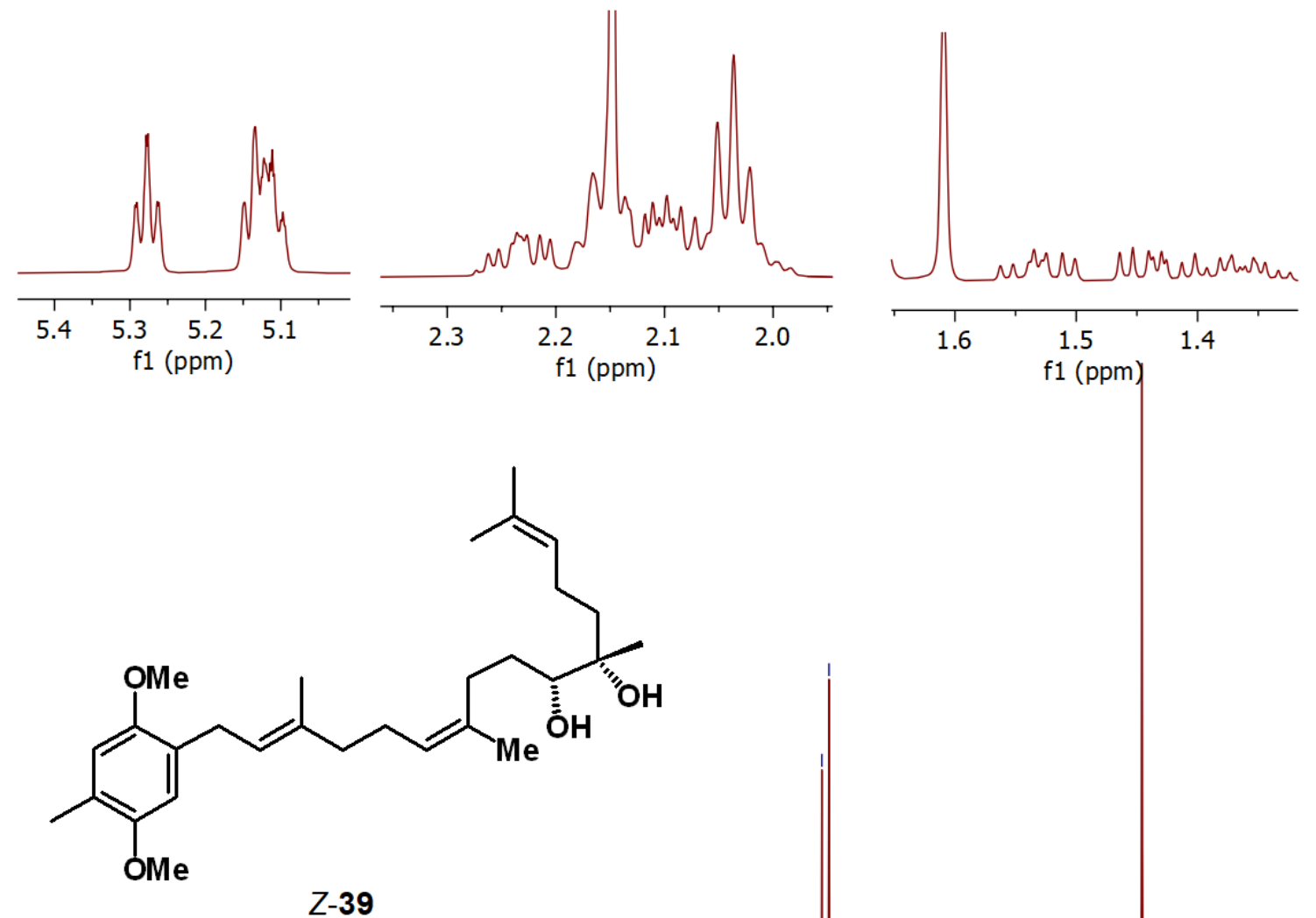

${ }^{1} \mathrm{H}$ NMR, $500 \mathrm{MHz}, \mathrm{MeOD}-d 4$

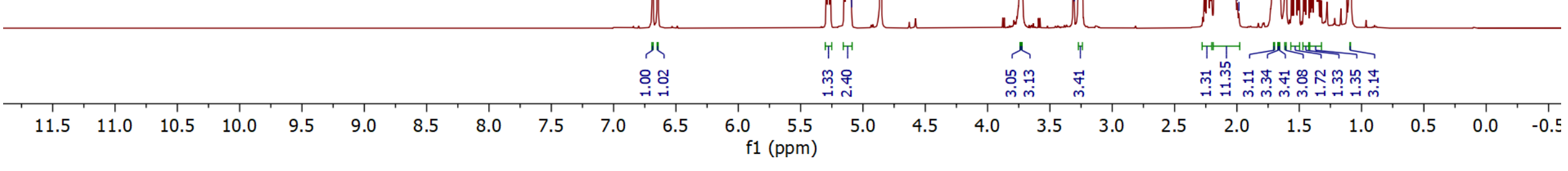




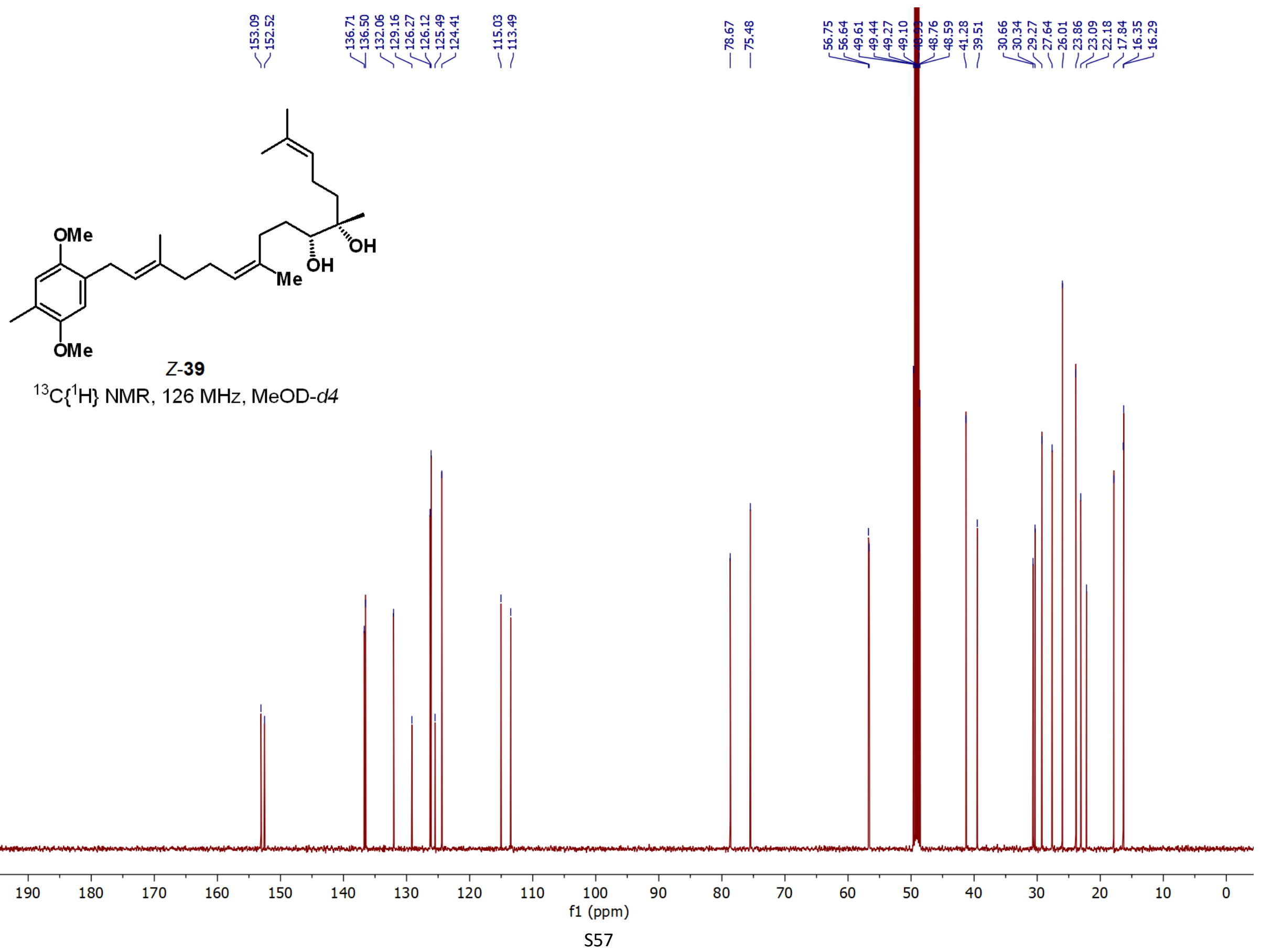




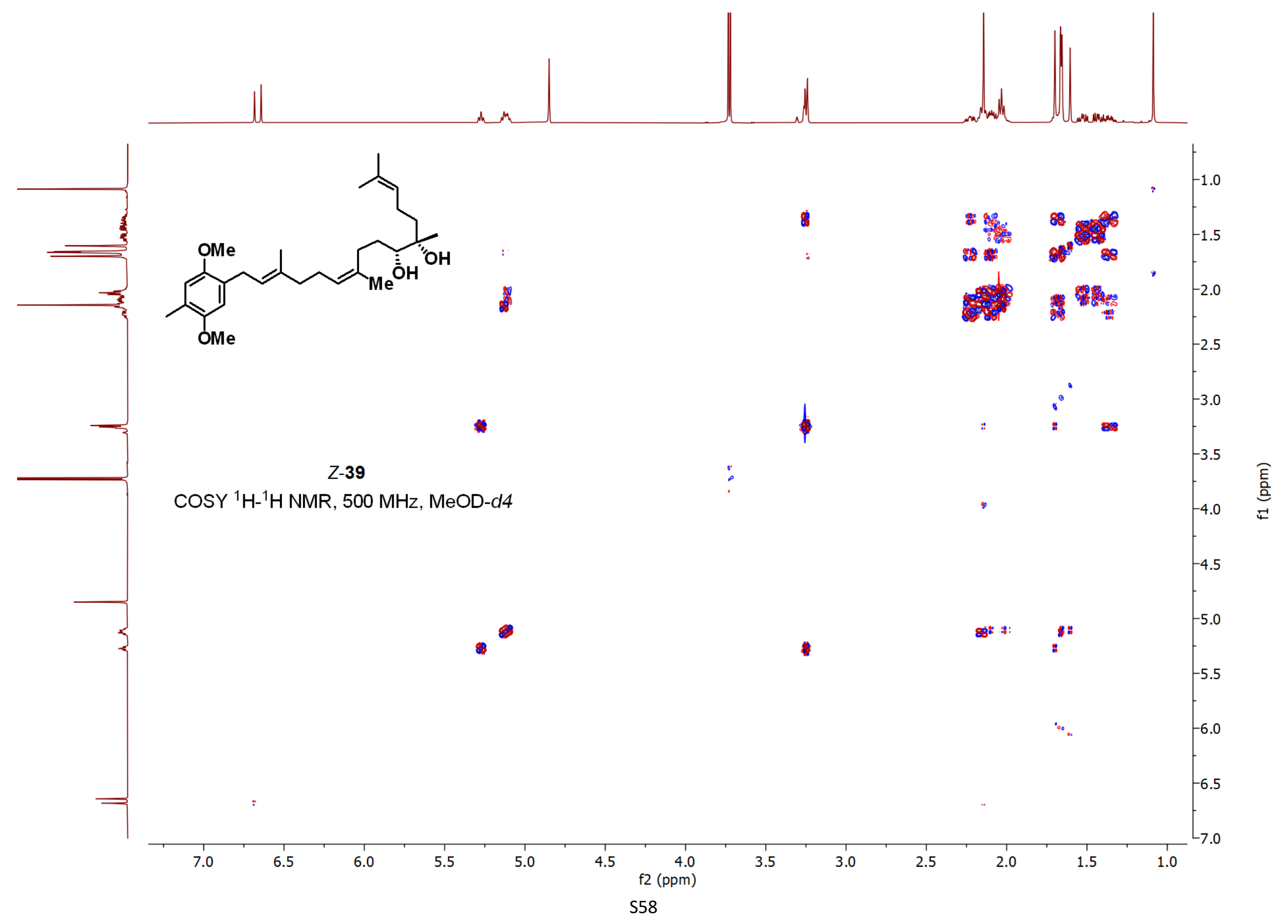




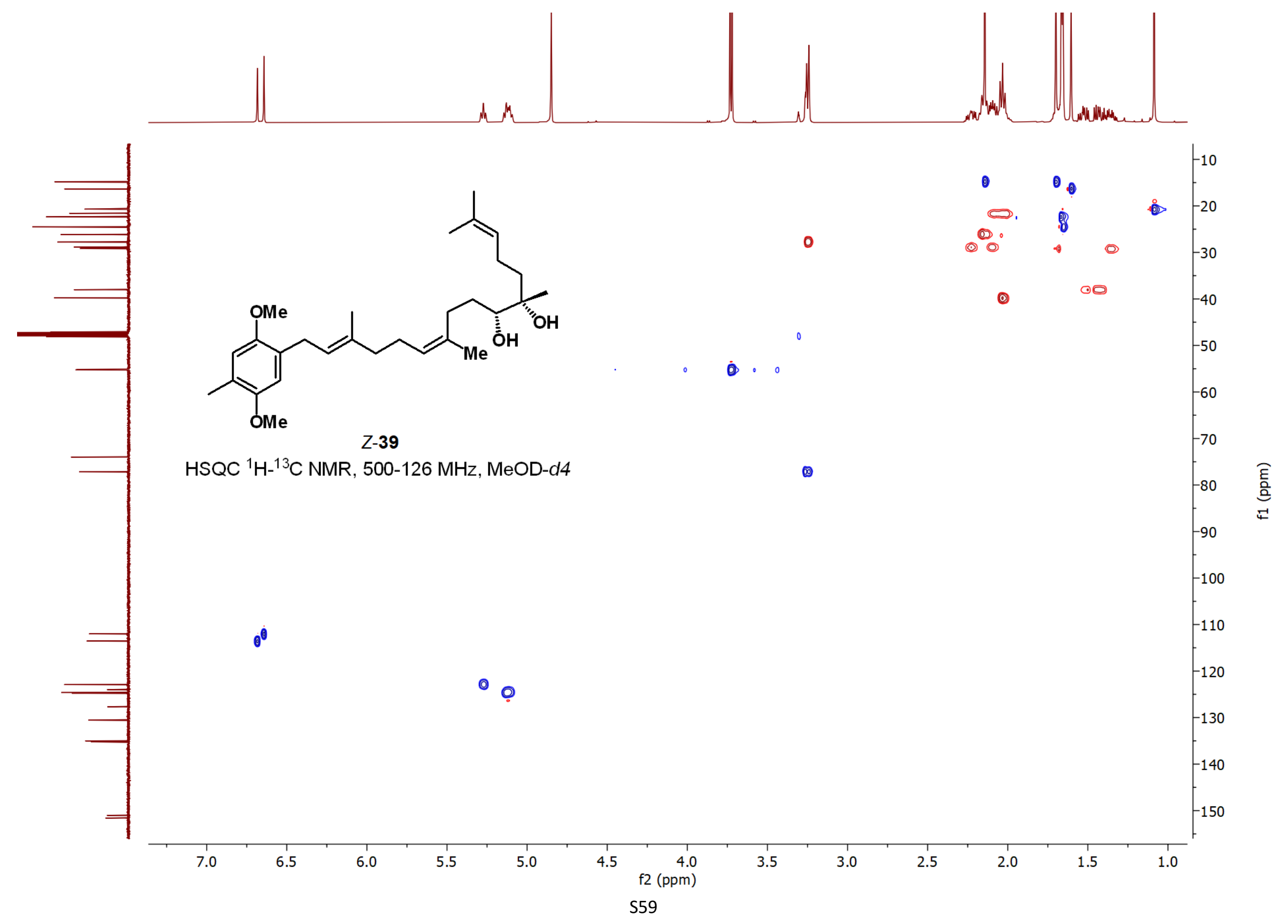




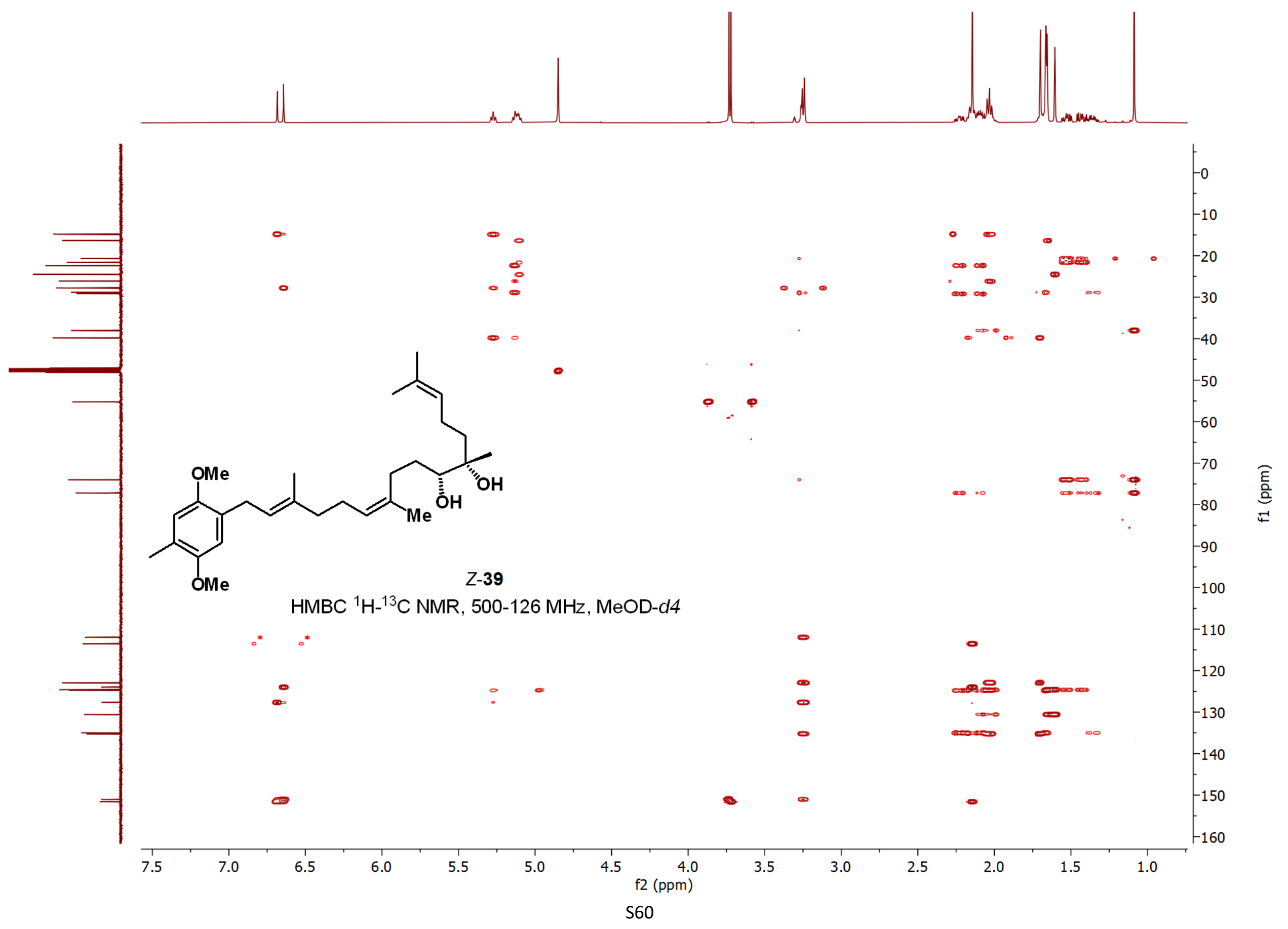




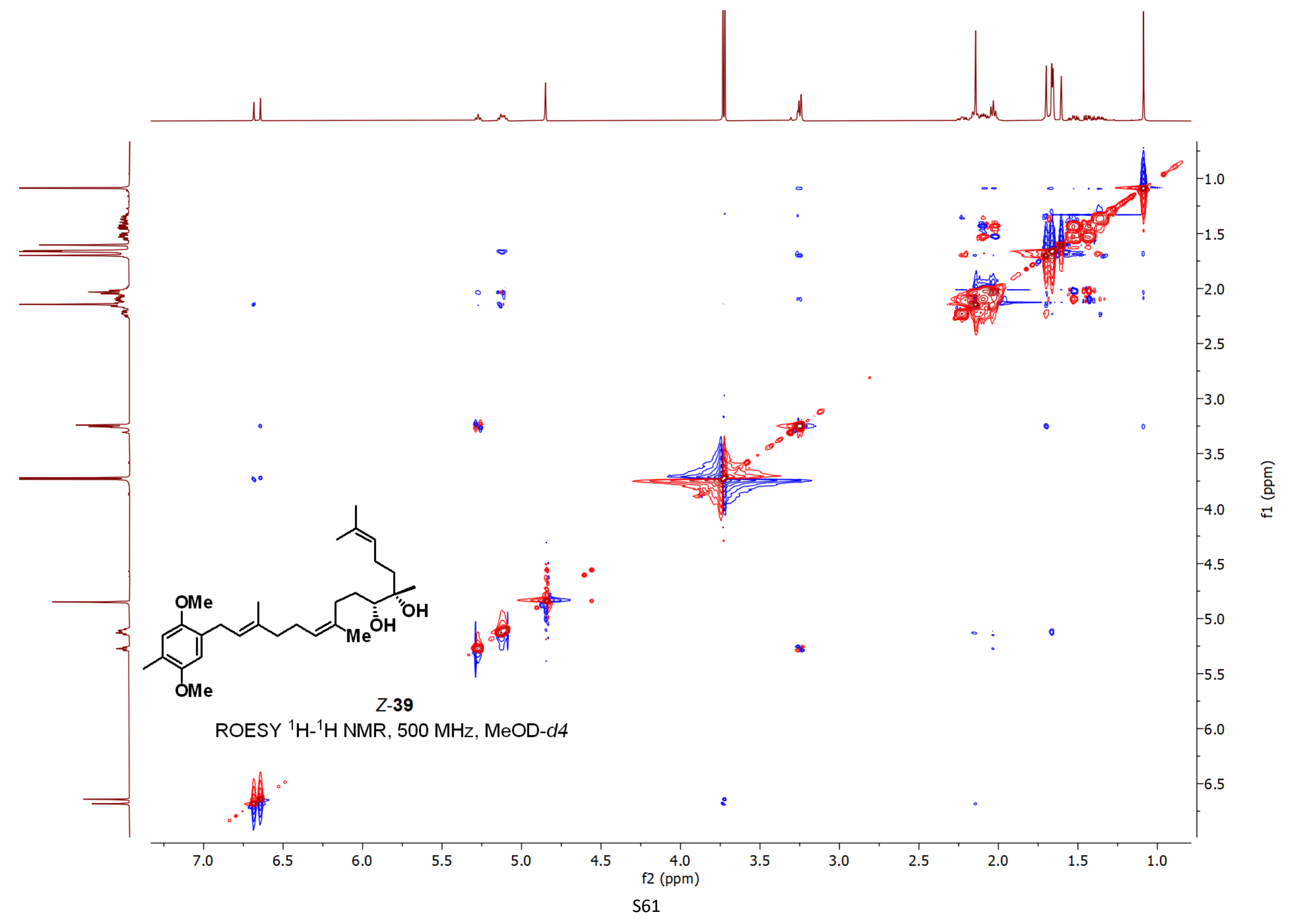




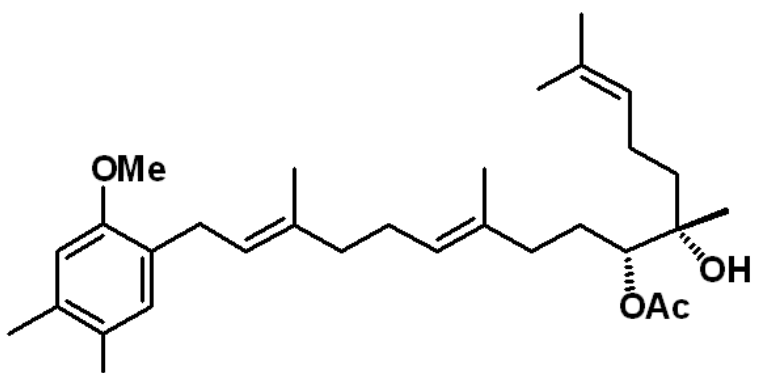

${ }^{1} \mathrm{H}$ NMR, $500 \mathrm{MHz}, \mathrm{MeOD}-\mathrm{d4}$

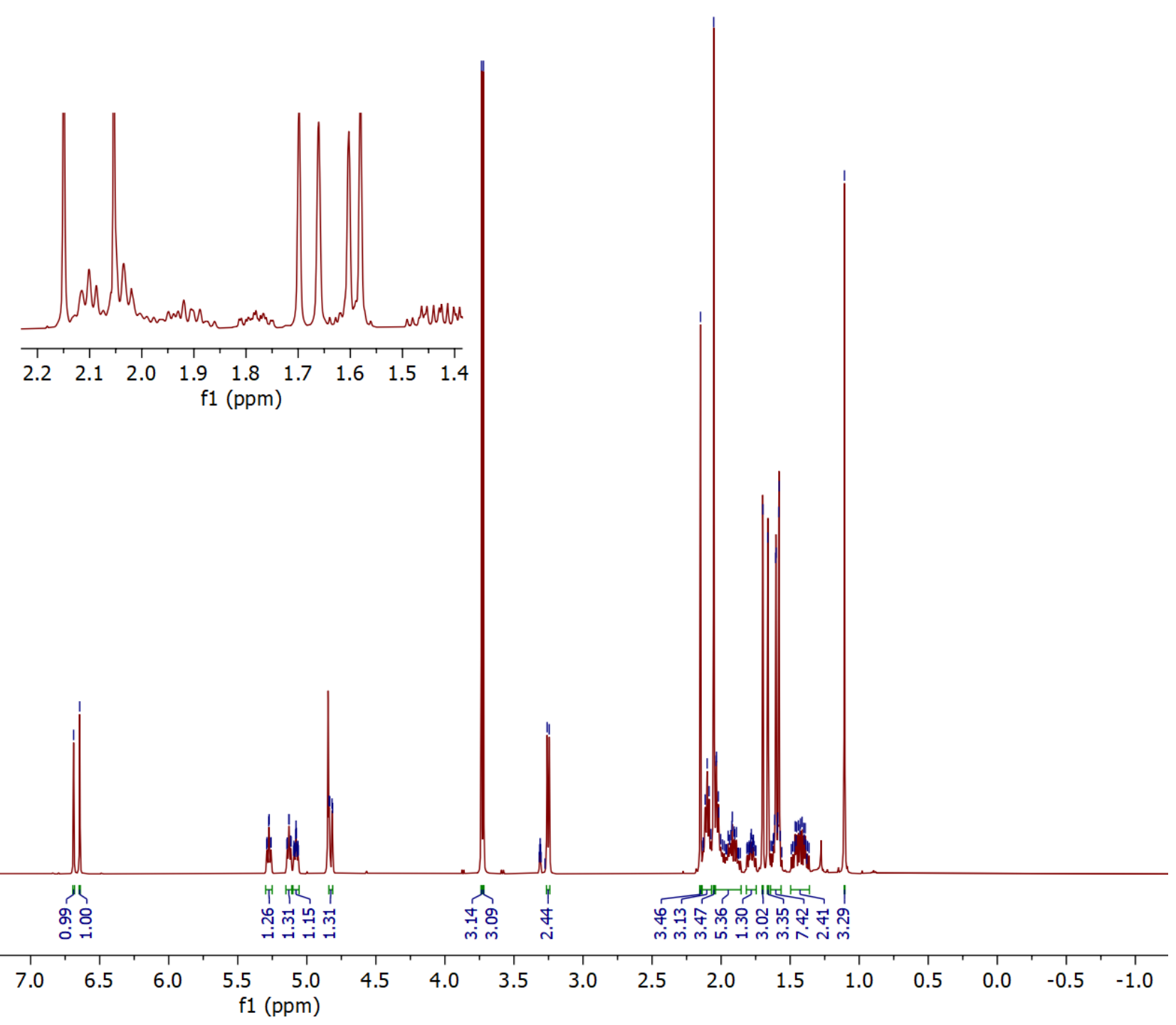

$\begin{array}{lllllllllllll}11.5 & 11.0 & 10.5 & 10.0 & 9.5 & 9.0 & 8.5 & 8.0 & 7.5 & 7.0 & 6.5 & 6.0 & 5.5 \\ & & & & & & & & & & & & \\ \text { f1 (ppm) } & \\ \mathrm{S} 62\end{array}$ 

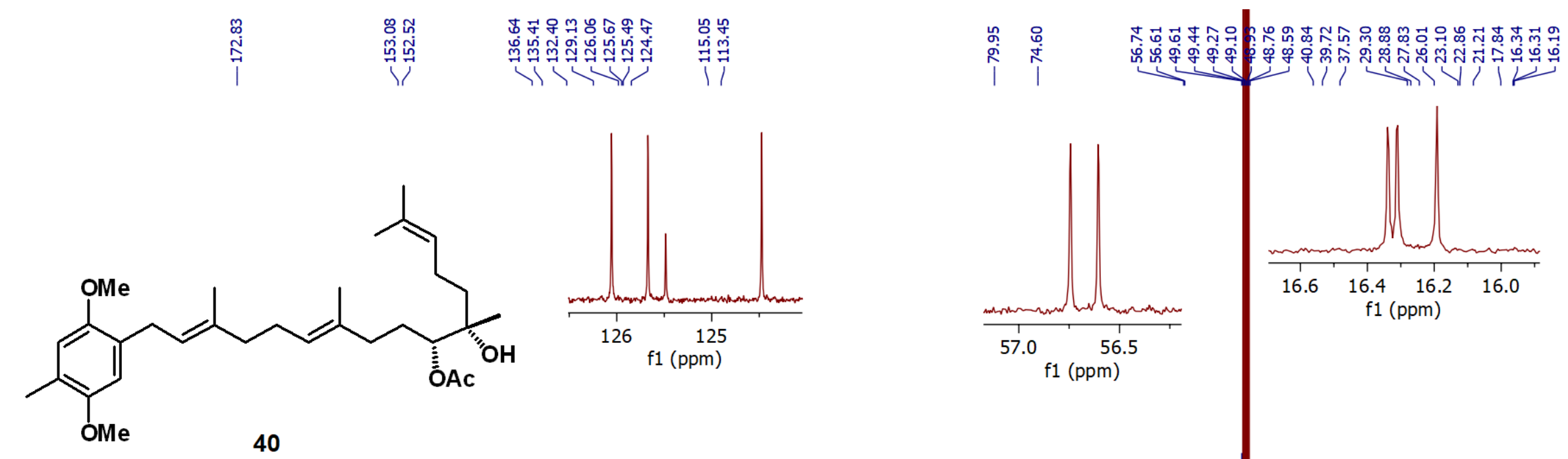

${ }^{13} \mathrm{C}\left\{{ }^{1} \mathrm{H}\right\} \mathrm{NMR}, 126 \mathrm{MHz}, \mathrm{MeOD}-d 4$

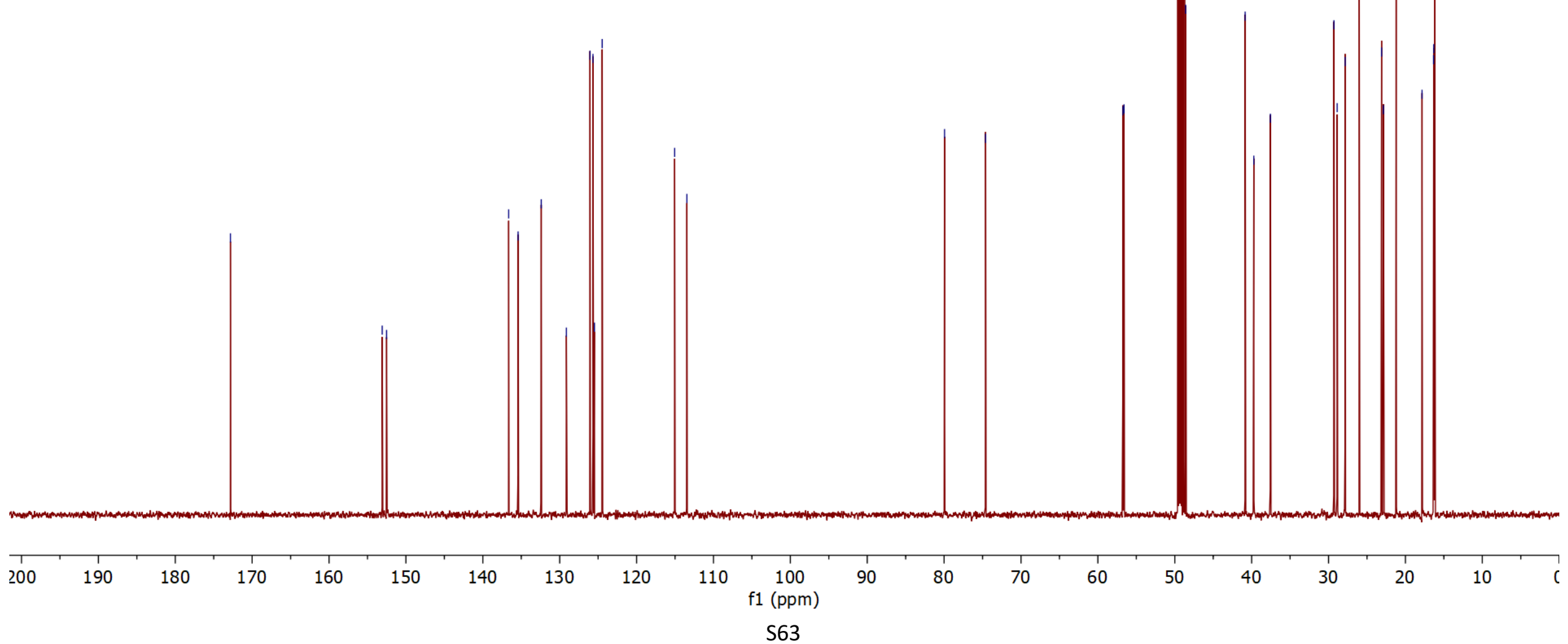




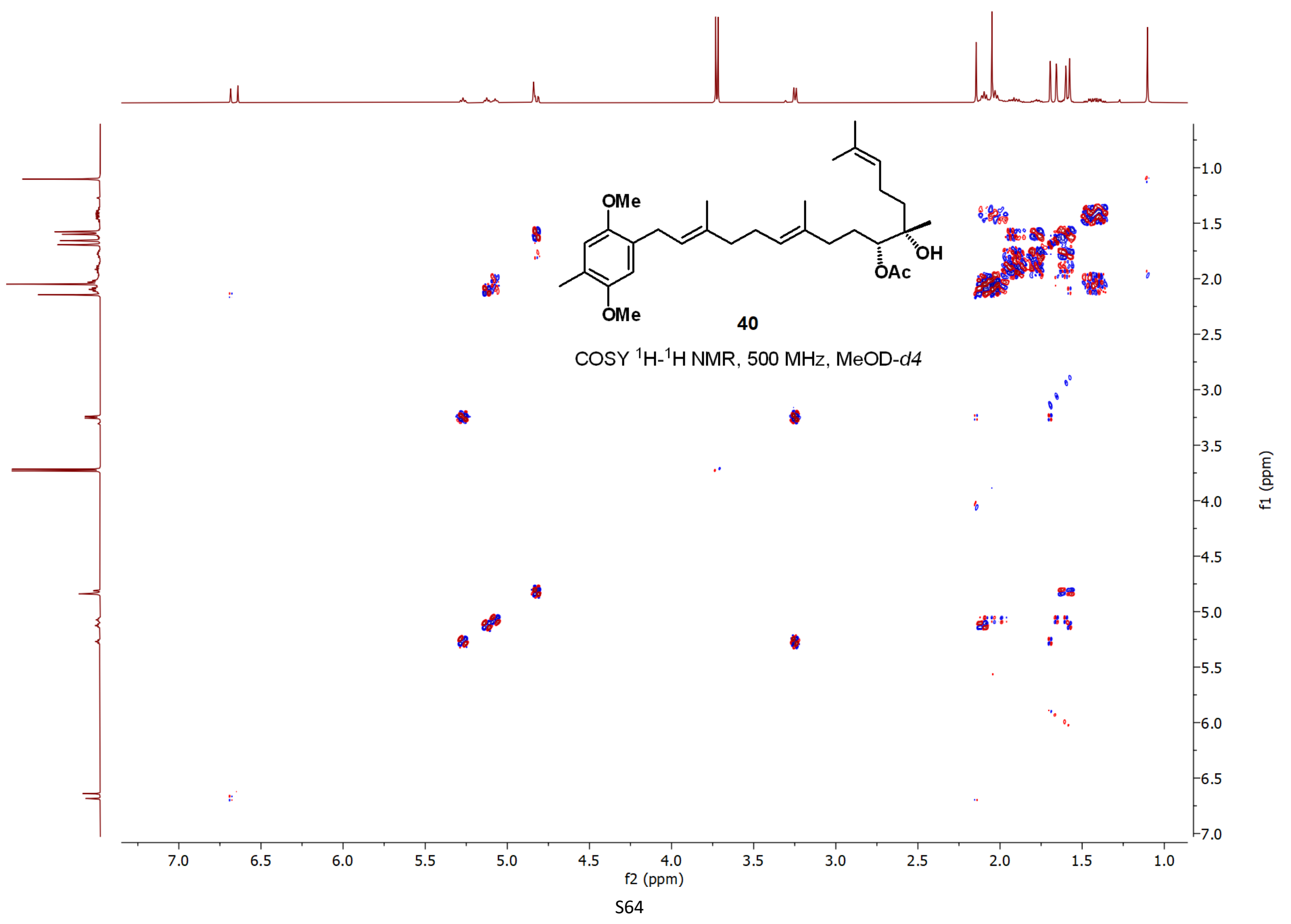




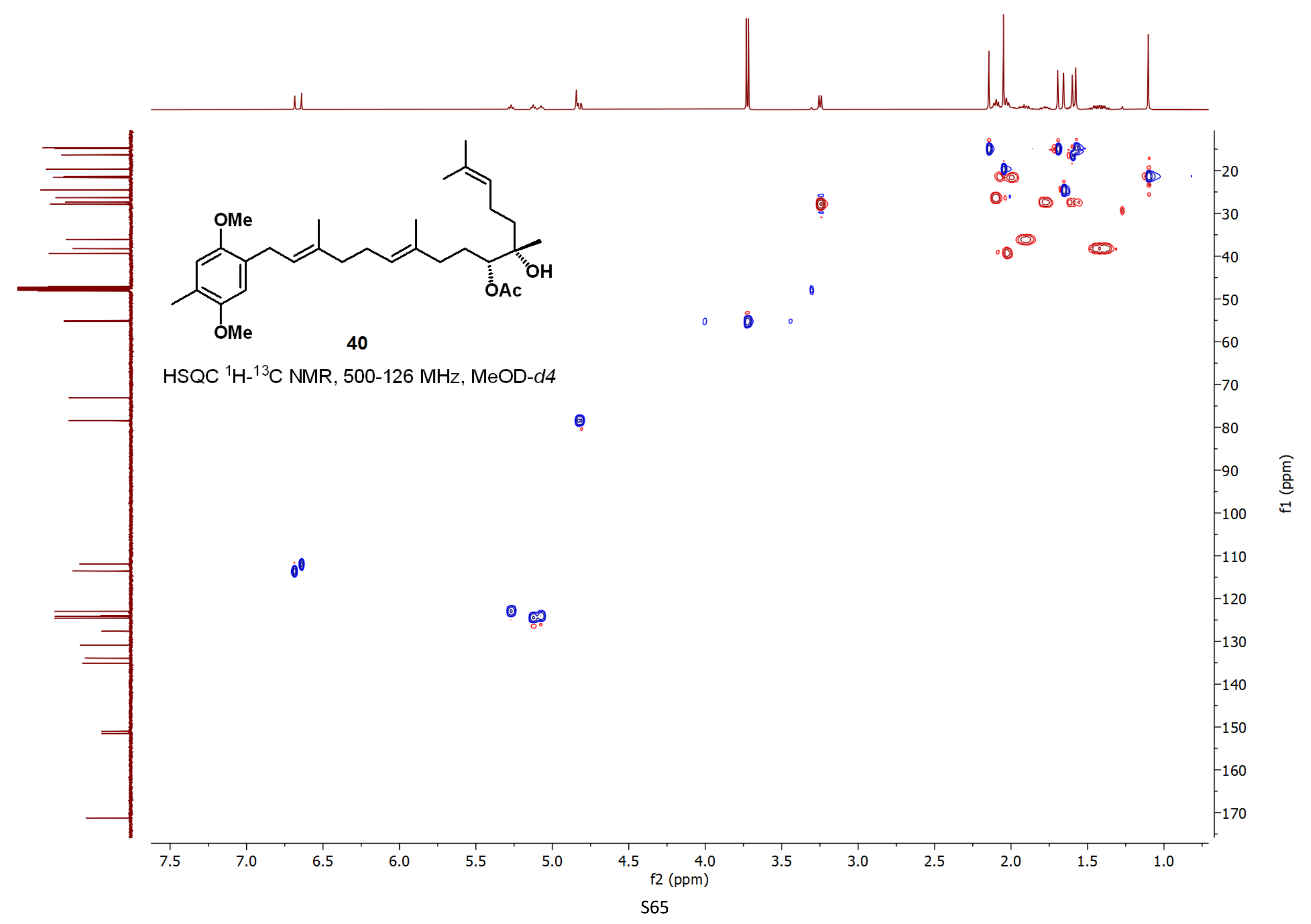




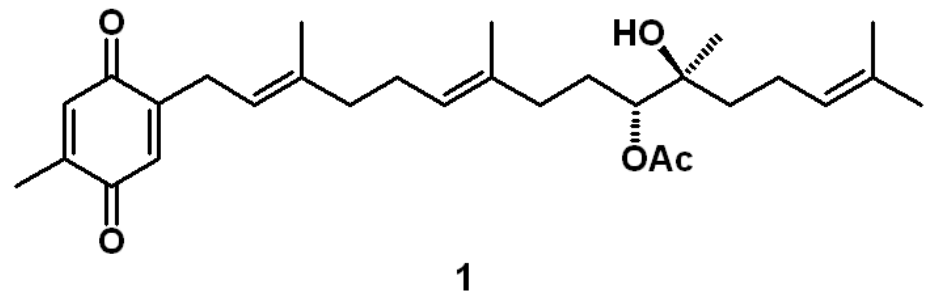

${ }^{1} \mathrm{H} \mathrm{NMR}, 500 \mathrm{MHz}, \mathrm{CDCl}_{3}$

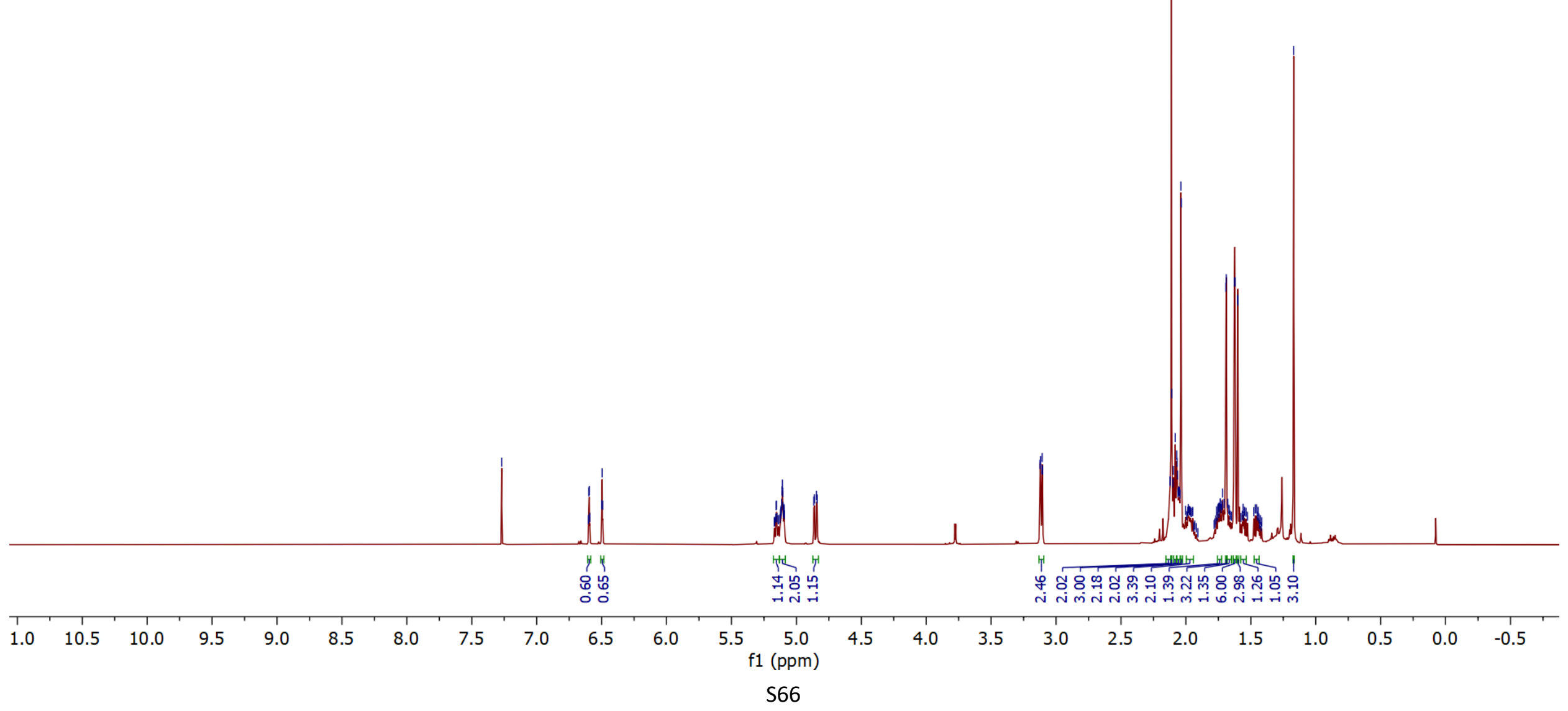


| |

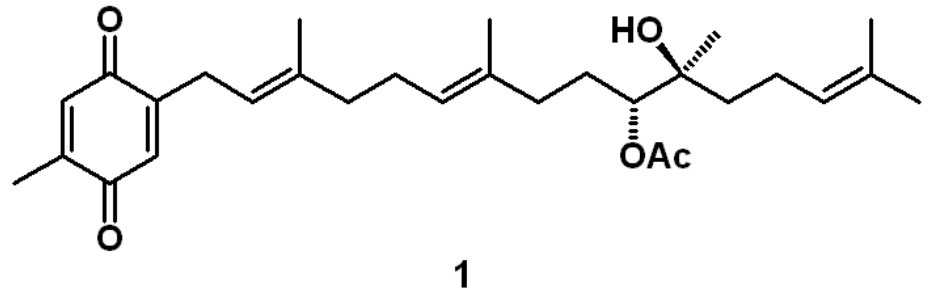

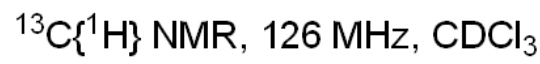

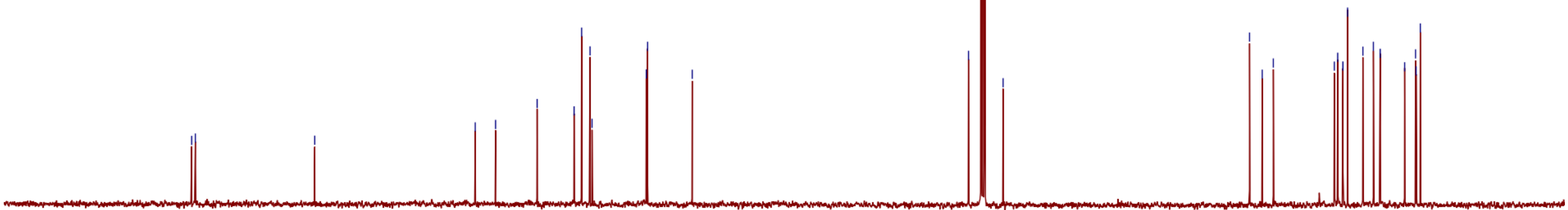




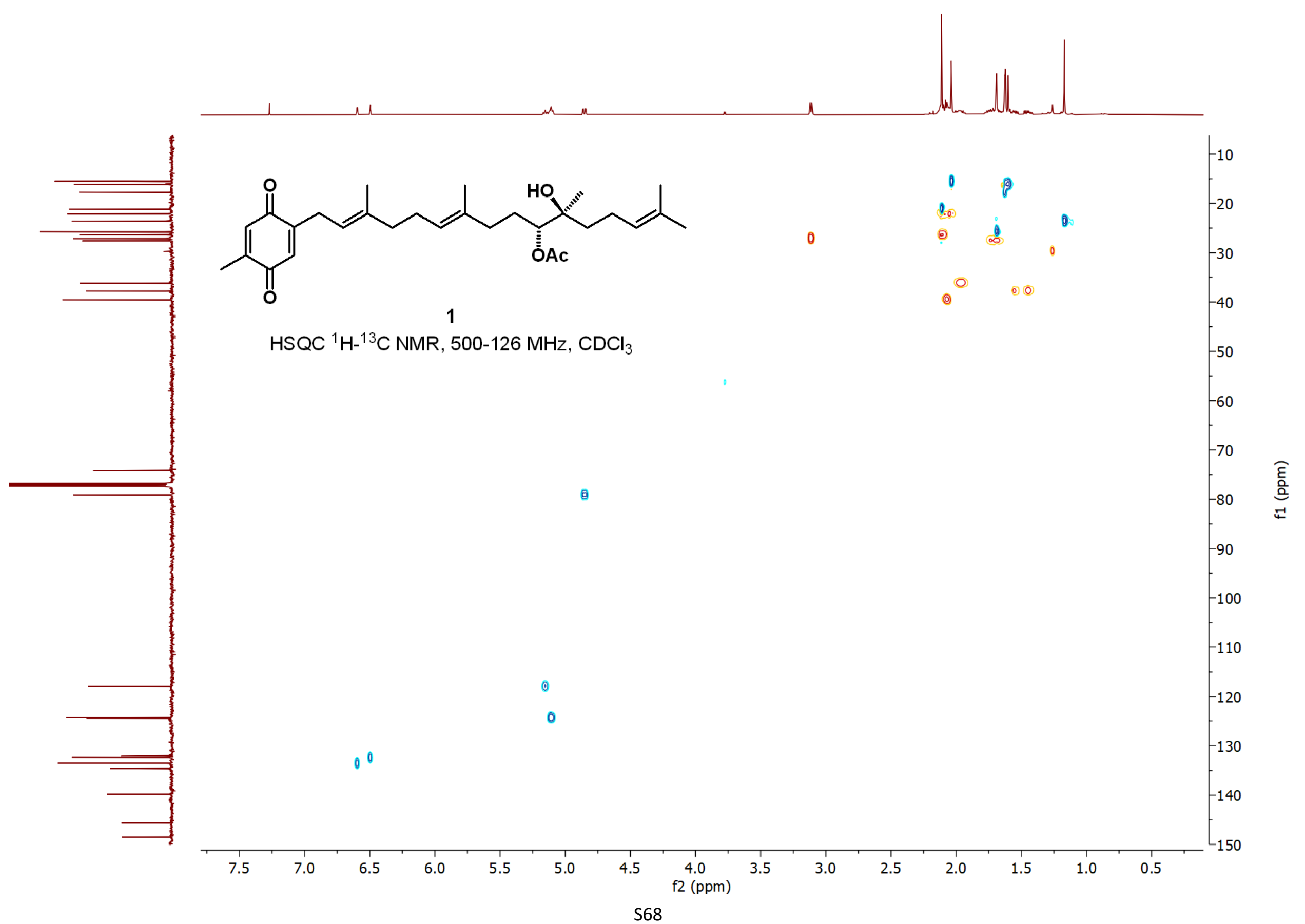

